
․

\section{REPORT TO AID ON AN NBS/AID WORKSHOP ON STANDARDIZATION AND MEASUREMENT SERVICES}

\section{Edited by:}

H. Steffen Peiser

Charles C. Raley

Penelope M. Odar

Office of International Relations

National Bureau of Standards

Washington, D.C. 20234

Held October 1-18, 1977

Issued May 1979

The Workshop was conducted as a part of the program under the US/NBS Agency for International Development PASA TA(CE) 6-71

Prepared for

Agency for International Development Department of State

Washington, D.C. 20523

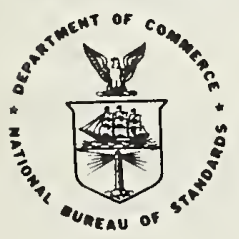

U.S. DEPARTMENT OF COMMERCE, Juanita M. Kreps, Secretary Jordan J. Baruch, Assistant Secretary for Science and Technology NATIONAL BUREAU OF STANDARDS, Ernest Ambler, Director 

INTRODUCTION, Mr. H. Steffen Peiser, Chief, Office of

International Relations, National Bureau of Standards,

Washington, D.C., UnIted States ....................... 1

PHOTOGRAPH ...................................... 2

PHOTOGRAPH IDENTIFICATION $\ldots \ldots \ldots \ldots \ldots \ldots \ldots \ldots \ldots \ldots \ldots \ldots \ldots \ldots$

WORKSHOP PARTICIPANTS AND BIOGRAPHICAL DATA ............. 5

AGENDA OF WORKSHOP $\ldots \ldots \ldots \ldots \ldots \ldots \ldots \ldots \ldots \ldots \ldots \ldots \ldots \ldots \ldots \ldots \ldots . \ldots . \ldots . \ldots . \ldots$

CONTRIBUTED PAPERS BY PARTICIPANTS FROM OTHER COUNTRIES

PROGRESS REPORT ON METROLOGY AT THE ARGENTINE REPUBLIC'S

NATIONAL INSTITUTE FOR INDUSTRIAL TECHNOLOGY,

Prof. Rafael Stelnberg, Chief, Physics Department, Instituto

Nacional de Tecnologia Industrial, Buenos Alres, Argentina ...

STANDARDIZATION, QUALITY CONTROL, AND METROLOGY IN BANGLADESH,

Mr. Abu Hossain Khan, Director, Bangladesh Standards

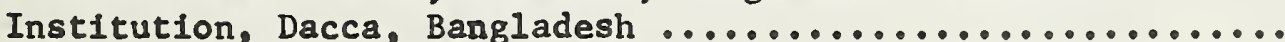

STANDARDIZATION AND MEASUREMENT SERVICES IN BOLIVIA,

Eng. Hernando Montano V., Chief, Engineering Division,

Direccion General de Normas y Tecnologia, La Paz, Bolivia ....

METROLOGICAL SERVICES IN THE ARAB REPUBLIC OF EGYPT, Dr. Mohammed M. Ammar, Director, National Institute for Standards, Academy of Sclentif1c Research and Technology, Cairo, Egypt 
SOME PROBLEMS IN THE ENFORCEMENT OF COMPLIANCE WITH STANDARDS

IN GHANA, Dr. G. Yao Ahlijah, Principal Scientific Officer,

Ghana Standards Board, Accra, Ghana ...................

MEASUREMENT SYSTEM IN INDONESIA, Dr. Bambang H. Hadiwiardjo, Deputy Director, National Institute for Instrumentation, Indonesian Institute of Sciences, Bandung, Indonesia ........

NATIONAL STANDARDIZATION SYSTEM FOR INDONESIA, Mrs. Sriat1 Djaprie, Assistant Deputy Chalrman for Technology, Indonesian Institute of Sciences, Jakarta, Indonesia ........

ORGANIZATION OF THE ELECTRICAL DEPARTMENT OF THE KENYA BUREAU OF STANDARDS, Mr. James D. Gikand1, Senior Electrical Standards Officer, Kenya Bureau of Standards, Nairob1, Kenya .........

INDUSTRIAL SURVEY IN KOREA, Dr. Choonghi Rhee, Chief, Temperature Standards Laboratory, Korea Standards Research

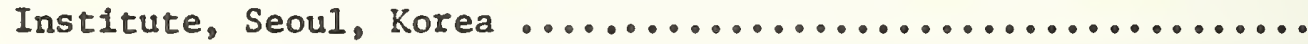

STANDARDIZATION AND MEASUREMEIT SERVICES AND THE PROBLEMS ENCOUNTERED IN MY OWN COUNTRY, Mrs. Anacleta B. Mascarinas, Chief, Inspection and Certification Division, Philippines Bureau of Standards, Manila, Philippines ...............

STARTING FROM SCRATCH IN THAILAND, Mr. Chalwal Sangruji, Acting Director, Thal Industrial Standards Institute,

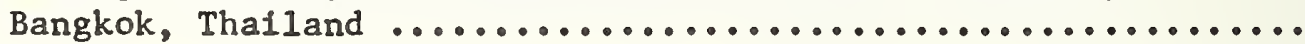

CONTRIBUTED PAPERS BY PARTICIPANTS FROM INTERNATIONAL ORGANIZATIONS

ASMO ACTIVITIES IN THE FIELDS OF STANDARDIZATION AND METROLOGY, Eng. K. I. Abulyosr, Head, Standardization and Metrology Department, Arab Organization for Standardization and Metrology, Calro, Egypt ............................

THE INTERNATIONAL ORGANIZATION FOR STANDARDIZATION, Dr. Robert Oteng, Director, Development Committee, International Organization for Standardization, Geneva, Switzerland 
SOLUTIONS LOOKING FOR PROBLEMS IN DEVELOPING NATIONS,

Mr. L. E. Gatterer, President, Lawrence Gatterer Associates .. 111

INVENTION AND TECHNOLOGY, Mr. Jacob Rabinow, NBS Consultant .... 115

REMARKS, Dr. Victor Rabinowitch, Director, Board on Science and Technology for International Development, Commission on International Relations, National Academy of Sciences, National Research Council .......................... 129

PARTNERS IN THE PURSUIT OF PRECISION (The Past as Prologue), Mr. William A. Wildhack, Associate Director, Retired, National Bureau of Standards ....................... 137

QUESTIONS AND ANSWERS ADDRESSED BY PARTICIPANTS

QUESTIONS AND ANSWERS ADDRESSED BY PARTICIPANTS OF THE NBS/AID WORKSHOP, OCTOBER 1977 
For the seventh time, my NBS colleagues and I are pleased to present the summary report of a Workshop on Standardization and Measurement Services. For two weeks distinguished technologists from twelve less industrialized countries visited the United States to see how standards and measurement services are applied in the U.S. public and private sectors. The purpose of such an exposure is not necessarily to encourage duplication overseas, but rather to bring about an awareness of some approaches and then to let the observer decide which aspects might benefit his own country.

Each year an attempt is made to vary the U.S. Institutions visited by the Workshop group. In contrast to previous agenda, this year the program began with the national tour followed by the overview of the National Bureau of Standards in Gaithersburg. A special two-day Seminar entitled "Standardization in Support of Development" was intended to serve as a reference point for the $1979 \mathrm{U} . \mathrm{N}$. Conference on Science and Technology for Development. (The proceedings of this Seminar are available in NBS Special Publication 507, issued in May 1978.)

This report outlines the program that was followed, as well as several of the evening talks given by invited speakers and individual reports presented by the participants on issues related to standardization and measurement in their countries. Two distinguished representatives of international organizations, Dr. Robert Oteng, Director of the Development Comittee, International Organization for Standardization, and Englneer Kamal Abulyosr, Arab Organization for Standardization and Metrology, honored the Workshop with their attendance. Their international viewpoints enriched the discussions and observations of the Workshop.

On behalf of the National Bureau of Standards and the Agency for International Development, whose funds made the Workshop possible, I wlsh to express my gratitude to the many nationwide hosts who so generously welcomed the group to their institutions and made excellent presentations of their programs. My colleagues in other Federal agencies and those at NBS, both in Boulder and Gaithersburg, gave generous support.

A spectal word of thanks is due the Office of Sclence and Technology at the Agency for International Development, especially Mr. William Roseborough, whose interest in our program has been most valuable.

H. Steffen Peiser

Chief

Office of International Relations 


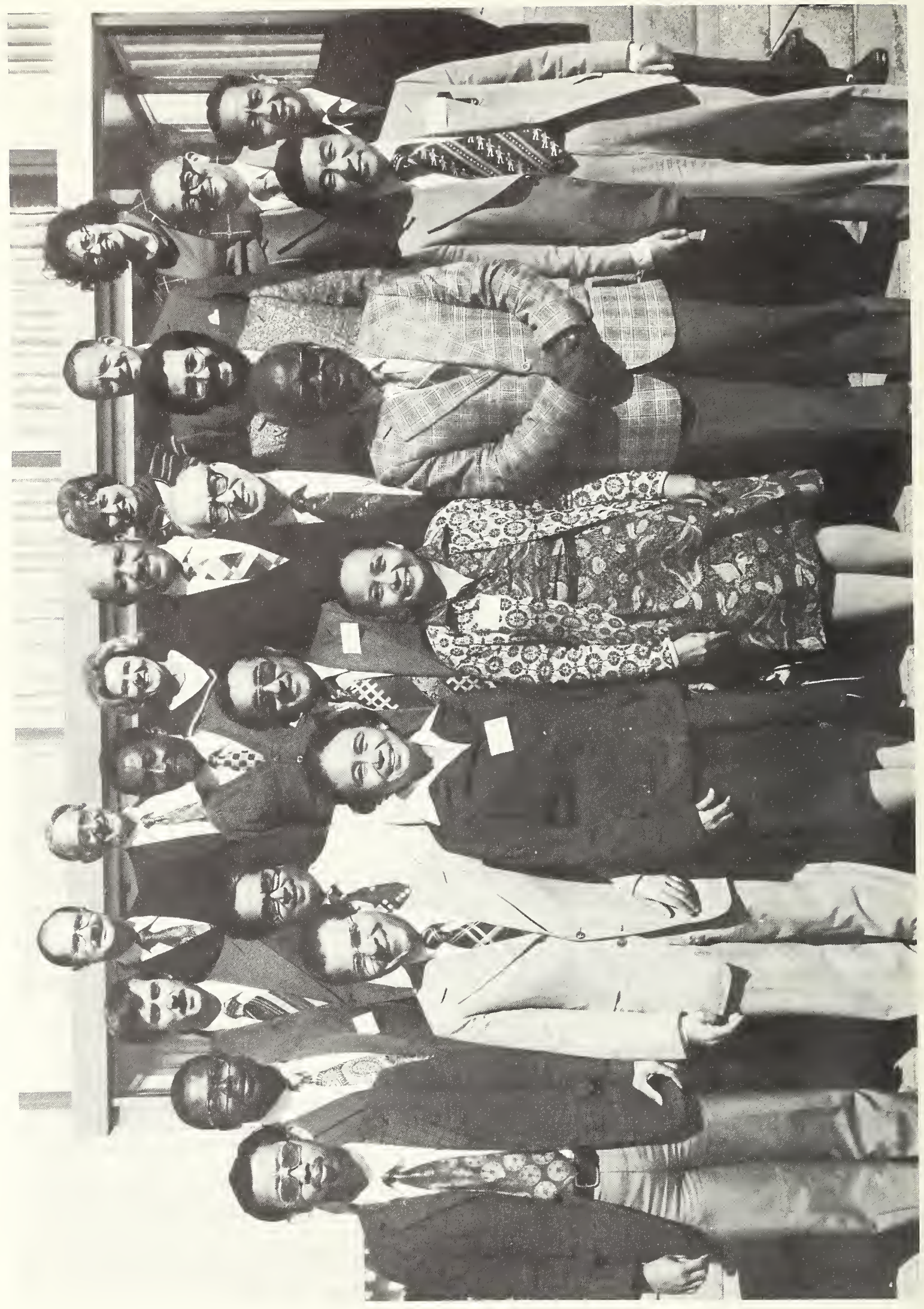




\section{Front (left to right):}

Dr. B. Hadiwlardjo; Dr. M. Ammar; Mrs. A. Mascarinas;

Mrs. S. Djaprle; Dr. R. Oteng; Dr. C. Rhee.

\section{Middle (left to right):}

Dr. G. Ahlljah; Dr. A. Khan; Mr. H. Montano; Dr. E. Brady;

Mr. M. Mos-haf1; Prof. R. Stelnberg; Mr. C. Sangruj1.

Back (left to right):

Mr. C. Raley; Mr. N. Raufaste; Mr. S. Pelser; Mr. J. Gikandi;

Mrs. D. Bluebond; Eng. K. Abulyosr; Mrs. J. Mejeur; Mr. J. Birch;

Mrs. P. Odar. 



\section{National Representatives}

1. Prof. Rafael Steinberg

Chief, Department of Physics

Institute Nacional de Tecnologia Industrial

Libertad 1235

Buenos Aires, Argentina

Professor Steinberg, born in Buenos Alres, recelved his degree from the University of Buenos Aires, Faculty of Exact, Physical, and Natural Sciences. Since 1960 he has been Chief of the Physics Department, Argentine National Institute of Industrial Technology, and in 1976 he was elected President of the International system for Metrology.

2. Mr. Abu Hossain Khan

Director, Bangladesh Standards Institution

3-DIT (Extension) Avenue

Motifheel Commercial Area

Dacca 2, Bangladesh

Mr. Khan received a D.L.U. degree in Mechanical Engineering in England. Prior to 1971 he was Director of the Pakistan Standards Institute in Karachi. Since 1973 he has been Director of the Bangladesh Standards Institution.

3. Mr. Hernando Montano V.

Chief, Engineering Division

Direccion General de Normas y Tecnologia

Casilla 4430

La Paz, Bolivia

Mr. Montano, born in Cochabamba, Bolivia, received a B.S. degree in Engineering from San Andres University in 1972. He has been Chief of the Engineering Division of the Bolivian General Direction of Standards and Technology since 1977.

4. Dr. Mohammed Mahmoud Ammar Director, National Institute for Standards Academy of Scientific Research and Technology P.O. Box 2343, Dokki

Cairo, Egypt

Dr. Ammar received his M.S. from Cairo University in 1960 
and $\mathrm{Ph} . \mathrm{D}$. from Moscow State University in 1965. His specialties are physics and heat measurement. He has been Director of the Egyptian National Institute for Standards since 1976.

5. Dr. G. Yao Ahlijah

Principal Scientific officer

Ghana Standards Board

P.O. Box M. 245

Accra, Ghana

Dr. Ahlijah received a $\mathrm{Ph} . \mathrm{D}$. In Chemistry from the University of London in 1969. Since 1973 he has been Principal Scientific Officer, Ghana Standards Board.

6. Mrs. Sriati DJaprie

Assistant Deputy Chairman for Technology

Indonesian Institute of Sciences

P.0. Box 250

J1. Teuku TJhik Ditiro 43

Jakarta, Indonesia

Mrs. Djaprie, born in Boror, Indonesia, holds an M.S. degree in Engineering from Syracuse University (1960), an M.S. degree in Metallurgy, University of Sheffield (1972), and a Diploma in Organization and Structure of Science and Technology from the University of Manchester (1972). She attended the 1975 Cornell University Summer Institute in Sclence, Technology, and Development.

7. Dr. Bambang H. Hadiwlardjo

Deputy Director, National Institute for Instrumentation

Indonesian Institute of Sclences

Complex L.I.P.I., JI. Sangkuriang

Bandung, Indonesia

Dr. Hadiwlardjo, born in Banjumas, Indonesia, holds

Ph.D. degrees in Physics from the Institute of Technology

In Bandung (1966) and from Delft University (1969), as

well as a Certificate for Nuclear Magnetic Resonance.

8. Mr. Mohammad Mos-haf 1

Director, Division of Electrical and Electrotechnical Industries Institute of Standards and Industrial Research of Iran

P.O. Box 2937

Tehran, Iran

Mr. Mos-hafi, born in Tehran, received M.S. degrees in Power Transmission Engineering and Electronic Engineering from Tehran University. Since 1976 he has been Director of the Division of Electrical and Electronic 
Industries. (Paper for this report not available from Mr. Mos-hafi.)

9. Mr. James D. Gikandi

Senior Electrical Standards officer

Kenya Bureau of Standards

P.0. Box 10610

Nairobi, Kenya

Mr. Gikand1, born in Nyeri, Kenya, recelved a M.S. degree in Electrical Power Engineering from the Czechoslovak Technical University, Prague, in 1971. Since 1975 he has been Senior Electrical Standards officer, Kenya Bureau of Standards.

10. Dr. Rhee, Choonghi

Chief, Temperature Standards Laboratory

Korea Standards Research Institute

P.0. Box 333

Dae Jeon, Korea

Dr. Rhee, born in Inchon, Korea, recelved an M.S. In Physics from Seoul National University in 1962 and a Ph.D. in Physics from Brown University in 1969. In 1977 he became Chief of the Temperature Standards Research Laboratory, Korea Standards Research Institute.

11. Mrs. Anacleta B. Mascarinas

Chief Standards officer

Inspection and Certification Division

Philippines Bureau of Standards

P.O. Box 3719

Manila, Philippines

Mrs. Mascarinas, born in Celeu, Philippines (deceased 1977), received a Bachelor of Laws degree from Far Eastern University in 1952. She became Chief Standards officer in 1976.

12. Mr. Chaiwai Sangruji

Acting Director, Thai Industrial Standards Institute Department of Science

Rama VI Street

Bangkok, Thailand

Mr. Sangruji, born in Bangkok, recelved an M.S. degree in Chemical Engineering Practice from Massachusetts Institute of Technology. Since 1967 he has been the Acting Director of the Thai Industrial Standards Institute and Chief Engineer, Ministry of Industry. 
13. Eng. Kamal I. Abulyosr

Head, Standardization and Metrology Department

Arab Organization for Standardization and Metrology

P.O. Box 27, Dokki

Cairo, Egypt

Mr. Abulyosr, born in Calro, recelved a B.S. degree In Electrical Engineering. Since 1969 he has been Director of the Standardization and Metrology Department, Arab Organization for Standardization and Metrology.

14. Dr. Robert Oteng

Director, Development Committee

International Organization for Standardization

Case Postale 56

1211 Geneva 20, Switzerland

Dr. Oteng received a Ph.D. from the University of London. Since 1972 he has been Director of the Ghana Standards Board. In addition he is currently Director of the Development Committee of the International Organization for Standardization, Geneva. 
National Bureau of Standards Agency for International Development

WORKSHOP ON STANDARDIZATION AND MEASUREMENT SERVICES

$$
\text { October } 1-18,1977
$$

\section{October 1, Saturday}

$$
\text { AM - PM Arrive Denver, Colorado, U.S.A. }
$$

October 2 , Sunday

12:00 Noon

Al1-Day Outing, Dinner and Talk

Mr. L. E. Gatterer

President, Lawrence Gatterer Associates

October 3 , Monday

$$
\begin{aligned}
& \text { 9:30 AM } \quad \begin{array}{l}
\text { Hewlett-Packard Company } \\
\text { 815 S.W. Fourteenth Street } \\
\text { Loveland, CO } 80537 \\
\text { (303) } 667-5000
\end{array} \\
& \text { Host: Mr. C. Waller } \\
& \text { Chief, Product Assurance Division } \\
& \text { 1:00 PM } \quad \text { Institute for Bas1c Standards } \\
& \text { National Bureau of Standards } \\
& \text { Boulder, CO } 80302 \\
& \text { (303) 499-1000 } \\
& \text { Host: Mr. B. W. Birmingham } \\
& \text { Deputy Director, IBS/Boulder }
\end{aligned}
$$

October 4, Tuesday

$9: 30 \mathrm{AM}$

Solar Energy Research Institute

1536 Cole Boulevard

Golden, CO 80401

(303) 234-7171

Host: Mr. D. Taylor

Public Information office 
$12: 00$ Noon

Colorado School of Mines

1500 Illinois Street

Golden, CO 80401

(303) $279-0300$

Host: Mr. C. S. Morris, Director

Public Relations

\section{October 5, Wednesday}

$8: 30$ AM

Dana Corporation

8000 Yankee Rd.

Ottawa Lake, Michigan 49267

(313) $856-5111$

Host: Mr. W. T. Groves, Vice President Technical Services

3:00 PM

Chemical Abstracts Service

P.0. Box 3012

(2540 Olentangy River Road)

Columbus, $\mathrm{OH} \quad 43210$

(614) 421-6940

Host: Dr. D. Myers, Manager

Project Coordination Department

October 6, Thursday

9:00 AM

Toledo Scale

P.0. Box 1705

(350 W. Wilson Bridge Rd., Worthington)

Columbus, OH 43216

(614) $438-4548$

Host: Mr. T. M. Stabler, Manager

Weights and Measures

1:30 PM Department of Food Science and Nutrition Ohio State University

2121 Fyffe Road

Columbus, $\mathrm{OH} 43210$

(614) 422-6281

Host: Dr. T. Kristoffersen, Chairman 
October 7, Friday

$9: 00 \mathrm{AM}$

$11: 30 \mathrm{PM}$
GenRad, Inc.
300 Baker Avenue
Concord, MA 01742
(617) $369-4400$

Host: Dr. J. F. Hersh, Manager

Standards Laboratory

Massachusetts Institute of Technology

77 Massachusetts Avenue

Cambridge, MA 02139

(617) $253-2851$

Host: Mrs. V. Lyons, Assistant for International V1sitors

October 8, Saturday

$$
\text { AM - PM Free }
$$

October 9, Sunday

$$
\text { AM - PM Free }
$$

October 10, Monday

AM Free

3:00 PM AMP, Inc.

Technical Services Division

2100 Paxton Street

Harrisburg, PA 17105

(717) $564-0100$

Host: Mr. K. G. Conrad

October 11, Tuesday

$9: 30$ AM

Bureau of Standard Welghts and Measures Department of Agriculture

Commonwealth of Pennsylvania

2301 N. Cameron Street

Harrisburg, PA 17120

(717) 787-9089

Host: Mr. W. F. Junkins, Director

7:00 PM Dinner and Talk, Dr. A. Crane

Office of Technology Assessment,

Energy Group, U.S. Congress 


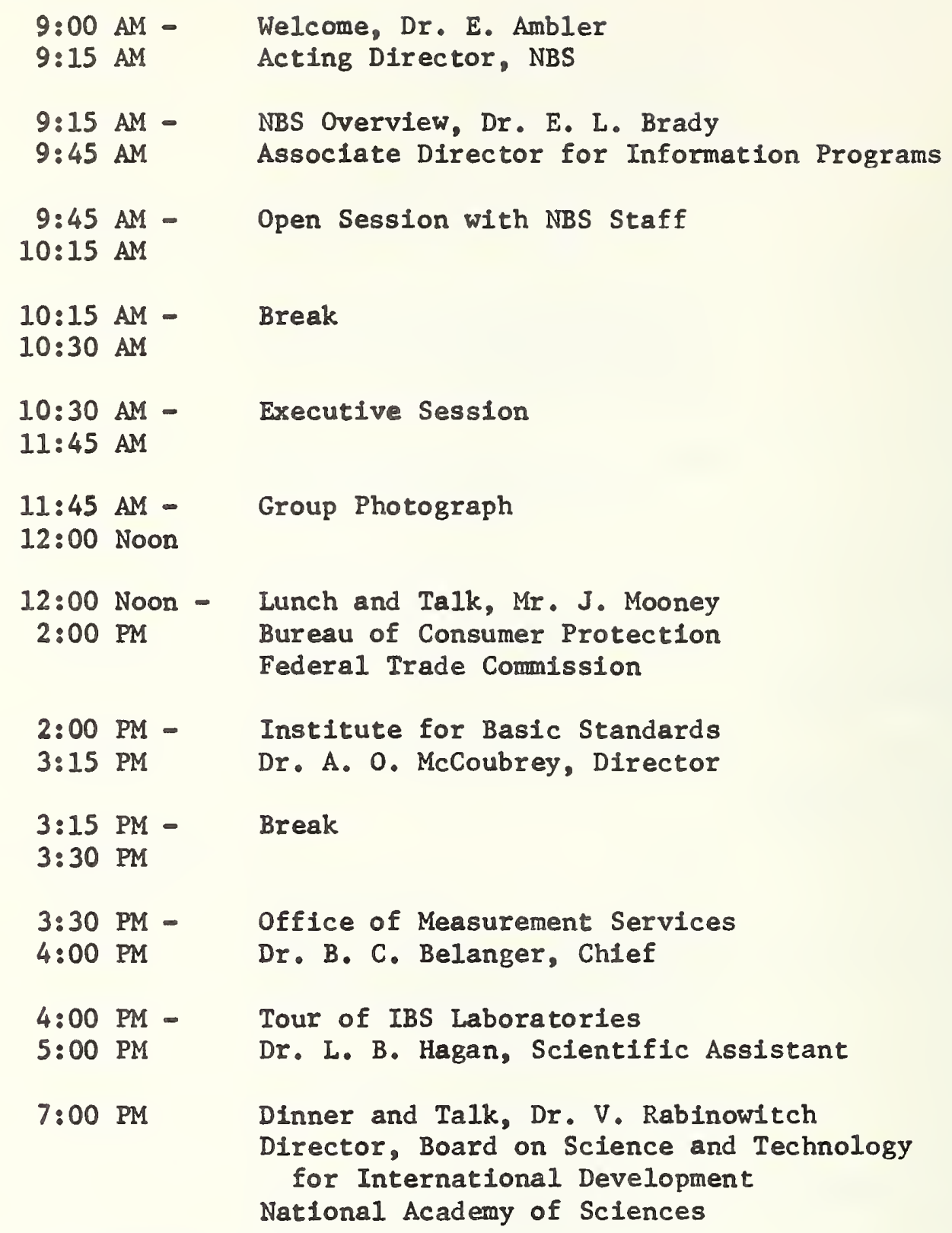

October 13, Thursday

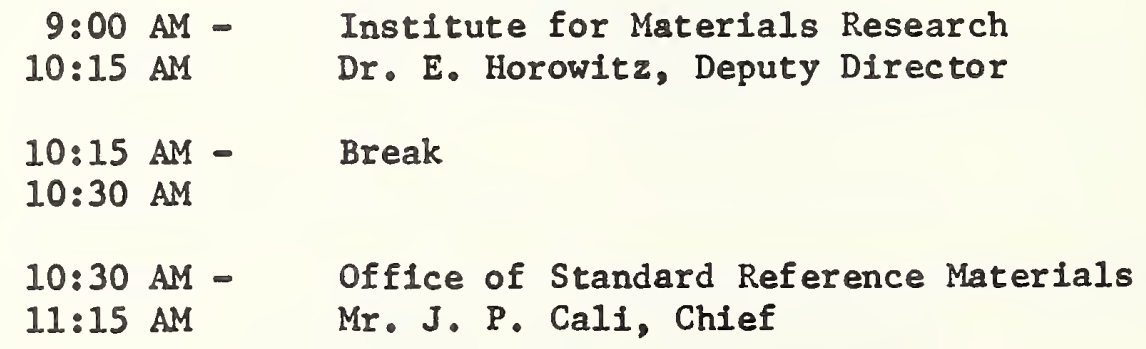




$\begin{array}{ll}\begin{array}{l}\text { 11:15 AM - } \\ \text { 12:00 Noon }\end{array} & \begin{array}{l}\text { Office of Air and Water Measurement } \\ \text { 12:00 Noon - A. Hodgeson, Deputy Chief }\end{array} \\ \text { 2:00 PM } & \begin{array}{l}\text { Lunch and Talk, Mr. D. Shonyo } \\ \text { Forelgn Programs Liaison Offlce } \\ \text { National Technical Information Office }\end{array} \\ \text { 2:00 PM - } & \text { Inst1tute for App1led Technology } \\ \text { 3:15 PM } & \text { Mr. J. L. Haecker, International Coordinator } \\ \text { 3:15 PM - } & \text { Break } \\ \text { 3:30 PM } & \\ \text { 3:30 PM - } & \text { Tour of IAT Laboratories } \\ \text { 5:00 PM } & \text { Mr. J. L. Haecker, International Coordinator } \\ \text { 7:00 PM } & \text { Dinner and Talk, Mr. J. Rabinow } \\ & \text { Chief Research Engineer, IAT, NBS }\end{array}$

October 14, Friday

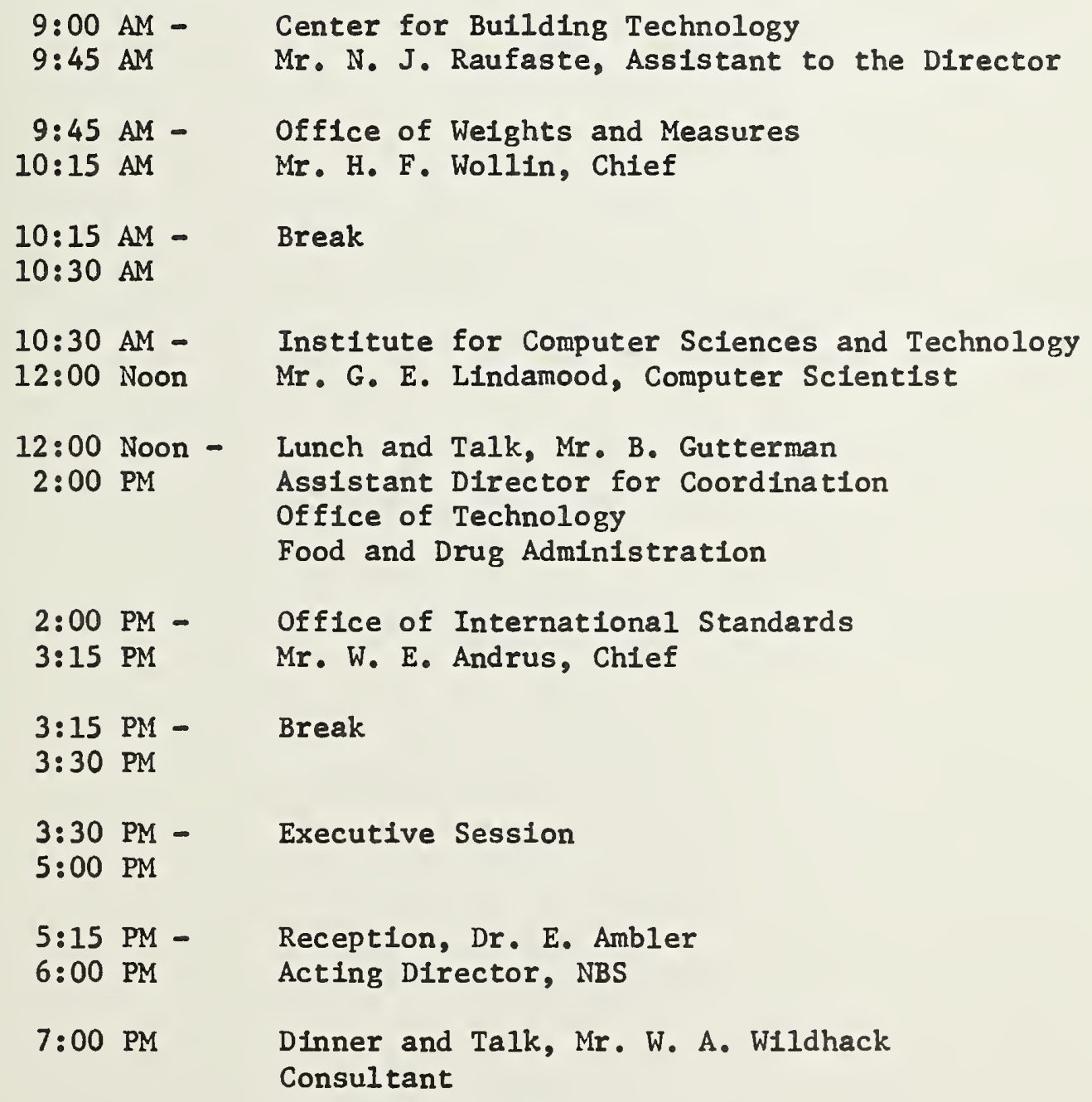


October 15, Saturday

$$
\text { AM - PM Free }
$$

October 16 , Sunday

$$
\text { AM - PM Free }
$$

October 17, Monday

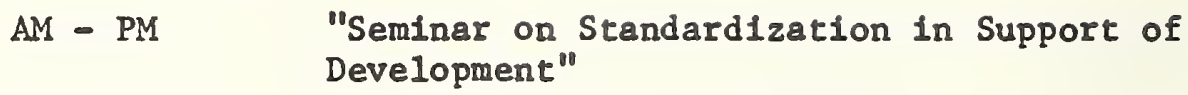

October, 18, Tuesday

$$
\text { AM - PM } \quad \begin{aligned}
& \text { "Seminar on Standardization in Support of } \\
& \text { Development" }
\end{aligned}
$$


CONTRIBUTED PAPERS

BY PARTICIPANTS

FROM OTHER COUNTRIES 

PROGRESS REPORT

ON METROLOGY AT THE ARGENTINE REPUBLIC'S

NATIONAL INSTITUTE FOR INDUSTRIAL TECHNOLOGY

by

Prof. Rafael Steinberg

Chief, Physics Department

Instituto Nacional de Tecnologia Industrial

Buenos Aires, Argentina

In a previous communication (NBSIR 75-769, Nov. 1974), a short reference was given on the institutional status of metrology in the Argentine Republic. That communication happened to be contemporary with the first steps towards the establishment of a coordination program among the sister institutions of the American countries (OASNBS, Boulder, Nov. 1974) following a recommendation formulated during the fourth CIECC (Consejo Interamericano para la Educacion, 1a Ciencia y la Cultura) meeting in Mar del Plata, Argentina, in December 1972. These developments gave birth to the present "Sistema Regional de Metrologia y Calibracion" (SIMYC), sponsored by the Organization of the American States (OAS) after final approval by the OAS technical organ in 1976.

SIMYC has the two following main objectives:

1) To contribute to the effective execution of the industrialization programs of the region by providing adequate metrological services in education, research, industry, commerce, and other areas, including those related to international certification of quality.

2) To optimize the use of available metrological resources of the member countries by coordination resulting from a uniform set of principles and rules of practice.

At present, active member countries of SIMYC are: Argentina, Bolivia, Brazil, Costa Rica, Ecuador, Jamaica, Mexico, Panama, Paraguay, and Uruguay.

The project has now been effective since March 1976. In order to evaluate its early achievements, a meeting was called by the OAS in Panama during the last week of September 1977. This meeting was also attended by Chile's, Colombia's, Peru's, and Venezuela's metrology bodies, which expressed their interest in becoming members of the system. The U.S. National Bureau of Standards, the Physikalisch Technische Bundesanstalt (PTB of the German Federal Republic), the International Organization for Legal Metrology (OIML), and the 
Development Agency of the Cartagena Agreement had delegates at the meeting by special invitation.

After hearing and discussing the detailed reports presented by the members, it became clear that everyone had been active in metrological projects in response to the industrialization programs of their countries. One of the main problems to be solved is that of adequate training of personnel.

In order to ensure the permanent continuation of the task initiated through OAS' special project, which is limited in time to two years, the participants agreed on the convenience of a proposal which was made to their respective governments and to OAS, suggesting the creation of a "Sistema Interamericano de Metrologia" (SIM). To that objective, a provisional committee was elected with committee membership by Argentina, Brazil, Mexico, Venezuela, and Panama.

It is the purpose of this paper to point out some actions taken by the National Institute for Industrial Technology (INTI) in relation to the objectives of the SIMYC project.

During the months of July to September 1976, two intensive courses in metrology (mechanical and electrical) were held in Spanish at INTI's premises in Miguelete near Buenos Aires. The lecturers and technical assistants were all from INTI's staff. The morning classes were in theory, and the afternoons were devoted to practical work, which consisted mainly in the handling of actual measurement situations from actual tasks required by INTI's customers. Thus, the trainees were offered an insight into what might be anticipated to be their own future tasks. The engineering metrology course covered subjects on geometrical, mass and force measurements; the electrical metrology course extended from d.c. to a.c. measurements and instrument calibration. Both courses were attended by 17 young engineers from 10 countries: Brazil (3), Bolivia (1), Chile (1), Colombia (1), Ecuador (2), Mexico (3), Peru (1), Paraguay (2), Panama (2), and Venezuela (1). The first Regional Course was dedicated to the recent 100th anniversary of the Meter Convention. It is, as is well known, the first international agreement on metrology.

In our view, the course fulfilled its objective: namely, to place the prospective metrologist in the proper atmosphere of work, where he has to cope with the kind of problems which he should expect in his future activities, thus supplying him with the right "feeling" which no other experience can offer. As far as we know, this is the only way to provide a reasonable solution to the most important of the many problems to be faced: the lack of trained competent people in the region. There is no alternative to the direct transfer of experience.

One of the possible limitations of our course has been the short time (three months) allowed, and we have to accept this criticism because our operational infrastructure did not permit us to extend the 
courses. The handling of a large group makes demands, such as for lodging, health problems, etc., which involve an extra effort to an already burdened administration.

Personally, I think better results can be obtained through a system of scholarships by which two or three students are assigned to a certain laboratory for a term not shorter than six months. This solution has a further advantage: after the first months, the trainees become true collaborators in the normal operation of the laboratory. They do not dislocate its operation, as otherwise is inevitable. During the years 1975-76, we also had this type of experience with specialists from Mexico. Two had master's degrees in optics from INAOE (Instituto Nacional de Astronomia, Optica y Electronica, Tonantzintla, Puebla), and two were mechanical engineers from the Instituto Politecnico, Mexico City. Their program originated out of an agreement between the Governments of Mexico and Argentina signed in 1975. This program will continue now with two other engineers: one from Instituto Politecnico and one from the Direccion General de Normas.

Since this type of arrangement has been recognized as effective, the Federal German Republic, through a technical assistance project with our country, has offered to support five full scholarships per year to be awarded to Latin Americans for assignment to INTI's Department of Physics, thereby supplying a most valuable contribution to the metrology profect.

As another instance of our participation in the fulfillment of the objectives of SIMYC, I would like to mention the direct and most rewarding cooperation between INTI and Uruguay (LATU, Laboratorio de Analisis y Technologia del Uruguay), Bolivia (DGNT, Direccion General de Normas y Tecnologia, La Paz), Panama (COPANIT, Comision Panamena de Normas Tecnicas y Tecnologia), and institutes of the member countries of the Cartagena Agreement (Bolivia, Ecuador, Colombia, Peru, and Venezuela).

In a final appraisal of this point, one could say that we in South America have now fully recognized that, if industrialization in our countries is to proceed, and particularly if our countries are to become exporters of industrial products, a sound foundation of reliable and internationally acceptable measurements is essential.

During the last years, a new step in this direction has been taken by INTI over a very specialized field of dimensional measurements. From time to time, our attention was drawn to the fact that some of our customers were having continuous trouble in keeping up their stock of reference API (American Petroleum Institute) gages in accordance with API rules which require periodical certification that the gages are within acceptable limits as specified by the corresponding API Standards. The certification itself can be made only by a very limited number of laboratories in the world which have been designated by API as official agencies for that purpose. The troubles arose in 
the rather complicated process required to have the gages exported from, and then returned to, the country after being certified.

Argentina has, from the early part of the century, been a petroleum producing country. Although the main enterprise (YPF, Yacimientos Petroliferos Fiscales) is state owned, a certain number of private firms take an active part in drilling, extracting, and refining operations. There exists, therefore, an intensive demand for tubing, pipeline, sucker rods, and other components of equipment, all of which are locally produced. Research into the market showed that there are around 30 active firms in this business of making components; some of them are large enough to sell abroad part of their production. The energy crisis has intensified petroleum exploration everywhere, and of course, in Argentina, too.

So, it seemed to us this was a measurement field worth entering for INTI. We had two men sent to Physikalisch Technische Bundesanstalt, one of the "official agencies," to learn the art with Dr. W. Beyer, head of the thread gage section there. Back at our laboratory, we had Dr. Beyer's personal assistance for three months. After considerable "non-official" work on API gages, we decided that one of the programs to be proposed under the SIMYC scheme would be the implementation of an API Gage Certification Laboratory, as some of the controls require the employment of API Regional Master Standards, which are very expensive.

Meanwhile, an inquiry over the 30-odd component makers informed us about the statistical distribution of the reference gages they owned, so that we were in a position to determine the types to be covered by the new service. A complete coverage would be economically unsound. This information and a description of the available measurement facilities at our laboratory were sent to API headquarters at Dallas, Texas, asking for a recognition of INTI as the "official certification agency." We recelved a letter dated September 1, 1976, signed by Mr. J. E. Ubben, Assistant Director, in which it is stated "that at the API Standardization Conference, June 14-18, 1976, the Executive Comittee on Standardization approved a recommendation of the Subcomittee on Gages and Gaging Practice to designate the Instituto Nacional de Tecnologia Industrial of Buenos Aires, Argentina, an Official Certification Agency for API Reference Master Thread Gages under API Std.5B and Spec.11B. This authorization permits INTI certification of all tubing and casing gages (except Extreme-line) in accordance with the requirements of $\mathrm{Std} .5 \mathrm{~B}$ and all sucker rod gages in accordance with Spec.11B."

It is also stated "that authorization to certify rotary-shouldered connection gages under Spec.7 will be held in abeyance, pending delivery of the Reglonal Master Rotary Gages which you are in the process of obtaining." This last statement refers to the provision of a set of Regional Master Gages which is now proceeding through the SIMYC project. 
The new situation offers a wealth of possibilities, such as:

1) Invigorating a specialized industry by removing the previously existing troubles and, more important still, by giving it sound technical support on an internationally agreed level.

2) Inducing the local making of gages (work and reference types).

3) Facilitating the exportation of components.

4) Serving the region, through certification of gages from neighboring countries. 

STANDARDIZATION, QUALITY CONTROL, AND METROLOGY IN BANGLADESH *

by

Mr. Abu Hossain Khan

Director, Bangladesh Standards Institution

Dacca, Bangladesh

First of all, I would like to congratulate the National Bureau of Standards for arranging this type of workshop on standardization and measurement. It is really gratifying to note that NBS has taken so much pain to propagate the various aspects of standardization and measurement through this Workshop. I also want to take this opportunity to express my profound thanks for inviting me to this Workshop.

Bangladesh came into existence after a liberation war in 1971. Before the liberation, there was a Branch Office of the Pakistan Standards Institution at Dacca. The writer was then Director of the Pakistan Standards Institution at Karachi. After liberation, the Branch Office at Dacca was named as the Bangladesh Standards Institution (BDSI) by the Government of the People's Republic of Bangladesh, and it became the Head Office with an Inspectorate at Chittagong, the port city. The writer, after the liberation, joined BDSI only in 1973 as he had been stranded in Karachi.

The Institution has been functioning in practice since 1974. There were nearly 400 Pakistan standards available in the library of BDSI. These standards were obviously adopted as Bangladesh standards,

because the Bangalees had contributed towards the formulation of these standards; and the standards were also sultable for Bangladesh. BDSI itself has formulated nearly 40 new standards within the domain of 2 Divisional Councils now in existence, $1 . e .$, (1) Agricultural and Food Products Divisional Council, and (2) Electrotechnical Divisional

Council. Twenty more standards are under preparation. A Certification Marking Division has started work in practice from 1975.

BDSI at present has officers and staff for the following divisional councils and divisions:

1) Agricultural and Food Products Divisional Council

2) Electrotechnical Divisional Council

3) Certification Marking Division

* The views expressed in this article are the writer's own and should not be considered as the official views of the Ministry of Industries. 
The following divisional councils are officially established, but no positions have yet been filled due to shortage of funds:

1) Jute and Textile

2) Chemical

3) Civil Engineering

4) Mechanical Engineering

The urgent work for these above-mentioned four divisional councils is carried out by the existing BDSI officers and staff. In addition, BDSI is also investigating some aspects of metrology. Though the International Metric System (SI) has not yet been officially introduced in Bangladesh, there are many industries which measure their production, distribution, and sales in the metric system. The Government has asked BDSI to investigate the problems to be expected when switching to the metric system and to find out the approximate cost and optimum length of the transition period. BDSI is at present collecting data for this purpose.

BDSI became a member of the International Organization for Standardization (ISO) in 1974. In the following year, it also was made a member (contact point) of the Joint FAO/WHO* Codex Alimentarius Commission by the Government of the People's Republic of Bangladesh based on the concurrence of the Ministry of Agriculture and the Ministry of Health and Population Planning.

BDSI is financed mainly by a grant-in-aid from the Government of the People's Republic of Bangladesh. The Ministry of Industries is the administratively responsible ministry of BDSI. The Director is the principal executive officer appointed by the Government. The policies for running the affairs of BDSI are framed by a General Council. The President of the General Council is the Minister in charge of the Ministry of Industries.

National standards are formulated through the structure of divisional councils and sectional committees as is usually practiced in other countries. BDSI performs its dutles as Secretariat and obtains general consensus of opinion by all interested representatives from Government, autonomous private and public organizations, manufacturing units, experts, consumers, etc. There are nearly 70 such sectional committees engaged in the formulation of national standards. BDSI has to consult and draw assistance from other national and international standards, which serve as useful guides in the formulation of Bangladesh standards. BDSI at present has no testing facilities of its own, but usually sends representative samples collected by the BDSI staff to the Central Testing Laboratories or any other suitable laboratory organization for testing. BDSI is trying to establish a testing laboratory, so that it can carry out tests for the purpose of standardization.

* Food and Agriculture Organization of the U.N. and the World Health Organization 
All of us know that a standard normally consists of the following sections: foreword, scope, terminology, requirements, methods of testing, packing and marking, sampling plan, criteria for conformity, etc. Bangladesh does not have the resources to carry out research required for the formulation of standards. The testing equipment is mainly produced by the developed countries. It is therefore imperative for the developed countries to produce standard testing equipment instead of introducing too many varleties. If this aspect of standardization could be improved, I think all the national standards bodies of the world would be in a better position in formulating their specifications and codes of practice. On definitions and terminology, BDSI consults with ISO, International Electrotechnical Commission (IEC), British Standards (BS), American Soclety for Testing and Materlals (ASTM), and FAO/WHO Standards. Only when there is controversy about a term do the BDSI sectional committees or divisional councils define that term for our own requirements. Sometimes BDSI is faced with different terms for one and the same item by various organizations mentioned earlier. In such cases, our divisional council or sectional committee has to decide to adopt one or define another term independently. While formulating the standard requirements, BDSI has to find out whether the indigenous item is intended for export. If so, international requirements must be incorporated, otherwise the item may not be accepted by the importers abroad. Here we would like to mention our belief that once an item conforms to the requirements of the relevant international standards (such as FAO/WHO tandards), there should not be any question of conforming to any other food regulation or laws of a particular country. It is not always possible for an exporting country to conform to various food regulations of different importing countries.

In certain cases, the BDSI adopts or endorses ISO, IEC, BS, ASTM, and Deutsches Institut fur Normung (DIN) specifications to a certain extent, although it has to incorporate the local climatic conditions and investigate the availability of testing equipment in the country. Unfortunately, we do not have the resources to carry out research, so we must accept the results of research done by developed countries.

Although our country has basically an agro-based economy, the various industries necessary to supplement agriculture have to be developed. For example, agricultural implements, fertilizer, and even educational services to farmers to encourage work in a standardized manner would be necessary to achieve economic emancipation of our nation. Through standardization, order can be achieved out of chaos.

It is understood that standardization and quality control are based on technical know-how. All the developed countries have acquired not only this knowledge, but also are capable of producing the needed plant, equipment, and machinery. It is, therefore, necessary for developed countries to impart not only their knowledge, but also distribute that plant and equipment to the underdeveloped and 
developing countries. Thus, the developed countries are in a position to save the world from famine, disease, war, and mass starvation. All this can be achieved in an efficient way through standardization. This is the way to cut the variety of items for one and the same purpose, for saving wastage of raw materials, and for reducing cost. It is my belief that standardization is an anti-inflationary tool, and as such, it will have to play an important role because the supply of raw materials is limited in this world.

In Bangladesh, the Government has already put some items under compulsory certification marking by BDSI. These items are: cane molasses, electric fans, plugs, biscuits, etc. They cannot be exported without the standard mark. BDSI has so far issued licenses for biscuits, cable, and wire, and is investigating the quality of certain items for 1ssuing licenses.

BDSI has a lot of problems such as an acute shortage of accommodations, funds, and officers and other staff. However, the Government through the Ministry of Industries is considering our case with an open mind and sympathetic attitude. Hope exists that we will be able to overcome our difficulties in due course.

Standardization makes a vital contribution towards the economic development of any country. It is cruclal for a developing economy. The goods exported from a developing country must conform to national and international standards. Once sub-standard goods are recelved by the importing country, it will resist the import of that commodity from that vendor country. Thus, the market for that particular developing country is gravely threatened. On the other hand, if the exportable goods of the developing country conform to the relevant standards, a strong foothold in the export market may be gained. The developing country may get a chance even to increase the price on the basis of quality or find a market for non-conventional items. The developed countries did not attain their present status in the field of standardization overnight. Similarly, the developing or underdeveloped countries find it very difficult to implement many features of standards without having the resources and relevant technical knowhow. In this respect, therefore, developed countries have to come forward to provide technical assistance to further strengthen the standardization, quality control, and metrology programs of the underdeveloped or developing countries. It may not be out of place to mention that when raw materials are supplied by the developing countries, it will be even beneficial for the developed recipient countries to know in advance that the raw materials conform to national or international standards. Thus, it is in the best interests of both developing and developed countries to help each other in these fields for the economic development of all the nations and thus help to narrow the gap in standards of living. As the world is becoming a close-knit society, all the nations must realize that isolation of one particular nation from the rest is not possible. Standardization, especially international standardization, can with other factors play a vital role for achieving the ultimate goal of all the nations of the world. 
by

\author{
Eng. Hernando Montano V. \\ Chief, Engineering Division \\ Direccion General de Normas y Tecnologia \\ La Paz, Bolivia
}

\title{
1. GENERAL BACKGROUND
}

For a number of years, the Government of Bolivia has been taking steps to promote standardization, quality control, and metrology to regulate the growth and development of domestic industry. Through the Supreme Decree (DS) No. 08487 of September 25, 1968, an autonomous "Bolivian Standards Institute" was established in the country. The Constitution of the Institute was approved through DS 08899 of August 19, 1969. However, the Institute never started functioning because of lack of experience in the management of the Institute.

With the establishment of the Ministry of Industry, Commerce, and Tourism (MICT) for the formulation and execution of the national policy for industrial development, in accordance w1th DS 09195 of April 30, 1970, MICT took the initiative in creating in 1971 within its structure the General Directorate of Standards and Technology (DGNT) for the development of standards and for improvement of technology in domestic industry. The Department of Technology was previously functioning in the General Directorates of Industries of MICT, but was transferred to DGNT when the latter was created in 1971.

The national industry was assured a market in public sector consumption through DS 9984 of November 5, 1971. For emphasis on quality control in industry, the Decree made it obligatory that goods would only be accepted by the public institutions if they bore quality certification by DGNT indicating conformity to the requirements of contract stipulations.

DS 12914 of October 3, 1975, prohibited import for a period of two years of a number of products which were also manufactured in the country, so that the national industry would receive a wider assured market and thus be given a chance for establishing itself. The Decree also enjoined the domestic industry to inftiate programs for the improvement both in the quality and the quantity of its production for being competitive internationally during the period.

For consorted efforts towards standardization, quality control, and metrology, DS 12309 of March 17, 1975, made DGNT solely responsible for the promotion of all relevant activities and, under Article 2 of the Decree, entrusted DGNT with the following functions: 
a) The establishment and development of Bolivian standards.

b) The adoption of foreign standards to serve as temporary Bolivian standards.

c) The awarding, regulation, and inspection of quality markings in conformity with Bolivian standards and certification of individual lots.

d) The coordination of activities with other public and private institutions to promote standardization, quality control, and metrology at all levels.

e) The development of technical, financial, and human resources, necessary for accelerating programs in these fields.

f) The coordination with other involved institutions for the control and inspection of the use and fulfillment of the Bolivian standards in all sectors.

g) The preparation of a Law of Measures in Bolivia and its implementation.

From the above, as well as from the remaining formulations of the DS, the intention of the Government is evident in creating an integrated organization for standardization, quality control, and metrology. The Decree also brings out the recognition that only with the combined efforts in these three flelds, effective contribution towards industrial and economic development of the country is possible.

The Flve-Year Plan for the Economic and Social Development of Bolivia (1976-80), approved through the Decree Law 13630 of June 7, 1976, emphasized continuation of efforts on standardization and quality control as a strategy for the fulfillment of the industrial development plan of the country.

In December 1973, the Government of Bolivia decided to request the U.N. Development Program (UNDP) for technical assistance for a national program on quality control, recognizing that the experience and know-how available in the country in this area was limited. The request resulted in the UNDP Preparatory Project during 1976 (BOL/73/006) to:

a) Survey and assess the existing national activities in the flelds of standardization, quality control, and metrology.

b) Formulate basic guidelines for the organization and operations of a national system of standardization, quality control, and metrology.

c) Quantify further UNDP assistance in the implementation of the proposals during a large-scale project to follow. 
The mission of the expert during the Preparatory Project developed a Five-Year Plan for DGNT, in collaboration with the technical staff of the Government for the fulfillment of the project objectives. After assessing the present national activities in the areas under consideration, the plan included suggestions on the organizational structure, procedures, and work-flow based on preferred models, overall work program, and staffing patterns on each of the operational areas. It also recommended that DGNT be transformed into an autonomous institute for more flexibility of operation, after the national efforts in the areas have been reorganized on the basis of the proposals.

The urgency of the program lies in the fact that the creation of an effective national system for standardization, quality control, and metrology is considered by the Government as a basic requirement for economic development of the country, which the Bolivian Five-Year Plan for the Economic and Social Development aims to promote.

\section{REVIEW OF ACTIVITIES}

DGNT activities are carried out through 6 departments to which 38 technical staff members are allotted as follows:

Number of Technical Members
a) Standardization
b) Quality Control
c) Laboratory
d) Metrology
e) Technology
f) Technical Industrial
Information Service

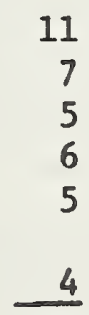

Total

In addition, DGNT has 19 supporting staff members for administration and other functions. The Department of Technology is engaged in diagnostic studies for different sectors of industry for transfer of improved technology to the industry. The Department of Technical Information to Industry has been split off recently from the functions of the Department of Technology.

DGNT has made it known that transfer of technology and industrial research is to be given less priority for the present than tandardization, quality control, and metrology. DGNT activities with respect only to standardization, quality control, metrology, and laboratory facllities are therefore reviewed at this stage. 


\section{STANDARDIZATION}

The First National Plan for Standardization dealt with the initial establishment of 30 technical committees (TC) and under them 183 subcommittees (SC) for development of standards. These TC's and SC's, for convenience of operation at the departmental level, have been grouped under the following five sectors:
a) Fundamentals
b) Chemistry and agriculture
c) Mining, metallurgy, and mechanical products
d) Materials for building and transport
e) Electrotechnical and electronics

From 1972 to June 1977, 220 national standards have been formulated, and 150 draft standards are still under discussion. None of the TC's, however, have been established, and the documents have been processed only through the appropriate SC's.

Scrutiny of the available standards indicates that most of these standards relate to definitions and terminology, methods of testing, methods of sampling, codes of practice, etc. Products covered so far are just specifications for cereals, one each for tin ingot, PVC pipe, ceramic tiles, alpaca fiber, portland cement, soap, flour, and a few more. Considering the large number of items being produced in the country, these efforts naturally do not have much impact either for regulating purchases of quality goods by consumers or government departments, or for guiding the production of goods by manufacturers.

In addition to the work of development of national standards, the DGNT also maintains liaison with international organizations in the field. As a member of the Pan American Standards Commission (COPANT), it has been participating since 1973 in the work of 4 technical committees as a "P" member and of 11 technical committees as an "O" member. The secretariat of the COPANT Committee C 33 with its 5 subcomittees is entrusted to Bolivia. In executing its responsibilities, DGNT has so far prepared eight COPANT standards which are in the last stage of their approval process. Since last year DGNT has been admitted as a correspondent member of the International Organization for Standardization (ISO).

There are a number of reasons why the standards development efforts are not leading to fully effective results so far. Some of these are:

a) The National Plan was put into effect all at once. The limited technical manpower resources were utilized to cover as many areas as possible. This procedure prevented truly systematic efforts being carried out in almost all areas in which some work has been initiated. 
b) In the Plan was the establishment of a number of TC's and under each a certain number of $\mathrm{SC}^{\prime} \mathrm{s}$. This decision was based on the experience of successful working in other countries, where the TC's develop and monitor the work program and the SC's examine and recommend the contents of specific standards. The national standards body acts in such a country as the coordinating organization for the activity. Standards developed through such a mechanism are generally based on the need of the country and are implemented voluntar $11 y-$-both by manufacturers and users, because a consensus standard so developed provides the best technical solution or compromise.

In the implementation of the Plan by DGNT, the structural changes introduced did not always have beneficial results. However, the fact that structural changes were necessary calls for a review of the details in the Plan about the number of $\mathrm{TC}^{\prime} \mathrm{s}$ and $\mathrm{SC}^{\prime} \mathrm{s}$.

c) For selection of subjects for standardization, DGNT has been guided either by other government departments or by the availability of standards in neighboring countries or in COPANT. As these selections were not based on the evaluation of the need of industry and users of standards, their collaboration in the development process has been only limited.

d) The problem of adequate experience of the technical staff becomes more complicated because of the frequent changes due to their leaving DGNT for better salaries elsewhere.

Following the work and the final report of the expert of UNIDO*, it was recognized that it was necessary to establish a suitable mechanism for associating representatives of industries, government departments, specialized agencies, consumers, etc., for the formulation and direction of the work program. Since this year, DGNT has therefore been doing its standardization work through a new mechanism. The socalled Standardization Advisory Commissions (CAN) were Instituted, one for each of the most important industrial fields in the country. of these Commissions, three are actually working; they are in the following fields:

a) Mining and metallurgy

b) Foods, chemistry, and agriculture

c) Mechanics

Another two CAN's will begin their work in the next few months. An estimate of the additional technical manpower and other resources required for undertaking the work has been formulated for approval through MICT.

* U.N. Industrial Development Organization 
Quality control activities were previously regulated through a division in the Department of Standardization. With more emphasis on the QC activity, a separate department has been created, starting in November 1975. The Department has been entrusted with all activities for the promotion of QC referred to in DS 12309. They include schemes for:

a) Quality certification by lots.

b) Certification of production to Bolivian standards.

The scheme for quality certification by lots has been developed for discharge of the responsibilities entrusted to DGNT by DS 9984. Since the certificates are not always to Bolivian National Standards, they are issued under the following titles to cover different situations:

Type of Certificates:

Quality Certification of Lots Quality Report

Declared Quality Report
Reference Standard:

Bolivian National Standards Standards of other countries Declared values

For the service, DGNT has been authorized to charge fees from the Industry departments.

The procedure enumerated in DS 9984 requires all goverment departments, statutory bodies, etc., to include in the tender notices details of the specifications to be applied to the goods to be supplied in accordance with approvals by DGNT. For consideration of the manufacturer's offer by the "Junta de Almonedas," the tenders are to be accompanied with a lot quality certificate by DGNT. Finally, each lot supplied by the approved manufacturer must be accompanied by a quality certificate from DGNT before payments are made.

Although this DS has been operative for five years, only a limited use has been made of DGNT services on the basis of the above. The few cases referred were for compliance with one or the other of the steps enumerated earlier. A review of these, however, indicated that to cover all the steps for all procurements by the public sector DGNT resources would need to be so much augmented that there would be danger of changing its character to that of a purchasing organization.

The DGNT scheme for quality certification by lots has thus been made use of voluntarily by a number of organizations for solution of their quality problems. During the period 1975-77, 88 certificates issued were for the following:

a) Quality control of imports and exports. 
b) Evaluation of quality by industrial units for effecting improvement.

c) Evaluation of technical specifications by consuming organizations to ensure supply.

The use of the scheme for the above purposes on a voluntary basis indicates its usefulness. For controlling the quality of imports and exports, the use of the scheme could be promoted further.

The scheme for certification of production to Bolivian National Standards was intended to be developed after arrival of the UNIDO expert. DS 12309 refers to operation of the scheme by DGNT, and a number of industrial units have indicated their willingness to join the scheme. An outline of the scheme, therefore, has been developed by the expert in consultation with officers of DGNT. To ensure support of the industry for their voluntary adoption, details are intended to be discussed with the association of industries before submitting a resolution to the Government. The draft resolution is simultaneously submitted for examination from the legal point of view.

\section{LABORATORY}

The DGNT laboratory has a total investment of US\$200,000 in equipments and consumables and started functioning from February 1975. As food QC laboratory, it has basic facilities, and some chemicals have also been tested. The laboratory is used for the following activities of DGNT:
a) Quality certification of lots.
b) Standards development.
c) Investigational work referred to the laboratory.
d) Laboratory service to check quality of some individual products.

The available facilities are inadequate to meet all demands on laboratory services. Some equipments are planned to be added during 1978.

Considering the wide areas of DGNT operations and additional demands for QC testing with the operation of the scheme for certification of production to Bolivian standards, expansion of the laboratory facilities is a basic requirement. The products to be covered include basic chemicals, cement, fertilizers, pesticides, soaps and detergents, non-ferrous metals, plastic products, glass bottles, dry cell batteries, cables and conductors, and textiles. However, for orderly development of the laboratory, facilities required for 
evaluation of all these products need to be assessed together for starting new sections of the laboratory. This requires a study which needs to be undertaken. In any event, the immediate action required is the creation of two sections, one for chemical and metal testing and the other for mechanical and electrical testing.

In addition to the above, a section for metrology is necessary. This would include legal metrology as well as facilities required for providing calibration and maintenance service to industrial units.

\section{METROLOGY}

The Government of Bolivia on September 30, 1893, adopted the Metric System of Measurement which was put into effect only on Apri1 21, 1930. However, full adoption of this system has not been achieved because of a lack of the appropriate regulations and the absence of procedures and material resources. This fallure was also due to external factors, some of which are the following:

a) The Law did not have the required scope for such an all embracing legal document.

b) The Law did not establish the specialized organization needed for adoption of the Metric System.

c) There was a lack of a minimum technical infrastructure.

d) There were external influences on the system of measurement used in Bolivia.

e) There were external offers for the installation of equipment and instruments in other than the Metric System.

f) There was a lack of diffusion and promotion of the Metric System.

g) The Law established units only for length, weight, area, volume, and capacity measurements.

h) The names employed for designation of the units and their symbols are not fully coherent with the logical system.

As a consequence of the above situation, some technical organizations in Bolivia carry out workshops on the use of units and the need for metrological services. The first work had been accomplished in 1956 by The Ministry of Agriculture by compiling over all Bolivia the units that were actually employed in commercial transactions for magnitudes of length, mass, area, and volume. This work established the existence of an important number of native units and others of old 
Spanish origin, many of them having the same name but different values when referred to the Metric System.

Subsequently in 1974, DGNT, with sponsorship by the Agency for International Development (USAID) and with the participation of the National Bureau of Standards (NBS), the Republic of Korea, Thailand, Turkey, Brazil, Ecuador, and with technicians of other countrles, performed the Survey on Standardization and Measurement Services in Bolivia. This Survey that lasted 25 days gave us an idea of the situation of Bolivian industry in the use of the measurement sytem. Reports concerning visits to industries show the use of the Metric System, though not in an exclusive manner. Some industrial subsectors show a heavy influence of the English system using the foot, Inch, pound, gallon, etc. Furthermore, we could see that the means for calibration of measurement instruments in industry were scarce.

This chaotic situation in the use of units contributed to the Government of Bolivia deciding in March 1975 to enact DS 12309, by which DGNT is entrusted w1th the elaboration of a Law of Weights and Measurements that will adopt the International System of Units (SI) throughout Bolivia and, at the same time, establish a metrological service at the national level.

As a consequence of this legal provision, DGNT established late in the year 1975 a Metrology Department. Its first task was to hold a "National Metrology Workshop," whose basic objectives were the following:

a) To disseminate knowledge of the units and SI in education, research, commerce, and industry.

b) To inventory possible laboratories that may participate in the national metrological services.

c) To analyze the use of measurement instruments and equipment that are employed in calibration or verification activities.

d) To study the adaptability of each sector to SI.

The fundamental results of this workshop were as follows:

We could establish in the different sectors studied that in Bolivia the exclusive use of the Metric System is not yet manifest. These sectors use at the same time units of English and old Spanish origin and a number of important native units of measurement. Metalmechanical, textile, and oll industry sub-sectors are the most influenced by English units in virtue of their concern for raw materials, machinery, instruments, and measurement equipment. Most of 
the performance measurements made in these sub-sectors are by the English system. The remalning sub-sectors, such as food and beverage, bullding materials, chemistry, pharmacy, and others, do not show major difficulties for adoption of SI. Nevertheless, each sector shows its own problems in the use of the Metric System. Usually there are some external factors applicable to each company that prevent the use of the legal system in force. Among these causes, the most important are the following:

a) Bolivia has imported equipment from developed countries, such as from England and the United States; consequently, it introduces to a technological process units foreign to the legal system in force.

b) The Anglo-Saxon equipments are designed preferably for processing raw materials coming from these countries in their own units.

c) The export markets are accustomed to some products in the English system of units so that Bolivian exportation enterprises are forced to make products in these units.

d) During the period in which the Metric System came into force, Bolivia did not make an effort to diffuse information on the advantages of this system for commerclal procedures.

e) Formerly, technical assistance was not given by the Government to Bolivian enterprises for using the new measurement units.

f) Conversion tables were not officially made, nor were standards and other technical documents supplied that allow the exclusive or parallel use of the legal system in force.

DGNT has now initiated the necessary action for the creation of a national measurement service for the development of all the metrological activities in Bolivia. During the past year, we recelved advice from Dr. Ajit $K$. Gupta, international expert of the United Nations, whose stay in Bolivia gave us the opportunity to set up the basis for performing these services. Taking into account the requirements described by DGNT and the knowledge imparted by consultants in metrology of the Organization of American States, this expert prepared a quinquennial plan for DGNT (1976-1980), which includes, besides other recommendations, the development of the national metrological services, with the following aspects:

a) The adoption of SI for all productive activities in the country must be executed through a central plan that guides and directs the national policy in the implementation of SI.

b) Taking into account the scope of the reform to the System of 
Units in Bolivia, as well as the technical and administrative requirements to put into effect this change, it is necessary to create the infrastructure that will be covered by the following divisions:

(i) Advisory Board for Metrology (CAM)

(ii) Central Bureau of Metrology (La Paz)

(iii) Central Laboratory for Metrology (La Paz)

(iv) Local Bureaus (La Paz, Cochambamba, and Santa Cruz)

The national metrological services described above had been foreseen to comprise the following activities:
a) Calibration services to industry
b) Legal metrology
c) Mechnical advice
d) Diffusion and training programs
e) International compatibility

\section{PLANS FOR THE FUTURE OF DGNT}

The review of DGNT activities on standardization, quality control, and metrology indicates the need for expert advice and guidance both for initiation and reorientation of the effort for all the activities. The same applies to the expansion of laboratory facilities to provide support for the activities and also for training of the technical staff. These are the other areas for which technical assistance has been requested by the Government.

The background information, leading to the present technical assistance project for 1976, refers to the project as preparatory in nature for conceptual formulation of a large-scale assistance project to commence in 1977 in the areas considered above. The duration of the largescale project has also been estimated to be about four years, and it is now only required to be quantified for inclusion in the new budget for 1977-81. The present project also refers to initiation of activities on specific areas for their continuation during the large-scale assistance project.

The project has provisions for two experts (three months each) and three consultants (one month each). However, due to the tight financial situation, the possibility of canceling or at least postponing these components of the project has been suggested. Since postponement of these components would only delay formulation and initiation of the large-scale project, the better course would be to include the provisions where appropriate in the large-scale project. 
METROLOGICAL SERVICES IN THE ARAB REPUBLIC OF EGYPT

by

Dr. Mohammed M. Ammar

Director, National Institute for Standards

Academy of Scientific Research and Technology

Cairo, Egypt

\section{Acknowledgment}

Before starting my talk, I would like to express my gratitude to the National Bureau of Standards and to the U.S. Agency for International Development for giving me the opportunity to attend this workshop and to represent my country and the National Institute for Standards before you. In my talk to you, I shall try to give you a picture of the metrological services in Egypt and to discuss some of our problems and what we are doing about them.

\section{Introduction}

The state of metrology in a country is one of the important factors determining the possibilities of scientific and technical progress, of improved production efficiency, and of high quality industrial production. This stems from the fact that the solution of the majority of scientific, technical, and production problems is based on the data resulting from measurements.

The use of inadequately accurate data obtained from measurements may lead to disastrous consequences, since it may lead to erroneous scientific conclusions, wrong technological decisions, and production defects. Therefore, to ensure the technological progress, high production efficlency, and high quality of the product, the country should effect a complex of arrangements designed to ensure metrological measurements which create conditions for no defect in production and guarantee high quality of measuring data. The establishment of such metrological service is, beyond doubt, a complicated and difficult task involving the training of skilled personnel, the creation of a technical base, etc.

However, this task may be considerably facilitated if the experience and the ald of the international organizations and the well-developed countries are employed in setting up such a service.

\section{The Structure of the Metrological Service in Egypt}

In the Arab Republic of Egypt (ARE) there are three organizations responsible for metrology and standards (see Fig. 1). 


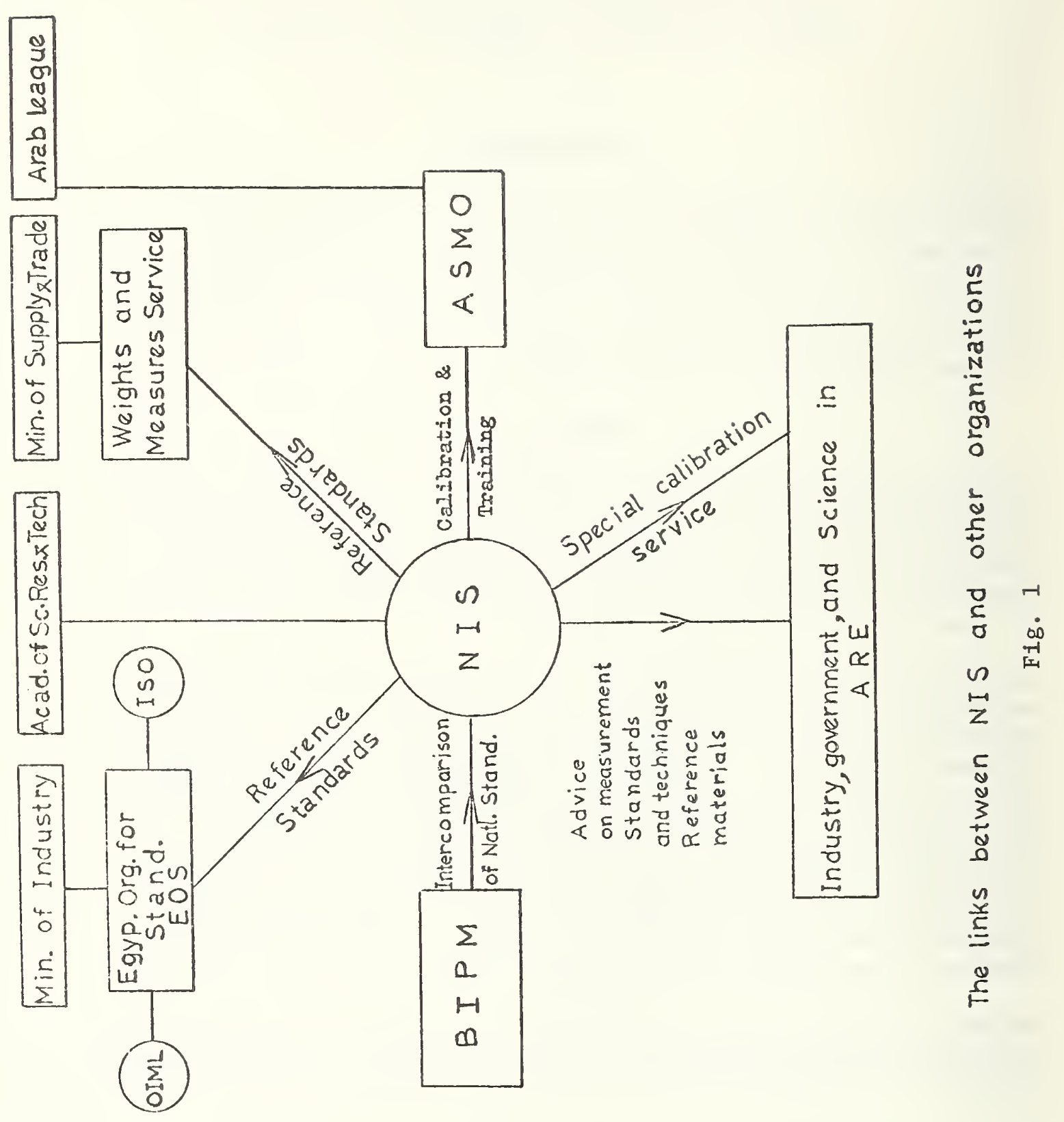


(1) The National Institute for Standards (NIS) is responsible for the scientific metrology and maintenance of the national standards.

(2) The Egyptian Organization for Standardization (EOS) is responsible for industrial metrology and standard specifications.

(3) The Weights and Measures Service (WMS) is responsible for legal metrology and calibration of weights and measures used in trade.

In the following I shall briefly mention the functions of each of the above organizations.

(1) The National Institute for Standards

After the large impetus towards industrialization in 1952, it was decided that the ARE should have its own national specifications and product standards for the various kinds of products. For the verification of compliance to such specifications, the existence of an institute for maintaining national standards is necessary. Thus, the establishment of the National Institute for Standards in 1964 was not a casual incident.

The main functions and activities of NIS are:

1. To maintain legal national standards of measurements.

2. To carry out research work in the field of scientific metrology to improve physical standards and methods of measurement.

3. To provide calibration services for science and industry.

4. To harmonize measurements between different institutions in the national measurement system.

5. To give advice upon request to government officials, manufacturers, and scientists with regard to physical standards and their use.

6. To prepare and supply Standard Reference Materials.

NIS consists of the following laboratories:

1. Length: including wave-length standards, line standards, end standards, constants in length metrology, and research work on length metrology and on laser applications.

2. Mass: mass standards, density standards, barometry, and manometry. 
3. Thermometry: temperature standards, thermal properties of materials, calorimetry, and viscometry.

4. Photometry: standards for luminous flux and intensity, and calorimetry.

5. Frequency: frequency standards and comparison of time intervals.

6. Electricity: d.c. standards, a.c. standards, and electrical and magnetic constants.

7. Acoustics: sound level standards, acoustic spectrometry, and acoustic properties of materials.

8. Radiation: $X$ and gamma radiation exposure standards and radionuclide standards.

9. Materials testing: (a) laboratory for testing of metallic materials;

(b) ultrasonic laboratory, for nondestructive materials testing;

(c) laboratory for safety tests; and

(d) laboratory for testing of textles, rubber, plastics, paints, and pigments.

At this time NIS is the most advanced metrology center in the Arab region. It has the most up-to-date equipment with the highest accuracy for establishing and maintaining the national standards.

The length department has established the length standard according to the international recommendation, that is, the standard radiation of ${ }^{86} \mathrm{Kr}$.

The mass department has in its custody the platinum Kilogram $N^{\circ} 58$ furnished by the International Bureau of Weights and Measures (BIPM) and callbrated there.

The frequency laboratory has established the time standard according to the international definition of the unit, that is, the cesium beam standard.

The thermometry laboratory has established the temperature scale from the triple point of water to the gold point according to the International Practical Temperature Scale, 1968.

The reference standards for the units of electricity, photometry, and radiation are periodically recalibrated against the BIPM standards.

For the time being, due to the shortage of testing laboratories in the country, NIS has extended its services temporarily to calibration of instruments used in industry, universities, and research institutes. 
NIS collaborates with the Egyptian Organization for Standardization. This organization is establishing quality control laboratories. NIS will be responsible for the periodic calibration and certification of the reference standards used in these laboratories.

NIS, with its broad objectives, aims at extending its services to all Arab countries; so it collaborates with the Arab Organization for Standardization and Metrology (ASMO) which takes as its major objective the harmonization of Arab capabilities in the field of metrology.

NIS collaborates with BIPM as was previously mentioned and also collaborates through EOS with the Organization International de Metrologie Legale (OIML).

(2) The Egyptian Organization for Standardization (EOS)

The Egyptian Organization for Standardization is the recognized body in Egypt for the preparation of documented national standards in all fields. Established in 1957, its main objectives are:

1. To set up standard specifications, to elaborate standards, and to ensure the conformity of materials and products to such standards.

2. To establish the necessary laboratories for industrial metrology at secondary and lower levels, arrange for the calibration of secondary physical standards, and to issue official certificates of calibration.

3. To offer the EOS quality mark. Manufacturers may apply to have their products certified through the use of the quality mark. Permission to use this mark under license from EOS is given only to a manufacturer complying with an agreed upon scheme of supervision and control which will include regular inspection and continuing independent testing of samples selected as required by the EOS inspectorate.

EOS has testing laboratories in Cairo for quality assurance. These laboratories have 16 sections for testing of materials and products, such as mineral oils, rubber, plastics, leather, paper, textiles, foods, building materials, glass and ceramics, wood and furniture, paints, metals, electric and electronic products, etc.

The EOS has joined the International Organization for Standardization (ISO) and OTML. 
The Weights and Measures Service is a responsibility of the Ministry of Supplies and Internal Trade. A central office is located in Cairo, and 30 district offices are situated throughout the country. WMS controls weights, weighing instruments, volume measures, length measures, gasoline pumps, gas meters, and water meters. WMS also operates a workshop for the repair of weighing machines, Repair staff are trained at the service workshop. The inspectors who are secondary and technical school graduates are further trained in the ministry. Weights, length measures, volume measures, and weighing instruments that are locally manufactured by prevailing regulations must be initially tested and stamped by WMS.

The central office of WMS in Cairo maintains the standards which are calibrated by NIS. That central office is well-equipped with standards and equipment.

\section{The Arab Organization for Standardization and Metrology (ASMO)}

The Arab Organization for Standardization and Metrology is an Arab League organization closely linked with the metrology and standards institutions in Egypt, so I shall discuss briefly its activities as clarified from Fig. 1.

In recent years, the Arab countries have realized the importance of standardizing and unifying their systems of measures and eliminating the diversity of local systems prevailing in each country and the disparities from foreign standards and systems. They have also realized that coordination of their efforts in the fields of standardization and metrology, both on the Arab and international levels, is necessary for the success of Arab industrial and economic cooperation and development. Consequently, ASMO was established in 1967. Among its aims and objectives are:

a) To urge the establishment of metrology and standardization institutions.

b) To unify technical terms, methods of testing, and measurements in the Arab States.

c) To coordinate and unify the specifications used in the Arab states, whenever possible, so as to ralse the standard of production and to facilitate trade exchange.

d) To prepare, train, and raise the efficiency of the various levels of specialists and technicians and qualify them for all the tasks that are related to standardization and metrology.

e) To promote relations and encourage cooperation between the institutions concerned with standardization and metrology in 
member states, taking advantage of facilities avallable in existing Arab laboratories.

NIS, Calro, acts as a consultant to ASMO in subjects related to metrology, gives training courses to technicians and speclalists from Arab countries, and carries out calibration of the reference standards of length and welght of the member states.

\section{Problems Faced by the Arab Countries}

Arab countries face a number of problems in organizing an efficient national measuring system and in setting up and operating metrology centers. The main problems may be:

(1) A lack of a uniform system of basic units. When units vary from locality to locality, sometimes without change of name, it always causes difficulties and confusion. This problem has been largely eliminated at the present time due to the efforts of ASMO. All the Arab countries have adopted the metric system (SI).

(2) A lack or inadequacy of trained manpower capable of tackling, the problems which face them. This shortage exists not only for top leaders and supervisors, such as scientists and engineers at postgraduate levels, but also for techniclans and technical assistants. ASMO with its responsibility for providing assistance in training has used the technical facilities such as are necessary for training, both in qualifled staff and equipment, and such as are already existing at NIS for annual training courses. They are organized by NIS and intended for techniclans and engineers working in standardization and metrology in the different Arab countries. International assistance through international organizations and developed countries is required to provide the necessary demonstration and training equipment. Greatly appreciated would be training fellowships for the staff of NIS avallable at the big national laboratorles. In this way, NIS could keep contact with the modern techniques and methods in this fleld.

(3) A lack of facilities for repair and adjustment of measuring instruments. This constitutes a handicap which is very critical. Steps should be taken to train the necessary number of instrument technicians. This can be achieved through the help of international organizations and instrument manufacturers.

(4) The realization and maintenance of primary standards is an expensive task, and this therefore presents a problem for developing countries. It may not be possible for every developing country to establish a laboratory for national physical standards. Even when such a laboratory is established, its malntenance is still very expensive. To solve that problem, developing countrles may arrange for regular calibration and certification of their reference standards against the primary standards maintained in the national 
laboratories of developed countries. However, this idea has the following disadvantages:

a) The absence of a well-equipped national laboratory for calibration of reference standards in these countries means that they will form a heavy load on the developed countries.

b) In the absence of a well-equipped laboratory, the right type of technical personnel is not attracted to this type of important research and development work.

These problems suggest some sort of a compromise. This would lie in the concept of regional grouping. It might be feasible for a number of neighboring countries to band together in a regional group to establish and maintain regional primary standards of highest accuracy which serve all the countries of the group. These regional primary standards laboratories could calibrate the reference standards of member countries. Besides that, this regional laboratory would be the proper place for bringing forward scientists and technicians of member countries.

The role of developed countrles will be to help these laboratories to be in contact with the ever progressing scientific front by joining the scientists of these laboratories in long- or short-term research programs in the development of measuring methods and instruments. This system is existing and operating in the Arab region. NIS in Calro serves the whole Arab region as was previously mentioned.

However, NIS is far from being complete and capable of handling all the problems. More contact with the similar national laboratories in the developed countries is required to improve 1 ts own services and to make it capable of functioning properly. 


\author{
by \\ Dr. G. Yao Ahlijah \\ Principal Scientific officer \\ Ghana Standards Board \\ Accra, Ghana
}

The Ghana Standards Board was established with a mandatory

Certification Mark Scheme. The law states that "no person shall

exhibit for sale, sell, distribute, prepare for export, export, or

otherwise dispose of, goods manufactured by an industrial process in

Ghana, unless:

1) he has a valid license to use the standard mark, to be called the Ghana Standards Certification Mark, relating to such goods;

1i) the goods bear a facsimile of that standards mark;

iil) the goods bear a label indicating that the goods are 'Made in Ghana'; and

iv) the goods bear code numbers indicating the batches of production to which they belong."

A manufacturer, therefore, has to apply to the Board for the Certification Mark for his product. However, before this mark is awarded, the staff of the Board have to inspect the factory and collect samples for testing.

The inspection report on the factory assesses the firm's manufacturing processes, its quality control system, and hygienic conditions where appropriate. The sample collected is tested, and the results considered for their conformity with the appropriate standard. The mark is then awarded for the product when the inspection report is satisfactory and the product meets the requirements of the relevant standard. The certificate is valid for one year, and there are random checks within this period to ensure that the manufacturer maintains the quality of his product. The application for the award of the mark is rejected when the product fails to satisfy the requirements of the relevant standard and/or when the inspection report is unsatisfactory. The applicant is, however, notified in writing as to the reasons for rejection and given time within which to rectify the faults. After being informed that the necessary rectification has been effected, the Board's technical personnel pay another visit to the factory and the whole exercise is repeated. 
The above necessary requirements for the award of the Certification Mark are very demanding. It is not surprising, therefore, that only the large, well-established firms are able to satisfy these requirements. The result is that there are a large proportion of products on the market which have not been tested by the Board or are rejected products. Such a state of affairs is unsatisfactory.

In order, therefore, to control the situation and get manufacturers to apply for the mark so that their factorles can be visited and their products tested, or to prevent rejected products from entering the market, the Board has instituted a number of measures.

Under an arrangement with the department stores, these firms would only accept products for sale from suppliers with valid certificates from the Board. Some of the department stores, however, are not willing to cooperate with the Board in this way because of the great demand for goods brought about by general shortages in the country.

In Ghana, department stores handle only a small proportion of goods. The greater part of buying and selling is carrled out in open markets, on street pavements, and by itinerant hawkers. This trade is dominated by the very resourceful market women. In this area, it is very difficult to exercise control on the goods sold because of the proverbial ingenuity of the market women to outwit the officlaldom. A classic example of their ingenuity has been their ability to outwit price control inspectors who have had to be withdrawn because of their inef fectiveness.

The other measure which the Board has tried, especially against rejected products entering the market, was the publication of the names of firms whose applications have been rejected together with the lists of the rejected products.

When this publication was first made in the official gazette, there was so much uproar by the manufacturers that this mechanism has never been repeated. In exceptional cases, however, the public's attention is drawn to products on the market which have not been certified by the Board through press and radio announcements.

Prosecution of a firm for infringement of the certification mark rules has been tried once, but the procedure was found to be slow and was bogged down by pressure on the Board to settle out of court.

As a general policy, the Board favors the educative approach rather than prosecution in the courts. It is the view of the Board that the manufacturers must be educated to appreciate the virtues of standardization and comply with the law regarding certification of products. It is only in exceptional cases when all efforts at ensuring compliance by persuasion or education fails that recourse can be had to prosecution. 
It must be mentioned that, apart from the standards body, the consumer has a big role to play in exerting pressure on the manufacturer to comply with the relevant standards.

One way of encouraging consumers to help the Board in this exercise is to report cases of sub-standard products.

The Board requires the consumer to submit a sample with each complaint. This sample is tested and a report issued to the consumer. With the Board's report, the consumer can make a claim against the manufacturer if the product is sub-standard. More often than not, the manufacturer is eager to replace the defective product. On the part of the Board, the manufacturer's certificate can be revoked if the faults found with the product are serious.

In the advanced countries, there are powerful consumer associations who even have their own laboratories. They are thus able to test products and pronounce on the quality of these products for the benefit of their members. This is not the situation in Ghana. The Ghana Standards Board Itself has, at the directive of the Government, made two attempts at promoting the formation of a consumer association. On both occasions, the associations formed have been short-lived.

One reason why consumers do not seem anxious to come together to protect their interests may be the fact that the Ghanalan consumer is restricted to a narrow choice of products. At Independence, a policy was adopted for the encouragement of manufacture of importsubstitution products. This policy has led to the establishment of monopolies. In addition to this, inflation and attempts to control the situation by import restrictions has led to a shortage of goods generally.

However, new economic measures have recently been announced liberalizing import controls. It is hoped that this new policy would improve the economic situation within the country thereby paving the way for increased standardization activities in Ghana. 



\author{
By \\ Dr. Bambang H. Hadiwiardjo \\ Deputy Director \\ National Institute for Instrumentation \\ Indonesian Institute of Sciences \\ Bandung, Indonesia
}

\title{
Introduction
}

In a developing country such as Indonesia, where the right and proper technology must be used, instrumentation has a very important role. Technology must be supported by instrumentation. Even what we call "traditional technology" needs to be supported by simple instrumentation to improve the products and their quality.

In the Indonesian National Development Plan, the agricultural sector has been emphasized as a priority area, and instrumentation is already taking a role, e.g., for agricultural data collection, a rice estate project, another on irrigation, etc. In the long run, especially in Java where there is a high population density, the development plan must emphasize industrialization. This means that the role of instrumentation is very important.

Some important components in instrumentation programs are:

\section{(a) Research and Development}

Research and development in the fleld of instrumentation for laboratories and process control have not yet been firmly established in Indonesia. Some research institutes such as LIN (Lembaga Instrumentasi Nasional-oNational Institute for Instrumentation) and others have, however, begun to carry out R\&D in this field, especlally in the adaptation of instrumentation to make it suitable for Indonesia.

\section{(b) Repair and Maintenance}

It should be expected that every instrument manufacturer has his own technical representative in Indonesia. In practice at this time are representatives or sole-agents, who do not offer an after-sales service. In general, research institutes in Indonesia do not have the capability for repairing and maintaining their instruments. In this field LIN can give a little help to other laboratories.

So far, the maintenance of instruments for process control in factories has to be done by their own technicians or operators in 
their spare time. The lack of experienced and qualified technicians is a serious problem.

\section{(c) Information}

Based on experience, information in the fleld of instrumentation can be included in a general science information network. LIN has already begun to prepare documentation and give information services in the field of instrumentation.

\section{(d) Installation}

In genera1, instrument installation is carried out by foreign companies or by the instrument manufacturers themselves. At the moment there is no Indonesian private specialist in instrument installation. LIN is beginning to give service for the design and installation of instrument systems before any private firm or individual is capable of doing this kind of job.

\section{(e) Calibration}

Indonesia has no national standardizing laboratory to which local companies, industries, research institutes, universities, and private and government laboratories can turn to have calibration work carried out against standards which are traceable to international standards.

Unfortunately at this time, there is no standardizing laboratory to which companies and institutions can go for callbration services. Moreover, in many institutions the awareness is limited of the critical advantages to be derived from employing instruments and maintaining them in good order. Few instruments are ever recalibrated. Reliance must be placed on the instrument holding the original calibration carried out by the manufacturer. In the course of time, and particularly in a country with a tropical climate, instruments will lose their accuracy and the measurement system will become unreliable.

The only institution which achieved periodic and regular recallbration of at least some of its standards 18 the Directorate of Metrology at Bandung. This institute is responsible for maintenance and regulation of weights and measures used in trade (mainly mass, length, and volume). It is not a national standardizing body in the broad sense of covering the complete range of physical measurements.

There are some research institutes which have their own calibration facil1ties, such as the Atomic Energy Research Institute for atomic radiation, the Power Research Institute for electrical quantities, LIN for physical quantities such as temperature, humidity, pressure, electrical quantities, low frequency, acoustics, etc., the Post and Telecomminication Research 
Institute for frequency, the Army Mechanical Industry for engineering metrology, the Metal Industries Development Center for engineering metrology, the Institute for Technology of Bandung for engineering metrology and electrical quantities, etc.

\section{(f) Manpower In Instrumentation}

Up till now specialist manpower in the field of instrumentation is very small, maybe fewer than 200 persons. There is always a great demand for instrumentation techniclans. From newspaper advertisements we frequently read requests for instrumentation technicians.

\section{The K.I.M. National Program}

To sum up the situation in Indonesia, various organizations have developed precision measurement facilities to meet their own specific needs. But Indonesia has no body or organization which is responsible for the custody of national physical standards in a way which ensures that they are consistent with the physical measurements of other countries, and for ensuring that measurement services are adequate to meet the needs of communication, mining, agriculture, science, medicine, and industry as the nation develops. Alone in the limited field of weights and measures to be used in trade, Indonesia has a functioning service.

Due to this situation, the Minister of State for Research made the decision that the K.I.M. program (for calibration, instrumentation and metrology) shall become one of the national research programs. In this respect, the Indonesian Institute for Sciences (LIPI) will act as the central focus for management of this system in cooperation with other institutes concerned. The execution of this program is the responsibility of LIN.

The program is not to be taken in the limited sense as stated in the title of the program. We have to understand it in the broader sense, which includes software and hardware inputs, the management system, the technical centers, the users, the means of enforcement, the dissemination of information, the training, the skills and know-how, and the technology itself. The program is to establish a national measurement system, which can be described as all of the activities and mechanisms that provide physical measurement data. Only in this way can we achieve our objective: quantitative knowledge required by our soclety. Of course, instrumentation and its technology must be acquired by Indonesia.

We define the program clearly as $K$, $I$, and $M$ with the purpose of emphasizing the specific elements in the approach and the implementation of each activity. For calibration we will stress the setting up of a network, strengthening the existing facilities and delivering their services to the users. These matters have already 
been discussed in depth in committee. The principal features of the National Physical Standards System in Indonesia can be seen in the dlagram.

Instrumentation and metrology are concerned not only with the technology itself, but also with maintenance and serviceability, with information, with formal and informal training, with skilis and knowhow, and with dissemination effort. Assistance and promotion for the establishment of a domestic instrument industry is included. Important also is social awareness, especially to people who are directly involved in KIM decisions, like top managers in industries, planners, designers, technicians, supervisors, etc. They have to understand the impact of KIM on their productivity.

\section{The Implementation of the KIM Program}

The solutions of the problems of this program are specific and have to match the situation and the environmental conditions. They must be practical and acceptable to the cultural, social, and polltical background structure. Nevertheless, new inputs can speed up the process. Comparative studies of models from other countries could be very valuable. They can help us to avold mistakes that have been made elsewhere and to learn from the successes that have been attained.

There is no doubt that the initlative for this program must come from the Government, since in developing countries like Indonesia, it is impossible to leave it to the private sector. As described earlier, the creation of an effective national KIM system is a process. The process itself must be programmed in such a way that the active participation of all who are concerned will occur. This approach is taken mainly because the available KIM resources are so 1 imfted in manpower and in precision equipment.

Awareness of KIM is the first necessary step to establish the national KIM system. This effort must be concentrated first on the group who are directly involved in KIM activities. All avallable media, professional organizatiuns, etc., can be very valuable tools for dissemination of information.

The formation of a national calibration network is another step that has to be taken to create a service system for calibration. (See the diagram of the National Physical Standards System, Figure 1.) There are still barriers to be overcome, but the situation seems quite promising. A National Calibration Committee is being built up by LIPI. The executive committee and the secretariat are organized by and located at LIN.

Manpower development is another effort needed to meet the demand originating from industries and research institutions for instrument repair and malntenance and for developing appropriate instruments if a 


\section{NATIONAL PHYSICAL STANDARDS SYSTEM}

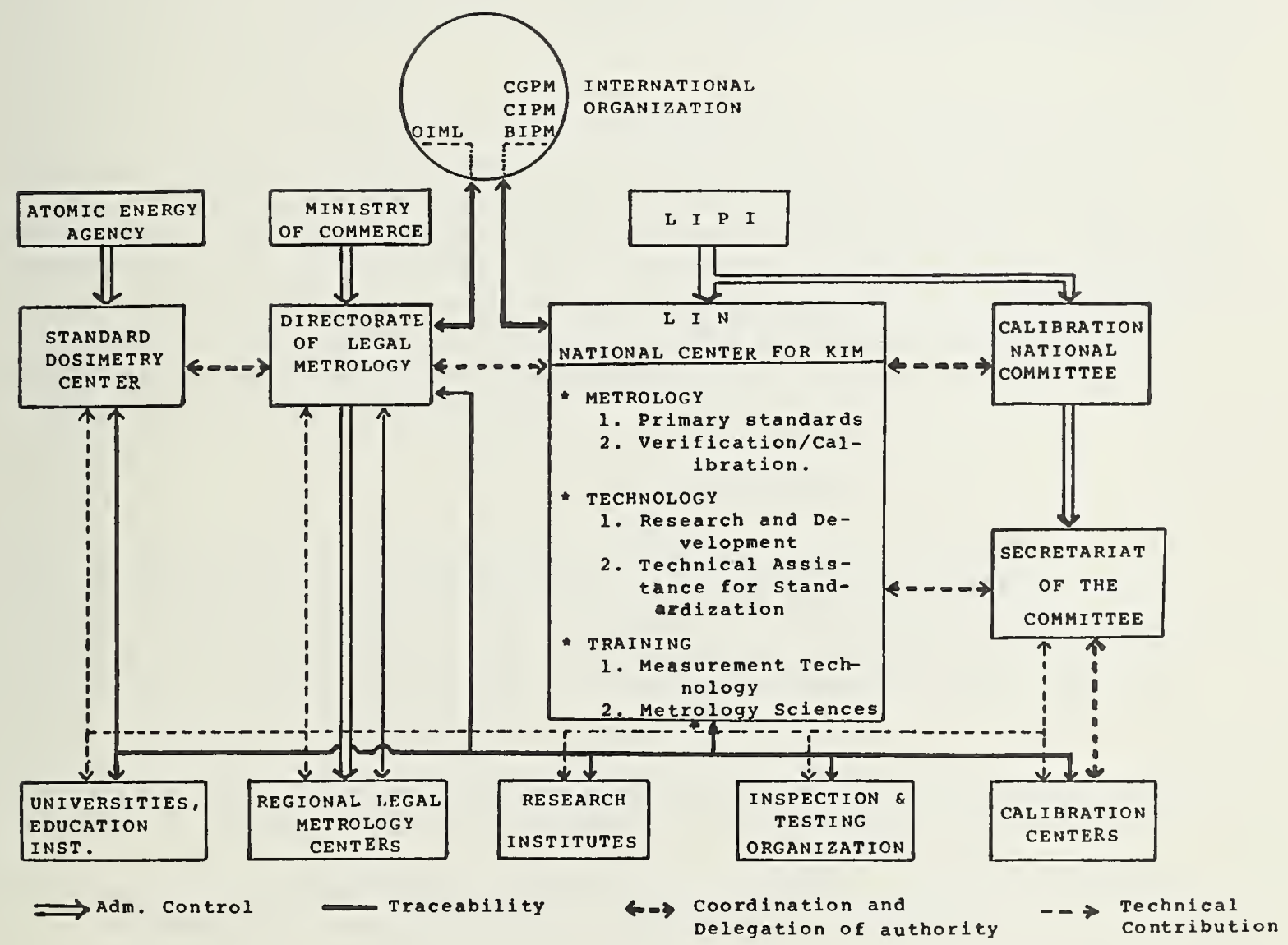

Figure 1 
new design is needed. Most of these efforts can be based on short courses or training through formal education institutions, or on-thejob training by R\&D institutions such as LIN.

LIN, as center for systems management, should have a substantial KIM capability to support the others. At the moment, IIN has a certain capability which is only the embryonic center for calibration, instrumentation, and metrology. New inputs are badly needed to strengthen LIN as the nucleus for the national system of KIM for expanding the available activities. We should lay the foundation on which later on the National Center for Calibration, Instrumentation, and Metrology in Indonesia can serve effectively for the benefit of the Nation. 
NATIONAL STANDARDIZATION SYSTEM FOR INDONESIA

by

Mrs. Sriati Djaprie

Assistant Deputy Chairman for Technology

Indonesian Institute of Sciences

Jakarta, Indonesia

\section{INTRODUCTION}

Standardization and related activities are important aspects of development, and they constitute an essential input for planned growth. The experience in other developing countries shows that the function of a national standards body is closely related to national planning and national development which calls for full government authority and financial support.

The fast pace of development and change in technology during Pelita I and the current Pelita II (National Plans), and others to follow, compelled various government agencies and departments to set their own standards to be able to execute their respective functions. With the continuing increase in development activities, it has been recognized that in order to ensure that standardization can serve national goals and needs, an effective national body should be established which would coordinate all standardization efforts, either by government agencies or in the private sector.

\section{STANDARDIZATION TRENDS}

In order to put the subject into perspective, I will briefly review the background of the standardization movement in Indonesia. Standardization activities in Indonesia actually started as far back as 1928 with the establishment of the "Fonds voor Normalisatie." In 1954, this private institution was later changed into YDNI (Yayasan Dana Normalisasi Indonesia).

During the last decade, standardization activities have taken great strides on the national scene. This can be attributed to:

(1) Rapid growth of development through the implementation of the consecutive five-year development plans.

(2) Rapid growth of technology due to the increase in domestic investment as well as influx of foreign technology.

(3) Expansion of foreign trade (for goods and services).

(4) Increase in international cooperation in economic and cultural fields. 
(5) Increase in consciousness of the applicability of the principles of standardization and the benefits to be derived from their adoption.

Most of the technical departments of ministries such as those dealing with Trade, Industry, Health, Public Works, Agriculture, Transportation, Mining, etc., according to the authority vested in them, are carrying out their standardization programs. As we look to our developmental impetus, it is a necessity that these fragmented approaches should be given clear direction to avoid overlapping areas of interests or even conflicting or inconsistent standards. We must make a deliberate effort to develop a national standardization system and cannot wait to see years taken up in its evolution. The absence of a central coordinating body will be keenly felt, as standards are becoming more and more an indispensible instrument in implementing government policies and programs, and because in the regional or international context, their absence will be a handicap for Indonesia. A two-day Seminar on Standardization held in February 1973 concluded that an effective national body should be established which would be in charge of coordinating all standardization efforts. Standardization efforts received a new emphasis in Pelita II by the formation of a Project on Standardization, Calibration, Instrumentation, and Metrology (74/79). The development of a national standardization system forms one of the priority areas in the overall research and development program.

\section{THE NATIONAL STANDARDIZATION SYSTEM}

A systems approach to standardization requires a clear insight into its components which encompass:

(1) R\&D, including planning and programming.

(2) Formulation of standards.

(3) Adoption of standards.

(4) Implementation of standards.

(5) Promotion of standards.

of these components, R\&D in standardization and adoption of national standards should be centralized and be the responsibility of a central body. This will be necessary to achieve national status. Formulation, implementation, or promotion may be decentralized, which is to say that it may be entrusted to various ministries and institutes with the central body acting as the coordinator. The number of subsystems to be integrated into the actual standardization system should be determined according to the functional characteristics of the system which should be determined through legislation.

\subsection{OBJECTIVES}

The immediate objectives of a national system include among others: 
(1) Coordinating the formulation of all necessary national standards.

(2) Dissemination of information on standards and related activities.

(3) Liaison between formulation and implementation or enforcement bodies.

(4) Determination of priorities in the standardization program.

(5) Coordinating effective representation in regional and international standardization activities.

A memorandum for establishment of a National Standardization System in Indonesia has been presented to the Government through the Minister of State for Research. The next step would be the establishment of the Standards Council, Divisional Councils, and Technical Committees. In a given situation such as in our own case in Indonesia, it would be possible to develop a workable system. Its effectiveness would generally be related to a national development goal, and it should be specially tailored to fit the sociopolitical environment and economic conditions. In any approach one should spell out clearly the stages needed to attain the objectives and the interrelationships between the various subsystems.

\subsection{THE SYSTEM AND PLANNING, PROGRAMMING, AND FORMULATION}

Since planning, programming, and coordination are the core functions of this system, it should include and represent a consensus of all interested parties. This could be achieved by setting up a structure as follows:

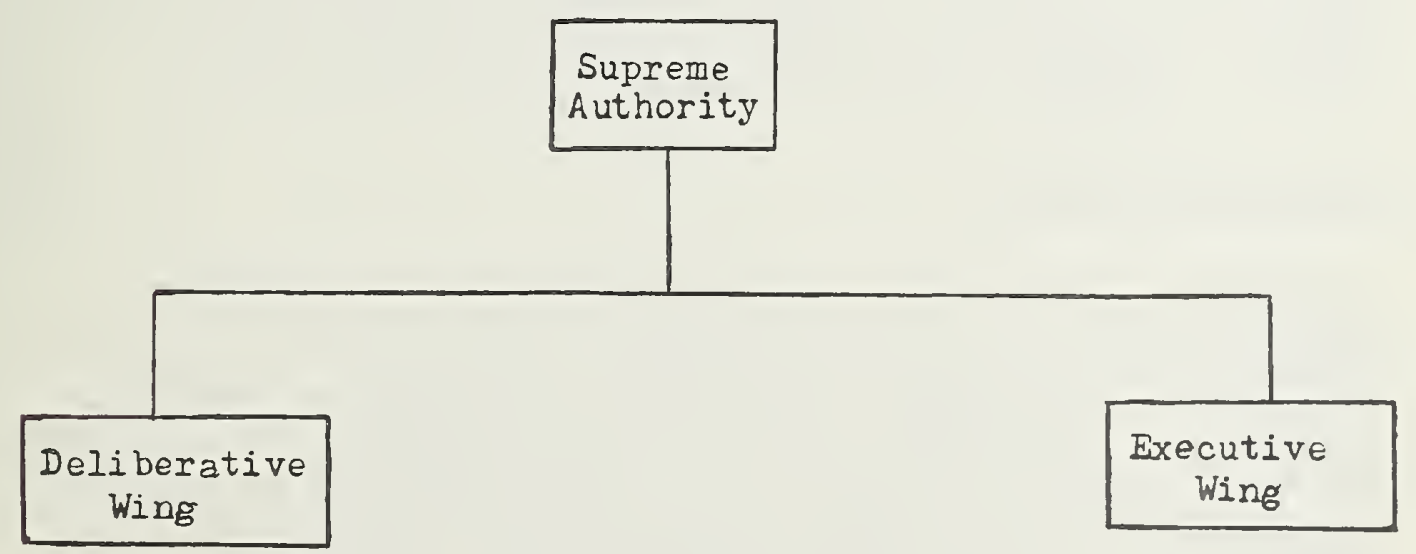


The Deliberative Wing consists of a hierarchy of councils as follows:

(1) Standards Counc11

Constituted with representatives from government ministries, research institutes, consumer organizations, and industry. This Council approves policies, priorities, and annual plans. The authority for adoption of national standards also is vested in this Council.

(2) Division Councils

For the formulation of national standards, it is customary to set up specialized groups to deal with specific sectors of the economy. In the initial stages, a few Division Councils need to be established in accordance with the national priority plan. Priority areas have been identified as:

(a) Agricultural.

(b) Food and Food Products.

(c) Housing, with emphasis on low-cost housing.

(d) Building Materials.

(e) Textile and Clothing.

(f) Safety Standards.

(g) Electro-technical.

(h) Structural, etc.

So far, five divisional councils have been set up, namely, electro-technical, documentation, building and construction units, and metals and machinery. It is proposed to decentralize the formulation of national standards, and various ministries and institutes with current standardization activities will continue to function within the framework of the new system. When the subject falls outside the scope of work of the now existing structure, the central authority may set up a new divisional council.

\section{(3) Technical Committee}

A technical committee is a group of persons with specialized knowledge with the task of collecting information, technical data, and preparing draft standards. Here again, the central authority, if necessary, may set up a new technical committee to deal with the formulation of standards under the supervision of one of the division councils. In our case about 49 technical comittees have been formed, concerned with the formulation of standards on information, electricity, telecomunication, electrical installations in buildings and ships, symbols, technical terms, units, drawing, etc.

The concept of a national standards system is actually an expression of the objectives and power vested in the Standards 
Council which are related to cooperation among existing organizations engaged in standards formulation, implementation (testing and certification), and promotion under a given set of circumstances. A workable system depends on the cooperation of all participating existing standards organizations. To understand what is meant by "existing standards organizations," one could look at the inventory work already carried out from which it has been ascertained that there are 104 organizations in Indonesia involved in standardization activities. Therefore, the first step to be taken is in the direction of coordination.

\subsection{THE SYSTEM AND IMPLEMENTATION}

As might be expected, the process of implementation of standards presents a more complex problem than that of standards formulation. It should be kept in mind that the principal use of standards for govermental purposes is to safeguard the people in areas such as health, safety, and general welfare. These standards may be implemented by mandatory enforcement through the respective responsible ministries and their agencies.

Conformity, another aspect of standards implementation, is dealt with by various agencies, either private or public, and includes such methods as inspection, testing, sampling, quality control, certification, labeling, and coding. This could involve either voluntary or mandatory implementation, but even so, some form of coordination would be necessary.

\subsection{THE SYSTEM AND STANDARDS PROMOTION}

Another important requirement for an Indonesian standards system is the promotion of standards which includes such activities as training, continuous "standard consciousness" programs to bring out the needs and benefits of standardization, information services, and consulting services. Training is a very important component, since standardization as an activity has only come to be recognized in recent years. Thus a national standards system has the responsibility of being the focal point for promoting continuing education and training programs.

As suggested earlier, it is not the intention of the central body to involve itself in the whole program of training, but a systematically designed program covering basic principles, philosophy, practices, methodology, economics, and social effects of standards can be handled most effectively by the central body. In 1976, a basic course designed for management and technical personnel was run in Jakarta (twice), Bandung, Medan, and Surabaya and was attended by 363 persons in a11. This amply testifies that there is a great interest and a great need for standards promotion. Four similar courses are scheduled for $1977 / 78$. Specialized topics such as quality control, 
testing, etc., if coupled with special research or testing facilities, will be best carried out by the respective agencies. The provision of information on standards by different organizations has in general been concerned with providing information on their own sphere of standards. As standards activities are increasing, the collection, collation, analysis, documentation, storage, retrieval, and dissemination of information have become important aspects. One can foresee that with the expanding standards activities at the national level, some form of central standards data bank will be required to afford ready accessibility to information on the national as well as the international level. At this moment the creation of a national standards information network joining all available information centers (YDNI, the International Organization for Standardization and the International Electrotechnical Commission publications and recommendations, and PDIN, the Information Agency within the Indonesian Institute of Sciences, etc.) would be the most practical solution.

\section{CONCLUSION}

I have attempted to summarize in brief our coordination efforts on standardization. It is our expectation that this framework can and will be discussed and assessed, so that we can improve our activities to promote a national standards system which will respond to Indonesia's needs. 
by

Mr. James D. Gikandi

Senior Electrical Standards officer

Kenya Bureau of Standards

Nairobi, Kenya

\section{Introduction}

The Kenya Bureau of Standards (KEBS) was established by an Act of Parliament in 1973 and commenced its activities on January 25, 1974. The alms and objectives of establishing the KEBS were, among others:

(a) To promote standardization in industry and commerce.

(b) To make arrangements or provide facilities for testing and calibration of precision instrument gages and scientific apparatus, by comparison with the approved standard gages and instruments.

(c) To control, in accordance with the provisions of the act, the use of the standardization mark.

Due to some technical problems, it was not possible to set up technical departments till the year 1975, when these were established, including an electrical department. Professional staff have since been recruited and trained in the standardization work with the help of other national standards bodies, for example, British Standards Institute, Indian Standards Institute, Holland, Sweden's SIDA, and also the United Nations Industrial Development Organization.

\section{National Standards Council}

The National Standards Counc1l, being in Kenya the supreme body of the organization in standardization, concerns itself with laying down broad areas of priorities from which to select the Industry Standards Committees. Recruitment of staff is aimed at satisfying the needs of these priorities. It is also the Council's duty to control the finances of KEBS, the appointment of staff, the entire management, and supervision of the affairs of KEBS, as set out in the Standards Act. This is done through a Staff and Finance Committee (within the Council) with a view to having a more convenient method of administering the affairs of KEBS. The Council also spells out the organization and the responsibilities of the various committees it sets up. The Council is the final authority to approve publication of Kenya standards. 
III. Organizational Structure of the Electrical Department

The Electrical Department was established later in 1975 as one of the departments of the KEBS, but the actual standards drafting did not start unt11 October 1976, due to some technical matters which had to be tackled.

The organizational structure of the Electrical Department is as follows:

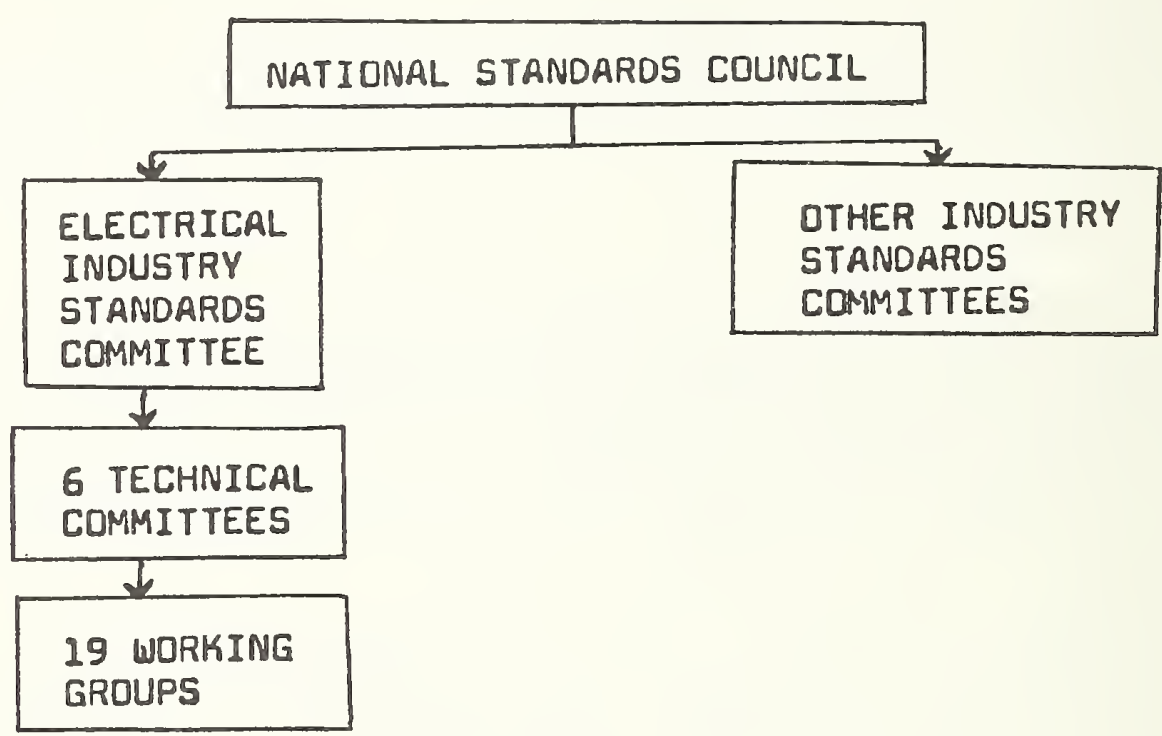

(a) Electrical Industry Standards Committee

The Electrical Industry Standards Committee (EISC) acts on behalf of the Council in supervising the activities of the technical comnittees under its sphere. EISC determines the priorities within the electrical industry, allocates projects to the technical committees, and lays down the terms of reference, the constitution of the technical committees, and their chairmanships.

(b) Technical Committees

The technical committees prepare committee drafts. A comittee is normally concerned with one standard or a small group of standards or even a wide range of standards in a given topic. They work in accordance with terms of reference given to them by the EISC which creates them. Normally a technical committee is split into smaller 
subcommittees (working groups) to tackle the various topics within the terms of reference. In the electrical department there are 19 such subcommittees within the 6 technical committees.

IV. Standardization Work in the Electrical Department

The six technical committees mentioned above are as follows:

(a) Symbols, Signs, Designations, and Definitions Technical Commit tee

(b) Electric Lamps and Wiring Accessories Technical Committee

(c) Switchgear and Distribution Equipment Technical Committee

(d) Extra-Low Voltage Equipment Technical Committee

(e) Conductors and Cables Technical Committee

(f) Communication Equipment Technical Committee

The above six comittees were established so as to deal with the standardization of electrical products or codes of practices which the EISC felt needed the first priority for the following reasons:

(1) Due to the fact that Kenya was a British colony, most of the British practices in electrical engineering were well established in this country before independence. Thus, the system's voltages in all the a.c. distribution and service lines are based on British standards, which are $240 \mathrm{~V}$ for single phase and $415 \mathrm{~V}$ for three phase supply, and a frequency of $50 \mathrm{~Hz}$. All the electrical equipment which was being imported into Kenya was therefore rated at the above mentioned voltages and frequency. After the achievement of independence in 1963, Kenya felt the need to expand her trade with other countries of the world.

Today electrical equipment is imported from many countries, and the problem which our country is faced with is that one can find equipment rated at voltages and frequencies other than the above mentioned ones being sold in the market. For example, equipment imported from continental Europe is rated at $220 \mathrm{~V}$ for single phase and $380 \mathrm{~V}$ for three phase. A case was reported when somebody purchased an ironing box rated at a frequency of $70 \mathrm{~Hz}$ ! Another complaint was that equipment imported from the United States was rated at $120 \mathrm{~V}$, and when the ignorant consumer connected it to our system, it started burning within a few minutes. Even if the consumer had not been ignorant, he would have been forced to purchase a transformer before he could use the equipment. Equipment rated at $220 / 380 \mathrm{~V}$ seems to function all right at the beginning, but the consumer should be informed that such equipment will have a much shorter life than that designed to operate at $240 / 415 \mathrm{~V}$. Such equipment could also be dangerous to the user, 
since the insulation is not designed to operate at $240 / 415+6 \%$ which is specified in our statutory regulations, inherited from the formerly existing British regulations.

Bearing all the above problems in mind, the "Symbols, Signs, Designations, and Definitions Technical Committee" was established so as to formulate a standard for "Standard Voltages and Frequency for A.C. Transmission and Distribution Systems" in Kenya. Once the standard becomes fully operational, all electrical equipment coming into Kenya w111 have to be rated at $240 / 415 \mathrm{~V}$ and $50 \mathrm{~Hz}$, as the standard will be enforced by the Ministry of Power and Communications, with the cooperation of the Import/Export Department of the Ministry of Commerce and Industry. Since the $240 / 415 \mathrm{~V}$ is also an IEC standard voltage, the committee did not see the need to change its voltage in Kenya, but will give consideration to adopting the newly proposed IEC standard voltage of $230 / 400 \mathrm{~V}$ in the future.

(2) There have been a lot of complaints about the quality of our locally manufactured electric light bulbs, which consumers say have a very short 1ife. After conducting investigations, KEBS realized that our local manufacturer only assembles components which are manufactured in Europe. After assembling he only tests a few bulbs on a sample basis, but does not have any sampling plans at all. It was therefore felt necessary to establish a standard which will guide the manufacturer in selecting the bulbs ratings and the quality of materials.

The standard will also guide the manufacturer in test methods, statistical methods of sampling, and conditions of compliance with the standard. Once our quality control laboratory is operational, the Bureau will be able to verify the quality of these electric bulbs and, therefore, be in a position to answer with confidence all the consumer complaints. This standard will also help the manufacturer to improve the quality of his products.

(3) Some time ago an elderly lady was trying to change a burnt electric bulb and in the process was electrocuted. Although on one hand, the lady was negligent in that she had not switched off the lamp switch, on the other hand, the person who had manufactured the lamps having a metallic body should have provided some means of earthing (grounding) this lamp. The lamp plug had only two pins, and had it been provided with a third earthing pin, the lady might not have died. having studied this case properly, the electrical department conducted investigations in Nairobi and discovered that many electrical appliances which are not fully insulated do not have any earthing means. A committee was therefore established to formulate a standard on the types of plugs and socket outlets to be used on the various types of electrical appliances in Kenya. After completing its original work, the committee will also establish specifications for household electrical appliances and also specify the maximum allowed leakage current on such appliances. Most likely such standards w111 
be enforced and will therefore solve the problem of people being accidentally electrocuted.

(4) Many cases have been reported of bulldings catching fire, and upon investigation, it has been found that a fuse which was supposed to disconnect a short circuit had not blown. Upon further investigation it was established that the rating of this fuse was so high that it was not possible for its element to melt on short circuit, and therefore, the conductors started burning with the eventual burning of the building. KEBS, therefore, felt the necessity of establishing a standard on the types of fuses which shall be used in Kenya. The standard will specify that no rewirable fuses will be allowed and that only cartridge types of fuses shall be used in all future electrical installations.

While on this topic a cominttee was requested to conduct investigations on the type of fire-warning devices used in tall bulldings (five storles upwards). To our dismay, it was realized that only about a half of such buildings have any means of fire alarms. The committee was therefore charged with the work of establishing a code of practice for the installation and servicing of fire-warning devices in Kenya. This code will serve as a useful guide for electrical contractors in the installations of such devices. Once finalized, the code will most likely become compulsory.

(5) Though not many consumer complaints have been recelved, other standards are being established for the sake of quality control and certification marking concerning the following products:

(1) Conductors and cables

(11) Primary and secondary batteries and cells

(iii) Swltchgear and controlgear

(iv) Communication equipment including:

- frequency division multiplex equipment

- antenna towers and supporting structures

(6) It was also found necessary to establish a committee to deal with the glossary of terms used in electrical engineering. This is supposed to facilitate the usage of a common language in all the standards drafted by this department. The same committee is collecting information concerning the types of symbols used in architectural drawings. This standard will help to establish common symbols which will be used by the varlous firms engaged in electrical engineering, who have come from different countries. 
The symbols will be based on the types of symbols recommended by the IEC (International Electrotechnical Commission), but considerations will also be given to already well established symbols in Kenya.

The Electrical Department is planning to extend its activities so as to cover other items in the future when more funds and manpower become avallable. 


\author{
by \\ Dr. Choonghi Rhee \\ Chief, Temperature Standards Laboratory \\ Korea Standards Research Institute \\ Seoul, Korea
}

\title{
I. Introduction
}

In the past decade, the Korean economy has grown very rapidly, and Korea has made major progress toward becoming a modern industrial nation. At present, Korea attains US\$10 billion of exports a year and GNP/capita has increased to $\$ 800$. In the fourth five-year economic development plan in the years of 1977-1981, Korea aims at attaining $\$ 20$ billion in exports and GNP/capita of $\$ 1,500$.

The economic strategy of the Korean Government now concentrates on developing heavy and chemical industries. These new industries are to be introduced on the basis of the light industry, strengthened during the first three five-year plans. The Korean economy has reached a transition period from labor-intensive to technology-oriented operation.

Although inspection of industrial products and export goods has been carried out according to the Quality Control Law by about 20 public and private inspection organizations, the measurement precision achieved is generally low compared with that in advanced countries. Calibration facilities are limited in number and capability and fail to cover all of the industrial firms spread over the country. It is generally still true that most people from techniclans working in factories to top managers in industry lack understanding of the importance of precision and a national standards system. However, they begin to realize that lack of precision places a barrier on the acceptance of manufactured products and should be overcome. For this reason, the Korea Standards Research Institute (K-SRI) was founded in 1975 to establish traceability and control by a national standards system in Korea. K-SRI will lead metrological circles in Rorea and support industrial firms to solve technological problems met by industries.

This year an industrial survey is being undertaken by K-SRI as an important project, which is supported by the Ministry of Commerce and Industry, the Industrial Advancement Administration, and the Ministry of Science and Technology. The National Bureau of Standards has been requested to act as consultant. 


\section{Industrial Survey}

\section{(a) Objectives of Survey}

The objectives of the survey are as follows:

1. To carry out a comprehensive investigation of the existence, maintenance, performance, and precision of calibration and inspection equipment and, if possible, to upgrade existing precision measuring equipment in industrial firms, public organizations, research institutes, and testing and inspection agencies.

2. To examine the manpower resources among measurement technicians and metrologists and the technological level required for establishing international credibility in precision measurement capabilities.

3. To assess the need for the establishment of high-level calibration and verification systems, and to use the survey for the systematic dissemination of standards and standard reference materials.

4. To grasp the status of precision measuring capabilities in support of heavy and chemical industries.

5. To identify problems in measurement practices and to formulate an effective and continuing technical assistance program by $\mathrm{K}-\mathrm{SRI}$ for industrial firms.

\section{(b) Survey Schedule}

The industrial survey is being conducted as a ten-month project from March to December 1977. In the first four months, several preparatory tasks were performed including the preparation of a survey questionnaire and slides and brochures to inform the public and industry of the importance of the survey, and including also the selection of survey institutions and the on-the-job training of survey team members.

On May 23, a preparatory workshop which was co-sponsored by K-SRI and NBS for the "1977 Industrial Precision Measurement Standards Survey" was held at $K-S R I$. K-SRI officials and a three-man visiting team consisting of Mr. H. S. Peiser and Dr. R. C. Sangster, both from NBS, and Dr. K. M. Chung from the Polytechnic Institute of New York, gave information on the importance of the survey to 100 participants from calibration organizations and industrial firms. The workshop produced several recommendations for the survey and suggested that two kinds of draft survey questionnaires could be made.

In June, a pilot survey was carrled out with the draft questionnaire, and final adjustments of the survey documents were made. During July 16-22, survey seminars were held at major cities to enlighten 
participants on the importance of the survey and the national standards system. The survey team consisted of $30 \mathrm{~K}$-SRI staff members and 30 members from universities.

The survey is being performed in two simultaneous steps: first, by mail, and second, by on-site visits during the period of July to September.

\section{(c) Survey Scope}

The survey is being conducted in 25 measurement categorles and covers 326 measuring equipments and standards. The selected categories are as follows :

1. Length

2. Angle

3. Surface finish and surface properties

4. Mass and weight

5. Volume

6. Density

7. Force and torque

8. Materials testing

9. Shock and vibration

10. Pressure and vacuum

11. Fluid flow

12. Time and frequency

13. Velocity and revolution
14. Electricity

15. RF and microwave

16. Magnetism

17. Acoustics and noise

18. Temperature

19. Humidity

20. Radiometry and photometry

21. Spectrophotometry and color

22. Optics

23. Radiation

24. Chemical analysis

25. Standard reference materials

Based on preliminary examination, about 3,700 institutions and firms were selected as the survey targets. This can be classified according to type of organization as follows: 


\section{Public Sector Institutions}

National standards institutions

Testing and inspection agencies

Academic institutions and research institutes

Defense agencies

Central administrative agencies

Local administrative units

Observatories

Broadcasting stations

Health and medical institutions

Commercial and industrial organizations

\section{Private Sector Organizations}

Agricultural, fishing, and mining

Civil and construction

Trade and transportation

Food, textile, clothing, paper, and printing

Chemical, plastics, rubber, and petrochemical

Non-metallic materials

Iron, steel, and foundry

Metal and machine

Electric, electronics, and communication

Transportation equipment

Metrological equipment 
Among these survey targets, 630 institutions were visited on-site. As a first step, survey questionnaires were mailed to more than 5,000 institutions, and it is expected that 3,700 questionnaires will be collected.

\section{(d) Survey Questionnaire}

Two kinds of survey questionnaires were prepared. The questionnaire I which is used by mail is much simpler than questionnaire II which is used for on-site visits. Questionnaire I is a two-page document consisting of five parts:

Part 1 - Organizational overview.

Part 2 - Precision level and utilization rates of precision measuring equipment classified according to 25 measurement categories.

Part 3 - List of affiliated organizations.

Part 4 - Problems and needed advice relating to maintenance of precision measuring equipment.

Part 5 - Desired services requested of K-SRI by surveyed institutions.

Questionnaire II is a six-page item consisting of five parts also:

Part 1 - Organizational overview including information on main products, manpower and technical capability in precision measurement, and training programs in measurement.

Part 2 - Precision level and utilization rates of precision measuring equipment, identified from a list of 326 types of precision measuring equipment.

Part 3 - Utilization rates of types of standard reference materials.

Part 4 - Present use and request for specific standard reference materials.

Part 5 - Froblems and needed advice relating to maintenance of precision measuring equipment as well as desired service requested of $\mathrm{K}-\mathrm{SRI}$ by surveyed institution.

\section{(e) Survey Report}

The survey report will be prepared by statistical methods of analysis of the compiled data from the questionnaire and by utilizing materials 
of industrial surveys performed in advanced countries. A main portion of the report will be in the style of a reference book describing the measurement system in Korea. This book will be avallable for reference by government organizations, industrial firms, academic institutions, and testing and inspecting agencies.

The report will consist of the following mafor parts:

1. Statistical treatment of data, classified according to 25 measurement categories and subdivided into the following topics:
a) Possession and maintenance of precision measuring equipment.
b) Frequency of calibration and inspection.
c) Precision level and utilization rates of precision measuring equipment.

d) Available manpower qualified as technicians and metrologists.

2. Possession and needs for standard reference materials.

3. Problems and needed advice, under the following headings:

a) Requests for calibration by national standards through K-SRI.

b) Inquiry for other calibrations by $\mathrm{K}-\mathrm{SRI}$.

c) Request for metrology seminars and training by metrologists.

d) Distribution of latest information on metrology.

e) Consultation on technical problems met by industrial firms.

f) Dissemination of SRM's.

g) Less expensive services for calibration and inspection.

h) Repair services needed for measuring equipment.

\section{Conclusions}

It is concluded that the industrial survey being conducted by malling of a questionnaire and by on-site visits is likely to be successful in several respects. It seems possible to achieve the initial objectives of the survey described in the beginning of this paper. Through the survey, the newly established K-SRI has already become well-known to many industrial firms and public organizations. Also, the survey activities enabled K-SRI to educate staff members about industrial activities and provided opportunities for establishing cordial working relations between K-SRI and industry.

It is believed that $\mathrm{K}-\mathrm{SRI}$ is conducting the first systematic industrial survey in Korea on metrology and that the resulting report will be referred to by many industrial firms and public organizations. The survey report can be used as a basic treatise on industrial standardization, and it will be an important step toward future progress in the use 
of metrological standards in Korea. K-SRI plans to continue to perform an Industrial survey as an important project in the future.

Finally, the author expresses his sincere gratitude to Mr. H. Steffen Peiser of NBS for his cordial invitation to this Workshop and for the opportunity to learn of the many metrological activities in the United States. The author also acknowledges the U.S. Agency for International Development for supporting him to attend. this Workshop. 



\author{
by \\ Mrs. Anacleta B. Mascarinas * \\ Chief, Inspection and Certification Division \\ Philippines Bureau of Standards \\ Man1la, PhIllppines
}

\title{
Introduction
}

In the Philippines, some form of standardization and measurement was belleved to have begun as early as 4,000 years ago as evidenced by the rice terraces in Banawe, Mountain Province, Phllippines, sald to have been built by the natives of the country. It is considered one of the seven wonders of the world. A system of standardization and units of measurement must have been employed in some way, otherwise, this beautiful work of art and the enormous structure could not have withstood the elements and force of nature for more than 4,000 years and would have been a helpless jumble a long time ago.

\section{$\underline{\text { Standardization }}$}

The formal introduction of standardization in the Philippines was in November 1947 when Executive Order No. 94, series of 1947, created the Division of Standards under the Bureau of Commerce. However, after more than ten years and the Government realizing the important role that standardization plays in the industrial development of the country, the Philippine Congress passed into law Republic Act No. 4109 on June 20, 1964, creating the present PhIlippines Bureau of Standards (PBS). It was only after one year that the implementation of the law was reallzed.

The first few years after its creation, most activities were focused on the organization activities and the establishment of necessary rules, regulations, and guidelines to ensure proper functioning of the new Bureau. The present PBS is composed of four divisions, each complementing and coordinating each other to achieve the desired goals, as follows:

1) Technical Division, charged with the establishment of standards.

2) Inspection and Certification Division, charged with the implementation of standards.

* deceased November 1977 
3) Field Operation Division, charged with the coordination of the implementation work of the field offices scattered all over the country.

4) Administrative Division, charged with rendering administrative services within PBS.

The Technical Division establishes standards for commodities in commerce and Industry for practices, processes, materials, and methods of sampling and testing. In the preparation of standards, priorities are given to industrial products, construction materials, and commodities which affect the health and safety of consumers. Any government agency, private organization, company, or the consuming public may request or recommend to PBS the establishment of standards for a specific product or commodity.

Relevant International recommendations and standards are considered or national standards of another country can be employed for reference purposes in the preparation of drafts of proposed new standards. In all cases, local conditions and experience are used to analyze, verify, and supplement some aspects of standards to ensure that standards developed are applicable to Philippine conditions. If a standard developed is found not reasonable or does not suit local conditions, it is immediately amended or corrected.

A technical committee is created to draft a particular standard. The members are drawn from all concerned sectors of the economy and include representatives of producers, consumers, the government sector, research bodies, chambers of commerce, and if necessary, consultant groups and experts. If the product for which a proposed standard is prepared is a complex one, the technical committee is divided into subcommittees which are each assigned to a particular activity. After the subcommittees have accomplished their assigned activities, their work is submitted to the Secretariat which is always the PBS. These drafts are next submitted to the parent technical committee for detalled review, scrutiny, and the issuance of a final draft.

After the completion of the initial draft of this proposed standard, copies of the proposed standard are prepared and distributed to concerned organizations and individuals for preliminary review and possible comments on their specific area of activity. Comments or corrections are requested to obtain ideas as to whether the proposed standard meets the needs of all concerned and suits local conditions in order to serve the best interests of all. This proposed standard is corrected from comments and corrections made by those to whom it was referred. This final draft is forwarded to the Philippine Standards Council for ratification and adoption.

The Philippines Standards Council is a permanent body composed of representatives of the different departments of the Government, 
private organizations, exporters, importers, and the consuming public appointed by the President of the Philippines. The Secretary of the Department of Trade is the Chairman of this Council.

As soon as the final draft of an established standard is signed by the Chairman, it is numbered and is called a Standards Administrative Order. This is published in the officlal Gazette, a Government publication, and after 15 days from the date of its publication, it comes into full force and effect and is ready for implementation.

PBS has established 286 standards since its creation in 1964. The Government as well as the private sectors are very cooperative in sharing with PBS their technical knowledge and expertise in the preparation of standards.

The Technical Division also examines, tests, and analyzes materials and products sampled at random from factories during plant inspections and samples picked at random from lots of products produced by factorles which do not hold license to use the PS mark. These samples may be taken at different stages elther before disposal or preshipment inspection under a so-called "ordinary" scheme of inspection. The Division also conducts investigations or research that may be necessary for conformity to standards and quality. When multiple tests are required of a certain product, the laboratories of the University of the Philippines, the National Institute of Science and Technology, and other government laboratories cooperate as officlal laboratorles for tests and analyses for PBS. For routine tests or simple analysis of inspection or for reference purposes, the PBS laboratory handles these activities. These laboratories are still very inadequate to serve all industrles whose products are subject to standardization. However, PBS is taking active steps to improve its present laboratory.

The Inspection and Certification Division is charged with the implementation of standards established by the Technical Division. Nothing would be attained by merely establishing standards if they were not applied. Without an implementing body, these established standards would be useless documents.

In the Philippines, we practice compulsory standardization and implement established standards by force of law. This is imperative in a country like the Philippines because standardization is a new activity in our country and the majority of the population, especially those of the the lower income group, are not yet standard or quality consclous.

PBS through the Inspection and Certification Division operates three schemes of inspections, as follows:

1) The Quality Control and Certification Mark Scheme. 
2) The "ordinary" scheme.

3) The issuance of the Semestral Commodity Clearance to qualified companies or factories registered with the Board of Investments. This is provided by Special Law, R.A. No. 6135.

In the flrst scheme, the company applies for the issuance of a license to use the Philippine Standards Certification Mark (PS). PBS sends a technical staff member knowledgeable on the production and quality control processes for the specific commodity. He inspects the quality control system of the factory concerned to see if it has the required technical personnel and laboratory equipment, and to find out if the factory can consistently produce a product of reasonable quality in accordance with pertinent standards. The inspector also samples the product produced during the time of the plant inspection. This sample is tested and analyzed in a laboratory to find if it conforms to the pertinent standards. The PS marking scheme is based on the establishment of a system of and statistical quality control at the factory level. In this scheme, quality control methods, inspection and sampling of products produced during plant inspection, and statistical and analytical techniques are used. The standards inspector then makes a detailed report of his inspection on a form provided for the purpose. The samples picked are divided into three parts. One part is kept in the factory for reference purposes, the second part is kept at the PBS laboratory for possible retesting, and the third part is for a laboratory test and analysis. If the samples tested and analyzed conform to the pertinent standards and if the factory processes and other requirements of PBS are met, the company concerned is issued the license to use the PS mark for a period of one year. The PS mark affixed or embossed on the product, commodity, or material is an assurance that said product, commodity, or material was manufactured in accordance with processes provided in sald standards. A PS license issued to a company or factory is a trust granted by PBS to the company with the expectation that it will produce a quality product provided in pertinent standards. It is a mark of assurance by the company that the product produced conforms to the pertinent standard. The company also guarantees that a standards inspector with proper authorization can enter, at reasonable working hours, into their factory or plant to ascertain by inspection and sampling whether materials, products, commodities, practices, and processes conform to established standards. PBS revokes or cancels the license to use the PS mark for violation of certain provisions in pertinent rules and regulations.

The "ordinary" scheme of inspection is adapted by PBS to products or commodities produced by factories which are not holders of a PS license, either because they do not have any quality control system in the manufacture of their product, no laboratory of their own, or lack technical personnel. Under this scheme, pre-disposal or pre-shipment 
inspection is carried out on every lot produced. Random sampling is made on every lot, and the samples picked are tested in the PBS or other government laboratories. Before receipt of test results confirming that the product sampled conforms to established standards, the lot from which the samples were picked shall not be released. Any product found not conforming to pertinent standards shall be disposed of only in the manner provided by law.

The third scheme of inspection is for the issuance of the Semestral Commodity Clearance to qualified companies registered with the Board of Investment as provided by a special law, Republic Act No. 6135, to give incentives to local manufacturers. Under this particular law, the products produced are as yet without government standards and are intended for export.

Under this scheme, the company applies for issuance of the Semestral Commodity Clearance. The Bureau in turn sends a standards inspector to the company's factory to find if the said factory has a production process that assures production of quality products which conform to the specifications of its buyers or the consumers of the products. The standards inspector who conducts the plant inspection must take a sample of the product and, if necessary, have it tested in the PBS laboratory. He makes the required report of his inspection on a form provided for the purpose. If the products sampled conform to pertinent specifications and the factory meets the requirements of PBS, it is issued a Semestral Commodity Clearance for a period of six months. The factory is subject to routine inspection for the duration of that commodity clearance.

PBS also provides technical assistance to industry in order to improve the quality of their products. It is authorized to collect inspection fees, license fees, commodity clearance fees, and laboratory fees for tests and analyses.

Standardization, although not the solution to many development problems, is one of the effective tools that helps accelerate the development of a less developed country like the Philippines. Standardization in developed countries is in many fields voluntary, which is not true in my own country. We have to implement standards by force of law. In this activity, we have encountered many problems.

\section{Problems Encountered in Standardization Activity}

In a developing country like the Philippines, standardization is not an easy task. Taking into consideration the economic and financial condition of the majority of the population, standards of quality are considered only as of secondary importance. Standardization is good if one can afford it; if not, one can always resort to substandard products which are naturally lower in price and within reach of the consumer. Substandard products are still preferred to quality products of higher price. This attitude of some people has encouraged 
less scrupulous manufacturers to surreptitiously manufacture and dispose of substandard products. Our standards inspectors find that they have a hard time running after these kinds of manufacturers. However, for building materials and products which affect the health and safety of consumers, pertinent standards are strictly enforced, and violators of the provisions of the pertinent standards are punished as provided by law.

On the issuance of the Semestral Commodity Clearance based on buyerseller agreements, the consumer countries are the ones who impose their views with regard to the standard or quality of the product they need. Most of the time, this is disadvantageous to the producing country. However, if the financial condition of PBS improves and enough technical personnel are available, this situation may soon be corrected by establishing more standards for varfous commodities in conformance with international standards.

Problems in industry are varied. Some employ managerial and technical resources while others do not have the financlal capacity to do so. As a result, in the Philippines there are still many factories that cannot be granted a license to use the PS mark due to lack of a quality control system in their production processes either because of the unavailability of laboratory equipment or personnel to do technical work. Their products are therefore subjected to the "ordinary" scheme of inspection, which is more costly for the manufacturers and at times cumbersome and tedious for both the manufacturers and the standards inspectors.

A serious problem in national standardization is the continuous rise in the cost of raw materials and production which have an adverse effect on the low-income population.

Another very serious problem in our standardization activities is the lack of adequate laboratory equipment. At present our laboratory has only a handful of instruments, although we have the necessary technical personnel. In view of this handicap in our standardization work, we have applied a system of quality certification with the cooperation of government laboratorles. For very urgent cases we even employ the laboratories of private companies, but the tests and analyses are performed by our own technical personnel. Government laboratories are busy performing their own laboratory activities and cannot readily accommodate the work of PBS. Our own laboratory and the laboratories of these cooperating government agencies are very inadequate and cannot meet the demands of our expanding industry.

Our poorly equipped laboratory is manned with technical personnel, many of whom had advanced training in more advanced countries in their particular line of work. However, these trained personnel are of no practical value and use unless we have our own well-equipped laboratory. No amount of extensive campaign on standards implementation will produce the desired result in the absence of a 
well-equipped laboratory. Due to lack of laboratory equipment for test and analysis activities, PBS is greatly hampered. Delays in obtaining test results also restrict the certification work. This has caused complaints from industry.

\section{Metrication and the Problems Encountered}

At present, the Philippines does not have a law authorizing metrology activities. Meanwhile, the measurement activities are concentrated on metrication.

Units of measurements in the PhIlippines had been greatly influenced by the systems of measurements brought to our shores by various colonizers of our country. Units of measures of the most diverse origin from the pre-Spanish time to the American era were used. The concept of measurement and the application of measuring instruments in the economic and technological activities of the Filipino people were as varied as the various colonizers. The Philippine Government was aware of the many benefits that would derive from a single system of measurement units, not only in our country but of the whole world. Therefore, the relevant recommendation by the International Bureau of Weights and Measures (BIPM), was immediately welcomed by the Philippine Government which issued Presidential Decree No. 187 on May 10, 1973, recognizing only the metric system of weights and measures and enjoining complete adoption of the system in the Philippines effective January 1, 1975. However, certain complications in the establishment of standards were encountered. Big factorles and industrial establishments, for example, found the law implied investments in machinery and equipment. The term was therefore extended by another two years on January 1, 1977. In some cases, for which it was extremely difficult to make the change from the English to the metric system, extensions of the time for implementation were granted on a case to case basis. Meanwhile, before the end of the term granted, they are expected to have partially adopted the metric system.

To fully realize the objectives, the Decree created the Metric System Board with the Secretary of Trade as Chairman. The Government realized the importance of the metric system from the start and has given support for the implementation of 1 ts program. The implementation of the Metric System Law has gradually remedied the chaotic use of the different weights and measures of the country.

PBS assists the Metric System Board in the preparation of various metric system information materials, such as conversion factors and tables, and it performs allied activities for the proper implementation of the law. PBS has established 11 standards on metrication. The following activities are performed for the success of the metrication program:

1) Sufficient publicity is furnished for use on radio and television and in newspapers, magazines, and other 
publications to persuade industry, commerce, and the general public on the desirability of using the metric system.

2) Tables of equivalents are published in order to avoid confusion and these are furnished to the general public.

3) Explanatory and informative descriptions are incorporated into teaching programs and primary education.

4) Books for primary and elementary school levels are revised to incorporate the metric system and/or change al1 other systems of weights and measures to the metric system, while those at high school level will be revised as soon as the metric system is fully implemented.

5) National standards for materials, commodities, products, processes, practice, and tests are revised in order that units of measures used other than the metric system be changed accordingly.

The progress of metrication in the Philippines is as follows:

1) Measurements of all kinds, like land surveying, weighing, measurements in length, etc., are made in the metric system.

2) For legal acts carried out with reference to measurements, use of the metric system is required and no equivalent is permitted; however, during this transition period, use of other units may be permeted on a case by case basis.

3) For any agricultural, commercial, or industrial activity, only measuring units in the metric system are authorized (however, on a case by case basis, during the transition period, other units of measure may be allowed).

4) Standardization of metric packing and packaging of various consumer, commercial, and industrial products are undertaken.

5) Various national standards are now revised to change other units of measures to the metric system.

6) Newspapers, magazines, and other publicity media publish advertisements with measures mostly in metric system.

In general, almost all activities are now regulated in accordance with the international system of measurement, and we who are involved in this activity are quite satisfied with the initial results. However, 
in spite of the encouraging results in our infial measurement activities, we are faced with varlous problems as follows:

1) At present, the PhIlippines does not have a law authorizing metrological activity in the country.

2) The very few number of metrological specialists with required training in metrology is very inadequate to serve the demand of our developing commerce, Industry, and technology.

3) We do not have any metrological laboratory equipped with the required metrological instruments.

4) No highly technical personnel is available to calibrate measuring instruments.

Whenever there are requests for calibration of measuring instruments, we seek the cooperation of the National Institute of Science and Technology for calibration of measuring instruments for mass and grain molsture meters and that of the Metal Industry and Research Development Corporation for calibration of length and other dimensional instruments.

An Ad Hoc Committee was recently created to study and prepare a proposed draft of a Presidential Decree providing authority for metrological activities in the country.

With all our sincere efforts to promote standardization and measurement services in the Philippines, it is sincerely hoped that in the near future we can join with similar activities all over the world to accelerate the development of the economy of all less developed countries and thus bring prosperity, happiness, and peace to the entire world. 
Mr. Chaiwai Sangruji Acting Director

Thai Industrial Standards Institute Bangkok, Thalland

I should like to express at the outset my gratitude to Mr. Steffen Pelser and the National Bureau of Standards that I am able to be here in Washington and indeed be talking to you now. I must say that I feel rather like a fishmonger showing the fishermen his wares-omuch of what I have to show will be thoroughly familiar to you. Nevertheless, there may be something of interest in the way we brought the catch in and how successful or unsuccessful we have been in presenting it to our public.

I do not Intend to bore you with precise structural details of the Thai Industrial Standards Institute (TISI) because there are many similarities in your own organizations, but the position in my country when we started and the philosophies which have governed our development may perhaps be of interest.

In the mid-60's, some seven organizational units existed which prepared and applied standards. They were specifically engaged in preparing standards for their own work areas, e.g., the Department of Health on foodstuffs and drugs, the Office of Commodity Standards on specifications against which approval could be given for export products, and so on. There was no across-the-board national standards organization, except a very small unit called the Committee for Tha National Standards Specifications which had neither the funds nor the technical backup to be able to have a profound effect on industry. As TISI progressed, this unit was later dissolved.

Some years in the late sixties were spent in feasibility studies, formulating the structure of a national standards body, and defining the laws and regulations which would give it authoritative structure. In December 1968, the Industrial Products Standards Act came into being, and we began assembling our team, deciding the membership of technical committees, establishing priorities-all the hundred-and-one detalls which go into building a national standards body.

It is probably worth pointing out at this stage that the Ministry of Industry had very clear objectives about what they wanted the Institute to achieve. These were:

1. To raise the general level of manufacturing quality in order to encourage our people to buy Thai products. The intention, obviously, was to achieve the double action of raising employment at home and conserving forelgn currencles. 
2. To rationalize industrial growth and bring Thal industry more into line with good international practices.

As we became more experlenced, the economic effects of variety reduction became evident and became a strong additional motive because of the inherent conservation of components and materials, much of which has to be bought abroad. Thalland has no multi-steel producing industry, for example.

We had determined from the outset that the structure of the organization should follow the pattern well tried in the older organizations-the production of standards by well-balanced technical committees on the consensus-of-opinion method--and all development has continued along these lines. Indeed, today we can call on the services of some 3,500 specialists from government departments and laboratories, universities, commerce, and manufacturing interests.

In hindsight, perhaps one of the wisest decisions we made was to assess the state of recognition of standardization, both in the public and private sectors, and begin a campaign of information and public relations. It is probably true to say that this aspect of standards preparation has only been acknowledged by some of the world's more experienced bodies in the last two decades. In our case, we began early in the $1970^{\prime}$ s on rather desert ground. It is fair to say that "standards" was something of an esoteric field and how they functioned was known to few in industry and Government.

The first priorities were to capture the interest of government officials who were associated with the development of the Institute and also to alert industry to the undoubted benefits of standardization. We had already foreseen this need and had appointed sultable staff, including a journalist. In 1972 we began a major output to business and technical journals and business sections of the popular press. Within two years, there was hardly an influentlal journal which had not carried a major feature about the Institute. Individual press releases were 1ssued, and later, exhibition displays were put on in various parts of the country. This process is maintained today and includes lecturing at universities, seminars, and public groups.

I would like to be able to tell you that the considerable output of persuasive material in the early years brought instant recognition of what we were doing. That, however, would not be true, and it is now apparent that information and public relations must exert a steady pressure which gradually brings results. However, there is no doubt that more people--especially in influentlal government departments-began to take notice of what we were doing ... and often became more cooperative as a result. For this reason alone, the effort was well worthwhile. Before I leave this subject, I should say that publicity was not almed at the general public. We were engaged to a large proportion on industrial standards, and it seemed to us that money and 
time had to be conserved to direct our efforts to Goverment and industry. It is only recently that we have begun to put pressure in the general consumer area because we have at least some certified consumer products. There is an old maxim that you never excite an audience unless you have something to show.

The scope of our standardization is widening and covers building components and materials, steel bars, various types of electric cable including stranded aluminum, soap, silverware, batterles, toothpaste, canned foodstuffs, various fish and flavor sauces, and many other types of products. Constructional materials feature largely in this and we have over 50 standards to date. I am happy to say that these standards have been issued to site inspection and specification personnel in the Greater Bangkok Municipal Authority and the Provincial Electricity Authority and are increasingly being used by the armed forces and other statutory bodies engaged in construction. At present 160 technical committees are at work on preparing other standards in well over 1,000 committee meetings a year.

All this activity is financed by the Government, and earnings in the way of sales of standards and other publications bypasses TISI and goes straight to the national Treasury. I am sure this is right for Thalland. If we had had to rely on industry membership fees and sales of standards, I hate to think what sort of report I would have been making now!

Undoubtedly, one of the boosts to this standards movement was the decision the Government took in 1973 to issue a regulation which requires all government purchasing officers to specify products to the TISI standards, where they exist, and to show preference for goods certifled by us. In fact, if they wish to deviate from the regulation, they must seek the permission of the Minister of Industry to order to another specification and must have a good reason for wishing to do this.

In 1973 another significant stage was reached when we issued our first certification licenses for portland cement and, soon afterwards, for steel bars for reinforcement purposes. This certification scheme is based upon a continuous survelllance system. I know that our European friends in CEN, the European Comnittee for Standardization, have been having vexed arguments on the merits of continuous or sporadic inspection for a European certification system, but we ourselves chose to adopt continuous surveillance in the light of the level of quality control consciousness of our smaller industries. We follow the normal practice of visits to factories, assessment of production and quality control systems, testing of random samples, and then, based upon our findings, recommend to the Standards Council either the award or refusal of a license. Refusal is always accompanied by detailed recommendations on what the company has to do to get the license, either in terms of test equipment, better materials, or better methods. Quite a few companies have been led to the point where they 
have been able to obtain the license on the second or third application.

We 1icense the use of two types of marks: one for those products voluntarily certified and the other for the same type of mark, but with a circle around 1t where a Royal Decree has been issued making the standard compulsory.

We have very few compulsory standards, and the policy for seeking legislation is whether the product is potentially dangerous to the public or whether it is important to the Thal economy. Thus, we have compulsorily certifled ballasts and electric wire (hazardous), canned pineapple (a growing export product), tapioca (export), matches (safety), and w111 next year certify safety glasses and steel bars in the interest both of public safety and of exports.

The International scene influences us both in preparing standards and in certification. The present Government is placing heavy emphasis on exports and foreign earnings, and I think I do not have to explain here why it makes good sense to align national standards with ISO and IEC documents or with widely recognized foreign standards where the former do not exist. In this connection, incidentally, we are happy to learn that ISO Is beginning to concern itself more with product standards Instead of terminologies, test methods, and the like.

At the present time, we have published some 250 national standards and have 1ssued over 450 certification licenses. This does not include tapioca 1icenses, whlch are a special case.

We have, 11ke most other bodies, a chronic shortage of staff, but even bearing this in mind, can, I suppose, reasonably claim steady progress. Yet when I look at the problems which still remain, I am sometimes tempted to wonder whether we have achleved anything at all! Statistics tell me that we have, and certainly we are beginning to see more industrial interest than we have done in the past, but the problems go on. Chlef among these are:

(a) Our needs for measurement services cannot be met by the over a dozen authorized laboratories we use.

(b) The harmonization of test methods and procedures among these author1zed laboratories.

(c) The difflculty of getting industry to use standards in their own right as economic working tools.

(d) Ensuring that technical committee members are always of the caliber that we need.

(e) Attracting good graduate staff on the low salary scales of the Thai Civil Service. 
Do these sound familiar? I know that one of the U.N. advisers we had working with us sald: "The moment a national standards body has no problems and is pleasing everyone, that is the time to shut up shop." There is some ray of comfort in this, but I can't help remembering that he will go home one day, and we will still go on tackling the problems!

Wry humor aside, I would just like to conclude with a glimpse of the future at TISI. It is safe to say that we have government support, and there are small signs that government officials, industrial people, and professional associations are beginning to understand what it is all about. There is a formidable amount to be done, both in the extension into work, such as fundamental standards and codes of practice in the future, and in the continued education of industry and the public. Internationally, the growing substantive strength of the ASEAN group and the moves already mooted to develop the science and technology section and include standardization has, of course, some significance for us.

Either way, the standards movement in Thailand has gained too much momentum now to unwind and we must plan for a busy future. At the Lima Conference when the United Nations countrles discussed world technology and trade, a resolution was made that the Third World should be in a position of supplying 20 percent of the world's manufactured goods by the year 2000. I am firmly convinced that standards organizations have an important key role to play in achieving what seems to many to be an impossible dream. Only time and experience will tell us what contribution TISI has made to Thai industrial expansion. 

CONTRIBUTED PAPERS

BY PARTICIPANTS

FROM INTERNATIONAL ORGANIZATIONS 

IN THE FIELDS OF STANDARDIZATION AND METROLOGY

by

Eng. K. I. Abulyosr

Head, Standardization and Metrology Department Arab Organization for Standardization and Metrology Cairo, Egypt

\section{Objectives}

The Arab Organization for Standardization and Metrology (ASMO) was established as a spectalized agency of the League of Arab States in the fields of standardization, quality control, and metrology. ASMO was intended to provide the scientific and technical basis for economic cooperation between the Arab States, and to facilitate industrial coordination and commerclal exchange between them. It also aims at raising the quality level of production, consolidating exports, and ensuring optimum utilization of investments used to import goods and equipment.

\section{Membership}

Eighteen Arab States are now members of ASMO and they are: Algeria, Bahrain, Egypt, Iraq, Jordan, Kuwait, Lebanon, Libya, Morocco, Omman, Palestine, Qatar, Saudi Arabia, Sudan, Syria, The Democratic Republic of Yemen, The Arab Republic of Yemen, and The United Arab Emirates.

\section{Activities and Achievements of ASMO}

\section{(a) Training Courses:}

Since its establishment, ASMO has devoted much attention to helping the Arab States in training personnel in the fields of standardization, metrology, and quality control. This is achieved by organizing basic and specialized training courses aiming at preparing the different levels of technical personnel required to meet the urgent and growing needs of the specific fields of standardization activities.

The total number of Arab specialists that attended the training courses organized by ASMO till May 1977 were 232, and also 39 others were sent to be trained in France, Iran, India, and West Germany.

\section{(b) Specialized Seminars:}

Fifteen seminars were organized by ASMO to study and analyze problems and difficulties pertaining to the implementation of standards and quality control procedures and to propose suitable solutions for these 
problems. The first Arab Standardization and Quality Control

Conference was also held during 1974 in collaboration with UNIDO. It was attended by most of the Arab States, as well as by representatives of the international and national bodies concerned with

standardization, quality control, and metrology.

(c) Unified Arab standards are issued to meet the needs of Arab industry and international and external trade. The standards issued are in 1ine, as much as possible, with the international standards and recommendations and are suitable for Arab needs. Arab States have shown interest in these standards and have taken the necessary steps towards their implementation in all fields of industry and commerce. This is because implementation of these standards tends to limit the diversity of standards for the same commodity and safeguard the interests of Arab consumers.

A number of technical committees have been set up within the framework of ASMO. Their flelds of activity were defined and their technical secretariats were accredited to some standardization bodies of member countries. These comittees prepare drafts for unified Arab standards in the following fields:

Technical terms - food products - chemical products - textile industry products - building materials - ferrous and non-ferrous products - electrical equipment and instruments - petroleum and petrochemical products - engineering and design drawing practice codes of practice in building construction - packing and packaging of agricultural and food products.

These technical committees have prepared more than 500 drafts of unified Arab standards, of which 365 were approved by the General Comittee of ASMO. Sixty-five percent of the adopted standards are based on corresponding international standards.

\section{Technical Studies and Projects}

ASMO undertakes several technical studies and projects.

(a) ASMO helps the Arab States in the creation and development of their national bodies, adhering laboratories concerned with calibration, quality control, and testing and analysis of raw materials and products according to practical and scientific principles suitable to actual needs of each country. The aim is efficient performance and economy in expenses.

(b) ASMO establishes cooperation and technical coordination between Arab laboratories, national bodies of standardization, and engineering inspectorates in order to exchange information and experience, ensure confidence in the quality and precision of products and equipment, facilitate commercial exchange, promote export, and assure quality of 
imports. To strengthen these programs, an agreement for cooperation between ASMO and the National Institute of Standards in Egypt was concluded.

(c) ASMO coordinates and develops the existing facilities for the maintenance and repair of measuring and testing instruments in the Arab States.

(d) ASMO establishes a correlation system between Arab Petroleum Laboratories aiming at ensuring reproducibility of the results and unification of the methods of testing of Arab petroleum products, so as to assure the confidence of domestic and world markets in their quality. This project was started in July 1973. The important petroleum bodies and laboratories of nine Arab states have joined this ASMO correlation system.

(e) ASMO carries out feasibility studies for:

(i) The establishment of a technical body to assist Arab states in assuring the quality and precision of imported equipment.

(ii) The creation of an Arab body to help in promoting exports and improve their quality and conformity to Arab and international standards.

(f) ASMO surveys the potentialities and requirements of the Arab countries in the fields of standardization, metrology, and quality control. Such a survey was carried out with the assistance of both UNIDO and UNESCO.

The results of this survey were used in:

(i) Drawing up an overall plan for the promotion of the activities of standardization, metrology, and quality control in the Arab region.

(ii) Proposing projects and technical assistance suitable for each country in order to fulfill their needs concerning personnel and basic facilities.

(iii) Planning and projecting an Arab center for documentation and technical information and another center for training and upgrading personnel working in the fields of standardization, metrology, and quality control.

(g) Among other technical studies and projects undertaken by ASMO are the preparation of the following:

(i) Laying down principles and procedures of establishment and development of national bodies of standards and metrology. 
(11) Draft model legislation for the organization of legal metrology in Arab States.

(111) Encouraging uniform terminology and nomenclature for materlals and products, instruments, and equipment.

(iv) Publishing a guide for the elaboration of Arab standards.

(v) Publishing specifications for the basic instruments and equipment for legal metrology laboratories.

\section{Documentation and Information Services}

The ASMO activity on documentation and information aims at providing regularly all member countrles with up-to-date knowledge and trends in the field of sclence and technology related to standardization activities. This is carried out through technical, informative, and statistical bulletins and simplified booklets about standardization, metrology, and quality control. ASMO has already procured a microfilm unit for such services and is currently publishing bibliographical lists of publications in the fields of standardization, metrology, and quality control in the Arab world. It contacts Arab and international documentation centers and is taking the necessary steps to be a member of the International Organization for Standardization Network.

\section{Regional and International Cooperation}

ASMO's cooperation at the regional and international level aims at harmonizing Arab standards with the corresponding regional and international standards, so as to improve quality of Arab products and promote their export. It alms also at supporting the common Arab interests in regional and international bodies, and coordinating Arab participation in such organizations.

In the framework of these efforts, long-term agreements on technical assistance were concluded with UNIDO, as well as with ISO, OIML, IEC, and Codex Alimentarius, in order to translate their standards into the Arabic language and issue them as Arab standards. As of January 1977 Dr. Mahmoud Salama, ASMO Secretary General, was elected to be the Chairman of the Development Committee of ISO. ASMO has also joined the European Organization for Quality Control and the American Society for Testing and Materials to benefit from their experiences and studies. This activity has been extended to cooperation with the African countries through the African Regional Standardization Organization, and with the European countries through the European Committee for Standardization (CEN), in addition to the Association Francals de Normalisation, the British Standards Institute, and the West German Standards Institution. Cooperation has started with Asian 
countries with the Indian Standards Institute, Iran's Institute of Standards and Industrial Research, and the Japanese Industrial

Standards Committee.

\section{Conclusion}

It is hoped that ASMO in consultation with the National Bureau of Standards would develop the already existing cooperation, particularly:

(a) For the exchange of views about subjects and problems of mutual interest in order to promote cooperation for the realization of their mutual and joint objectives in the development of standardization and metrology.

(b) For the exchange of experience, statistics, papers, documents, and technical information.

(c) For the development of the ASMO documentation unit into a bank of technical information for the benefit of the national standardization bodies and the industrial concerns in the Arab countries.

(d) For the development of regular, general, and specialized training programs for Arab engineers and technicians.

(e) For organizing of symposia and seminars for discussing those problems pertaining to the implementation of standardization and metrology procedures as well as those related to metrication.

(f) For propagating the use of reference materials and sophisticated instruments in Arab testing and calibration laboratories.

(g) For developing correlation systems between U.S.A. and Arab laboratories in order to harmonize testing procedures and results and minimize any divergence or disputes. 


\author{
by \\ Dr. Robert Oteng \\ Director, Development Committee \\ International Organization for Standardization \\ Geneva, Switzerland
}

\title{
Introduction
}

It is a great honor for me and my organization to have been invited to take part in this Workshop and Seminar organized by the National Bureau of Standards and the United States Agency for International Development. I thank, on my own behalf and on behalf of my organization, the organizers and particularly Mr. Steffen Peiser for extending the invitation to us.

I think that, for the benefit of my colleagues from the developing countries, this is a good opportunity to make a brief presentation of the International Organization for Standardization (ISO) and of its work. The need for standardization on the international level was felt more than 70 years ago when efforts were made at international agreements or specifications in the electrotechnical field. In the thirties, these international efforts were extended into other technical fields. As a result of a meeting held in London in 1946, 25 countries decided to create a completely new organization whose object was to facilitate international coordination and unification of industrial standards. This new organization began to function officially on February 23, 1947, and ISO was born as the specialized international agency responsible for standardization.

Membership of ISO

Membership of the ISO can be either at the "member body" level or at the "correspondent member" level. A member body of a country is that body representative of all standardization activities in that country. The decision as to which body becomes a member body in a country rests with the country concerned; if there is more than one body in a country dealing with standards, only one body can apply for ISO membership.

Member bodies are entitled to participate and exercise full voting rights on any technical committee of ISO, are eligible for Council membership, and have a seat in the General Assembly of ISO. By December of 1976, the number of member bodies was 64 .

A correspondent member is normally an organization in a developing country which does not yet have its own national standards body. Correspondent members do not take active part in the technical work, but are kept fully informed about such work. A correspondent member 
can always be upgraded to the status of member body after fulfilling the conditions for a member body as described earlier. By December of 1976, there were 18 correspondent members, all of whom came from developing countries and are mostly governmental institutions.

\section{Administration}

The ISO is governed by a Council elected from among 1 ts members and headed by a president and a vice-president. Presently 18 member bodies (in addition to the president and vice-president) form the ISO Counc11. It may be interesting to note that five of these members come from developing countries--Brazil, Ghana, India, Iran, and Egypt. The rest of the membership is as follows: France, United States, United Kingdom, West Germany, Denmark, U.S.S.R., Japan, Yugoslavia, Hungary, Netherlands, Austria, South Africa, and Canada.

\section{The Organization Structure}

The Council is assisted by various committees which together with the Council are headed by a secretary general. He is supported by two assistant secretaries general and six directors. Work at the Central Secretariat is divided into four main sections or departments and relates to the various council committees.

The four sections are:

(i) Technical Department--with subdivisions. Three directors are in charge.

(1i) Development Program--one director in charge.

(iii) Information and Public Relations-one director in charge.

(iv) Administration and Finance--one director in charge.

The various Council committees are [see chart next page]:

(i) Executive Committee (EXCO).

(ii) Planning Committee (PLACO).

(iii) Committee on Certification (CERTICO).

(iv) Development Committee (DEVCO).

(v) Standing Committee for the Study of Scientific and Technical Information (INFCO).

(vi) Committee on Reference Materials (REMCO).

(vii) Standing Committee for the Study of the Principles of Standardization (STACO).

Terms of Reference of Some of the Committees of Counc11

(A) EXCO has the following functions:

(1) To assist the Council with consideration of matters of administration and organization which may arise in the interval between Counc1l meetings. 


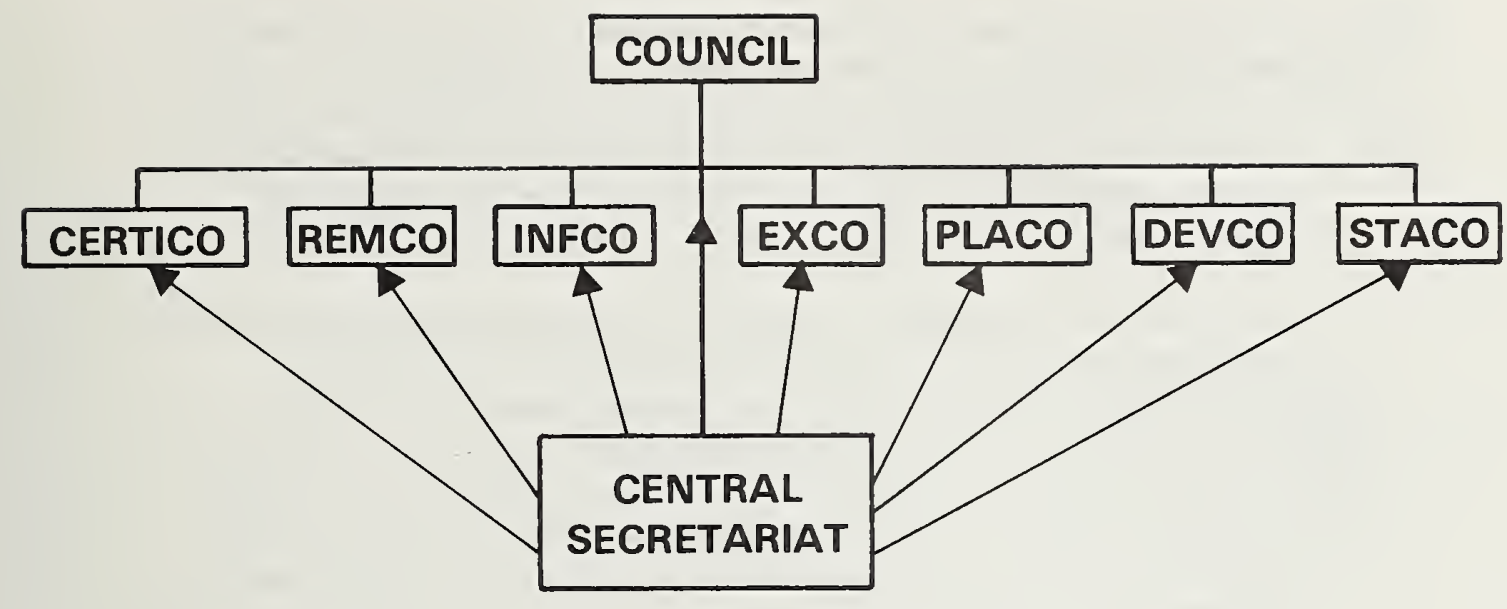

(ii) To act as a finance committee, reviewing, inter alia, the draft budget prepared by the secretary general and recommending a budget for approval by Council.

(iii) To act, where necessary, within the framework of previous policy decisions by Council.

(iv) To present reports for consideration at annual meetings of Council.

(v) To take action on behalf of Council on:

(a) The appointment of chairmen of technical committees.

(b) The decision as to the acceptance of funds from other sources--gifts, etc.

(c) The sanctioning of changes in the approved budget, not exceeding 10 percent of the approved expenditure for any one year provided that any deviation thus sanctioned does not affect the unit value or any principal decision of Council.

(B) PLACO has the following mission:

(i) To advise Council on all matters concerning the organization, coordination, and planning of the technical work of ISO.

(ii) To review the titles and scopes of individual technical committees so as to ensure the greatest possible coordination and avoidance of overlaps. 
(iii) To examine proposals for the study of new questions and make appropriate recommendations to Council.

(iv) To make recommendations to Council on all matters concerning the setting up and dissolution of technical committees.

(v) To act where necessary in the above matters within the framework of previous policy decisions by Council.

(C) CERTICO has the following responsibilities:

(i) To study means of securing greater mutual acceptance of the validity of national and regional certification systems and marks, as ensuring conformity with standards specifying the functions and properties of products, particularly when safety, health, or environmental factors are involved, and the definition of the rules and procedures necessary for securing a widening matrix of such agreements, recognizing that the use of national certification systems and marks as a protective measure will thereby be reduced.

(ii) To keep under review the development of national and regional systems so that, when in the future a need arises, progress can be made towards certification of ISO International standards and, in the meantime, to study how to protect the ISO work so that it can be used in the future as a mark of conformity to standards.

(iii) To examine how to control the use of ISO International Standards in certification systems.

(D) DEVCO has the following special opportunities:

(1) To identify the needs and requirements of the developing countries in the fields of standardization and related areas (quality control, metrology, and certification) and to assist the developing countries, as necessary, to define these needs.

(ii) Having established these needs and requirements, to recommend measures to assist the developing countries in meeting them,

(iii) To provide a forum for the discussion of all aspects of standardization and related activities in developing countries and for the exchange of experience between the developed 
and developing countries, as well as among developing countries, these functions to be pursued in close llalson with the speclalized agencies of the United Nations, with IEC, and with ISO Council Comittees.

(iv) To advise Council on the above matters.

(E) INFCO alms to satisfy the following needs:

(1) To assist the development of Information centers on standardization of the ISO Central Secretarlat and the ISO member bodles and of the links between them and so to establish an ISO Information Network.

(11) To appralse the program of the ISo Information Center.

(11) To foster profitable relationships with other international information networks.

(Iv) To advise Council on these and other matters related to the compllation, storage, retrleval, application, and dissemination of scientific and technical information on standardization.

The above descriptions are a few examples of the terms of reference of some of the Counc1l Committees of the ISO.

Technical Work in the ISO

All technical work of the ISO is carried out by technical committees. Usually, these are designated as TC's. Council is the body which makes a decision on the formation and scope of a technical committee.

EIther a member body or an international organization may find a need to introduce an Item into the ISO technical program. This proposal is then submitted for consideration by the ISO member bodies. If the proposal finds favor with the member bodles, a recommendation is made to Councll which may elther create a new $\mathrm{TC}$, or if there is already a TC competent to deal with the Item, it is accordingly referred to this TC.

Technical committees determine their own program of work and may appoint subcommittees ( $\mathrm{SC}^{\prime} \mathrm{s}$ ) or working groups (WG's) to cover different aspects of the work.

Every technical committee and subcommittee has a secretarlat assigned to an ISO member body. In the case of the technical committee, this assignment is made by Counc11, and in the case of the subcomittee, the assignment is made by the parent technical comnittee.

If a member body is interested in a technical comittee which has been set up, he has the right to be represented on that committee. 
Representation on a technical committee may take two forms: a Pmembership or an 0 -membership. A $\mathrm{P}$-member is a member who takes active part in the deliberations of the committee and has a vote. An 0 -member is a member who only wishes to be kept informed of the work of a technical committee or subcommittee. Such a member is known as an observer. He can attend meetings of the technical committee or subcomittee but has no vote.

\section{International Standards}

An international standard results from an agreement among the member bodies of ISO. Firstly, a document designated as a draft proposal (DP) is circulated for study within a technical committee. It then goes through several stages within the TC until an agreement is reached on it. It is then sent to the ISO Central Secretariat for registration as a draft international standard (DIS); the DIS is then circulated to all member bodies for voting. If 75 percent of the member bodies vote in favor of the DIS, it is recommended to the ISO Council for acceptance as an International Standard. Usually, it happens that all technical issues are resolved at the TC level; however, the member body and Council voting provide an important assurance that no important objections have been overlooked. The number of ISO standards published between 1960 and 1976 is given in the "ISO Catalog" which can be supplied on request.

\section{External Relations}

The work that ISo does is of interest to many international organizations, some of which make a direct contribution to the preparation of ISO standards. Others, such as intergovernmental organizations, contribute to the Implementation of ISO standards, for example, by utilizing them in the framework of intergovernmental agreements. The ISO has made arrangements to involve such organizations with all stages of the ISO work. For example, international organizations may make proposals for the preparation of ISO standards in a new field in the same way as ISO member bodies do. International organizations which can make effective contributions to the Implementation of ISO standards are expressly invited to comment on all relevant drafts. Technical committees are instructed to seek the full and, if possible, formal backing of the main international organizations in liaison for each ISO standard in which these organizations are interested, and so on.

A full list of links between the ISO and the various international organizations may be found in the ISO publication, "ISO Liaisons," which can also be obtained on request. However, it is necessary to mention that the U.N. specialized agencies and the International Electrotechnical Commission (IEC) work especially closely with the ISO. 
Perhaps before we conclude this brief presentation of the ISO, it may be necessary to mention the development program which the ISO has set up to deal with standardization matters of the developing countries. For as long as can be remembered, the participation of developing countries in ISO technical and other work has not been significant. Developing countries have complained that their views have not been taken into consideration in drawing up international standards. This to them means that what is called an International Standard is not really and truly international in its outlook.

Experience has suggested that there may be various constraints in developing countries which do not make the developing countries contribute as much as may be desired. These constraints may be different from country to country, and it is therefore necessary to try and evaluate these to find out what remedial measures can be applied. It is to this end that the development program unit has been strengthened. ISO, through its development program, hopes to make frequent contacts with directors of standards bodies in developing countries to assess their needs.

ISO hopes to mobilize the facilities existing in its entire membership for offering assistance to its developing country members. It hopes to strengthen its relationship with the U.N. and other AID agencies so that problems identified can be addressed to the appropriate agency for assistance.

The ISO, in all this, hopes also to infuse into its developing country members the need for a certain degree of self-help, since the old saying states that heaven helps those who help themselves.

Already, various agencles have been approached; the contacts with the directors of standards bodies in developing countries have begun. It is hoped that all concerned would cooperate to make this initiative a success.

I have tried to give a brief resume of the operations of the ISO. I hope that this has been useful, or at least that it has generated some interest which will lead to further inquiries being made. We at ISO shall be delighted to reply to them. The address of ISO is:

1, rue de Varembe

Case postale 56

1211 Geneve 20

Switzerland/Suisse 
EVLNING DISCOURSES

BY INVITED GUESTS 

by

Mr. L. E. Gatterer, President

Lawrence Gatterer Associates

It was a surprise to me to realize that in many respects developed countries are more change resistant than are less developed countries. The greater the degree of development in a nation, the greater the extent to which resources have been spoken for and decisions made. New technologies offer opportunities to utilize previously allocated resources in new ways, and thus tend to pose a threat to the established order of things. Might we not expect to find greater receptiveness to some innovations in developing countries than in developed countries? It has been suggested that indecision is the key to flexibility. The corollary is that inflexibility follows decision.

Consider the opportunities for using electromagnetic communications systems instead of cars and airplanes for bringing people together for meetings. Richard Harkness of the U.S. Office of Telecommunications considered the possibilities in a report titled "Telecommunications Substitutes for Travel." He reported that work done in England indicates that telecommunications are probably an effective substitute for up to 65 percent of all business meetings. That is an impressive statistic in these days of waning supplies of energy. Harkness pointed out that teleconferencing as a substitute for face-to-face meetings is a matter of supply of and demand for specialized services that cannot emerge until after research and experiment have established the feasibility and desirability of substitution.

A meaningful test of such services would necessarily require that an entire region, be it large or small, adopt suitable systems. In the United states that is sometimes easier said than done. To be sure, we have a single communications authority in the Federal Communications Commission (the FCC), but we have designed our affairs so as to insure a lively competition among the various independently owned services such as telephone, telegraph, cable TV, the radio broadcasters, the TV broadcasters, etc. Everybody is competing with everybody else and is very jealous of any inroads made by competing services. If the cable people propose to provide a data service over their lines that could as well be provided by telephone lines, there will surely follow a raging controversy that will certainly slow progress with regard to providing the proposed data service. It may take many years to obtain a proposal approved by the FCC if approval is obtainable at all.

In most other countries of the world, regardless of political orientation, the governments own and operate all of the communication systems. This approach would not be acceptable in the United States, and I do not mean to suggest that it ought to be adopted here. But it 
does have advantages, including that of a greater opportunity to integrate the facilities of diverse systems to accommodate new services.

It is relatively easy to establish such an innovative service in a country with non-existent, rudimentary, or obsolete communication systems. When there is little plant investment of current value, then few w111 be found to guard an established order of things.

If there is a desire to test an exotic telecommunications service, it might be somewhat easier to do so in a controlled telecommunications environment, especially in a developing country, than in a freewheeling, highly developed telecommunications environment such as exists in the United States.

The present circumstance emerging in Mexico may bear some relationship to my point. Mexico's principal city is, it is claimed, the world's largest. Mexico City is rated as having the worst pollution problem of any major city in the world. It has stupendous urban problems that will grow to proportions difficult to imagine: many suburbs have emerged without benefit of planning; the subway, while elegant, serves a very Iimited area; downtown traffic congestion is without comparison; and the telephone system is spotty and far from modern. One can imagine that Mexico City could benefit from substantial redevelopment.

Now consider the brightest spot in Mexico's economic future-her newly recognized petroleum reserves. Mexico has enormous oil reserves in the Campeche Bay area, the full extent of which has not yet been measured. The gas reserves, too, are huge. Evidently, Mexico will be in a position to produce real, exportable wealth with which to finance the acquisition of physical equipment and services to implement solutions to many of her urban problems in the coming decades. Does it not seem possible that Mexico will adopt exotic and innovative new teleconferencing services long before the United States? Is it not likely that many of the world's developing nations will adopt such services before the United States can?

There are many compact nations in which some new technologies could be tested on a whole country basis. Some such technologies could be tested in only a very limited way, or perhaps not at all, in the United States. There are some tests that must be conducted nationwide or at least system-wide in order to derive full benefit from the test. Such is the case with regard to a change in electrical power distribution and communication systems, to name only two.

One service that was proposed but seemingly cannot be implemented in the United States would have carried time and frequency information within the vertical interval of commercial television signals. Users of the service would monitor the commercial broadcast and recover the time and frequency information. The technique was demonstrated 
repeatedly and was found to be the most accurate technique known. In fact, no time standards were avallable that were good enough to define the limits of accuracy of the technique.

Special purpose equipment was developed at the National Bureau of Standards (NBS) for injecting time and frequency information into the vertical interval of commercial television programs. The equipment could handle a variety of information, including information that could be decoded and displayed as captions related to the television program. Obviously, that offered a significant benefit to the hard of hearing and to those to whom the local language is forelgn. Information could be infected so that a viewer with a suitably equipped set could display captions in his choice of more than one language.

NBS had proposed implementation of a time-frequency dissemination and captioning system at the time of the NBS-AID visit to Thailand in 1973*. There was considerable excitement. But the interests of a great many agencles and organizations were affected, and the proposal was running into trouble.

While in Thailand I inquired as to whether it would be difficult to secure permission for such a system there. I was assured that it would be quite a simple matter. The Thais were already using subtitles on some TV programs, in recognition that Thailand is a multi-lingual nation. The possibility of providing captioning in the viewer's cholce of languages had great appeal in Thailand.

Meanwhile in the United States, the NBS petition languished before the FCC for some years and ultimately was withdrawn. The Public Broadcasting System petitioned the FCC for permission to use the captioning technique, but time dissemination at present is a dead issue here. It will be left to some other nation to be first with that. Perhaps this honor will fall on Korea.

I am struck by the contradiction of the situation: The United States could not have demonstrated the accuracy of television time dissemination before its communication systems were in place. But, since Its systems are already in place, the United States is unable to enjoy the benefits of a television time dissemination service.

More generally, I am left with a persistent notion that there ought to be some interesting opportunities for bilateral interactions that would offer significant mutual benefit to both developing and developed nations. Scientists with an involvement in international relations should be alert for such opportunities. In addition to studying the unsolved problems walting in less developed countries,

* Report on an NBS/AID Survey of Standardization and Measurement Services in Thailand, May 22.-June 1, 1973, NBSIR 76-1190. (AID is Agency for International Development.) 
perhaps we ought to be paying attention to the unimplemented solutions that lie unexploited in developed nations.

It takes a nation with sophisticated systems in place to demonstrate the feasibility of some techniques. But the very existence of the tools needed to verify some techniques makes difficult the implementing of the techniques into services for evaluation from technical, social, cultural, and other viewpoints. A developing country might do a great service for itself and for all the nations of the world by seeking opportunities to be the nation to demonstrate new technologies. 
I would like to talk to you about inventions, partly because I am an inventor and because I would like to convince you that inventing is a form of art. I will start by telling you why I think technology is important, not only important to me as one who makes a living from it, but why it is important to various nations and to the world. Then, I will tell you about inventions, tell you some anecdotes, and hope that perhaps I can influence you about what you can do in your own countries to support inventions and technology. Incidentally, the United States can do much more than it does to encourage technology. In my opinton, we are not doing anywhere near enough and we are slipping technically. Originally, I was not going to say anything about this, but Steffen Peiser said that I can mention it because we are supposed to be honest tonight--and so I shall.

When one talks about technology, one comes to the realization that there are only three ways that a country can improve its overall standard of living. One way is the classical and old method of robbing somebody else. It is a good method; it has been practiced for many centuries. The rich countries of the world have made colonies out of the poor people, recelving their cheap labor and cheap materials. This method does not seem to work well, for some reason. The countries that were exploited do not seem to like it, so the method is outdated.

A second method to become richer in a total sense, and I am not talking about internal distribution of wealth, is to be very rich in natural resources--like Kuwait and Saudi Arabia. If you can sell these natural resources--that is, if you live on a sea of o1l, you can raise enough money and wealth to be a rich nation. This is very difficult today; very few countries have this quantity of natural resources. Certainly, we do not. Even Saudi Arabia, I understand, has some problems with having enough money for the other things they would like to buy.

A third way, and the only way left for an advancing nation to improve its total wealth, is to improve its technology.

There are minor methods, in addition to these three, such as improving the education of the people. This is very difficult in the United States; we are very educated now. More than half of our people of college age go to college, and it is doubtful that to aim for any larger percentage would be practical or necessary. A nation can also improve its productivity by better health care. Again, for a nation 
like the United States, it is not likely that this would lead to a major improvement in efficiency.

The thing that is left, then, is that for every hour of work we produce more goods. The question then is, how does one do this? We realize technology rests upon basic research (which is pure science perhaps); then the pure science results in advanced development, and finally, development leads to production by people like myself who are engineers. We have to support this whole chain to produce the result we want.

Then, there is the question of transferring technology from some nations to others; that is, from those we call advanced countries, like the United States or Germany, to countries that do not have the same advances in technology. The trouble with technology transfer is that it is very much like transferring trees or like the raising of cattle native to one country in another. You have to have the right climate to accept the technology. You can set out to transfer all the technology you like. Unless the country that receives it has the right climate, the technology will die. It is not enough to just build factories in a country that uses cheap labor; one has to transfer the thinking and the ability to grow and to develop the equipment locally. This matter of climate is what I would like to talk about today. Specifically, I would like to talk about inventions.

The thing that is interesting about inventions is that an invention, contrary to popular belief, is not the result of logical thinking. It is like any other art form; it is like composing music. One does not compose music by being a logical computer. I have heard some music composed by a computer and $i t$ is pretty terrible. One composes music as one does any other general thinking by a random process. Let me tell you how I think it happens.

There is a study that was made by Bill Shockley, a Nobel Prize winner for his work in transistors, which states that there is something very curlous about the human brain in doing original work. The study says that when you compare the ability of one man to another you find that the differences in specific abilities are very small. The best runner is not twice as fast as the average runner; the very fast heartbeat is not twice as fast as the average heartbeat. The I.Q. (that is, the intelligence quotient) of the best is perhaps 170 and the average is 100 , and it does not really make much difference what the I.Q. stands for. Shockley says that if you take any skill, any single ability of a human brain or a human body, the difference between the average and the best is small. However, when you compare the output of creative people, like writers or composers, you find the difference between the best and the average in output is not two to one. One man w111 compose hundreds, perhaps thousands of poems, while another composes nothing. He studied some of our great laboratorles, like the National Bureau of Standards, like the Bell Laboratories, and found that some 
people made a great many inventions, some made a few, and many made none at all. From this, he concluded that ability to create new things is not the result of a simple skill of a human brain, and that it takes a combination of features to create the result. I will spare you the mechanical details of his computation, but he points out, for example, that if it takes six ideas together to invent a particular item (that is, six ideas that were not connected before), then a man who could put six ideas together will solve the problem, and the man who can only put four ideas together at one time will not solve it. So, the difference in ability is not just six to four, but a very large difference because you are dealing with very large numbers of ideas in a person's brain.

It is my belief that original work is a random process of putting together things you can create in your mind in various ways as if one is playing with these things and then looking at the results to see if something new comes out--something new and good. Now, if you have good taste, as a result of good training, you can recognize the good combinations. If you do not have the training, you do not. So, one of the big tricks in inventing, or writing music, or writing literature, or painting is to have enough training and enough education in a particular art to have the good judgment to decide what is good and what is not. It is not enough just to compose music; one has to know what should be preserved and what should be thrown out.

Inventors come to NBS in connection with some of our programs and we receive many suggestions. Last year, we received some 6,000 inventions in the field of energy. Most of these were trash; there were only about 30 good ones. This is because many of the people who submit these inventions have no training; they do not know that the ideas they had were not good. One of the things that Shockley points out in his study is that to compose good things (that is, to produce good ideas), one has to produce a great many ideas. This is contrary to the belief that many people have; that those who compose the best also compose very little. This is simply not true historically. People who wrote the best books also wrote a great many books, except they knew what was good and that which was bad. They selected the best. The inventor, of course, has to do the same thing; he has a great many ideas--some he discards immediately, some he discards later. But, to get 200 patents, one has to invent two or three thousand items and discard most because the inventor himself is critical--and, if he is not, heaven knows his friends are. If you want to have inventions created in your countries, you have to have a climate which will induce people to try to do this a great deal. During this past year, my wife and I visited Hong Kong, Taipei, Singapore, and some other countries. I talked to some associations of inventors. In these places, we found that the people visited were very anxious to develop inventions at home because they realize that just to create production by cheap labor does not pay in the long run. It does not pay for several reasons. One is that eventually their wages go up, as they did in Japan, and one is no longer competitive 
just based on wages. Secondly, there is always someone else who is cheaper than you are. It is, therefore, not a healthy situation to depend only on low wages. One would like to have unique and special products. The Japanese learned this very soon after the war and they no longer depend on cheap labor. In fact, if something is very cheap, they would prefer to have it done elsewhere. They now develop their own cameras, their own television sets, and their own products of all types. We found that people in Hong Kong would like to do likewise. The question is, how does one set up a climate where people will do this?

I think that what I will say will really answer this but I would like now to give you some anecdotes about some of my inventions and tell you how the inventions happen to be made. I am not going to talk about those which are necessarily important, for which I received some award or money, but I will tell you about some inventions about which I usually do not talk because they are inventions which I personally happen to like. To an inventor, an invention may be admirable not just because it makes money. He may like an invention--his or someone else's--because of the excitement that it creates in his mind and because sometimes it is just fun.

I lived in Siberia for five years as a young boy, and at the age of nine my family went to Harbin, China. Before this, I saw only one automobile. It arrived in the city where we lived; it was surrounded by a large crowd of people when it stopped, and I did not really get a chance to get a close look at it. When we got to Harbin, I saw a great many cars and I noticed a very peculiar thing about them. I was accustomed to seeing wagons where the front wheels turned together on a single axis. I noticed that when an automobile turned its front wheels they turned on separate axes; that is, separate axles. They do not turn as the front wheels of a wagon. I found this very interesting. I climbed under a Model-T Ford; as you know, in those days you could get under a car; today you no longer can. I was, of course, much younger and much smaller. I carefully examined the mechanism for supporting the front wheels. I found that each wheel had its own little axle, and I thought this was most fascinating. I lay under the car, astounded by this great discovery. To me this was a very exciting thing. To this day, I get this kind of excitement when $I$ see an interesting device. Years later, I was reading a book on automobiles and I came across a section describing the differential gear. This is a mechanism in the rear axle of an automobile that permits one wheel to turn at a different speed from the other when the wheels are turning around a corner. The drawing in the book was very difficult to understand. It took me most of a night to unravel it. When I finally did understand it, I felt very excited and very pleased. I also thought it was a very brilliant piece of work; I still think so. I am telling you this to give you a feeling for the reaction that. I get--and $I$ am sure this is true of all inventors when they arrive at an idea which is new to them. 
We sometimes invent things that we know were done before; we do this as an exercise; we sometimes do it to save time rather than look up the information and sometimes just as a way of testing our own ability. For example, many years ago I was curlous about how do people keep the mirror of a large telescope from distorting its shape when it is tilted in following a star in the sky. I knew that they had solved the problem in the large 200-inch telescope, and I began to think how that was done. You see, if the mirror is horizontal, its weight keeps it in one shape. When the same mirror is vertical, that is, when the telescope is horizontal, the mirror is standing on its edge, and it must change its shape because it is very heavy. No matter how you support it with a rigid structure, the weight of a structure also changes its shape. Since the mirror has to be kept in its round shape very accurately to be a good telescope mirror, I wanted to figure out how it could be done. I did finally think of a system, using flexible supports which support the mirror at various points, and felt that this was probably correct. I wrote to the Observatory and received an answer, and I was very happy to read that the way I figured it out is the way it is done. I tell you this to point out that we have satisfaction in doing a job correctly even if there is no money involved, no glory, and the only one who knows about this good feeling is the inventor himself.

Let me give you another example of just solving a problem for its own sake. The problem was given to me this way. Two men land on a desert island; they find a bottle of water--a plain glass bottle, irregular in shape, and it is full of water to the very top. It has rained for a long time. There are no other utensils. The problem is for each man to drink exactly half and give the other half to the other man. The problem can be solved; without any other utensils, one can drink exactly half the bottle and both men will know that this is exactly correct. It took me about an hour to solve it, and I felt very good about this. Many years later, I was giving a lecture about creativity to the research staff at the Goddard Space Center here near Washington. I said, after I gave the problem to them, "If you solve the problem, call me anytime, day or night; I would like to hear from you." As I was walking out of the lecture ha1l, a young man came to me and said, "About that problem, Mr. Rabinow, about the bottle; I can do 1t." I said, "How?" and he told me; he had the correct answer. Then he said, "I can also do it when the bottle is not full. I can drink exactly half the water." I sald, "You must be joking." He said, "No," and he told me how to do it. I was astounded; it was the correct way to solve the problem when the bottle was not full of water. When I came back to my own laboratory, I told my engineers about this story. One of my engineers by the name of Bill Fisher looked me straight in the eye and said, "It can be done when the bottle is not full?" I sald, "Yes, it can be done." He looked for another moment and said, "Yes, I can do it," and he did it.

This illustrates a very basic thing about inventions. If you know that it can be done, or you assume it can be done, it is probably 
possible. If you assume that it cannot be done, you certainly will not try. So, it is important to create a climate where people believe above all else that things can be done. This philosophy becomes a way of life. Let me give you an illustration of it.

I had the problem to take off a piece of walnut paneling in our living room. I could not get at the edges to get behind it; the paneling was held by very thin, hidden nails driven through the wood and covered. I knew that if I had to pull the nails out I would damage the wood so that it would not be usable. I didn't want to get a new piece of wood because it had to match the rest of the paneling. I decided that the problem was solvable; I sat down on the floor and looked at this panel for close to an hour, saying to myself, "You teach people that if you assume a problem can be solved, it can be solved. O.K., do it." Suddenly, I had an idea. One takes a thin tool and drives the nails all the way through the wood into the wall. In other words, instead of pulling the nails out, one drives them through. The panel then falls off and all it has is a few little holes, which it had before, where the nails were driven and the nailheads were covered with putty. Now, you can pull the nails out of the wall, if you wish, or leave them in; do whatever has to be done and put the panel back with a few other small nails. I felt very proud of myself. When I came back to my office, I told my patent attorney that I had a brilliant idea how to take panels from walls. He listened to my story and laughed; he said, "Every carpenter in the world knows this trick. It is very old." Nevertheless, I felt good because I had solved the problem in what I considered an elegant way.

I could tell you some more stories about minor inventions; I could tell you about major inventions, like automating the Post office, but that would take a whole evening. Minor inventions are really more fun.

One of our friends, who is a professor of mathematics, during the war was living in Washington. His wife was working at the White House; she was a typist, among other things. She told us one day that she has to type every letter twice. The White House is very fussy about how their letters and reports look. They would like to have the lines come out even on both sides. Now, when you type on a conventional typewriter, the left margin is even; the right, of course, is not. This is called justification. The White House wanted their letters, or at least their reports, justifled on both sides. I said, "How do you do this?" She said, "I type everything twice. I type it first on a special form and see how many spaces are left on the right side or how many spaces my line runs over. Then I take a new typewriter, called a Varitype machine, where you can adjust spacing, and I put in a correction, either plus two or three or minus two or three. Then, I retype the whole page and now it comes out even and it looks more like a book than a typewritten sheet." I said, "Well, that's silly; there should be a typewriter that types even on both sides with one typing-with the first typing." My mathematical friend, who is a very 
brilliant mathematician, thought a minute and sald, "I will bet you that it cannot be done." So, we bet a quarter--25c. My friend should have known that an inventor will kill himself for $25 \mathrm{c}$ to win a bet. It is the principle of the thing. By the time we walked to their home, I had a solution and the solution would be to do as follows. The typewriter would not print the characters on the paper as you type but would set wheels. There will be one wheel for each letter; each wheel would have a complete alphabet on 1t. So, as you type, the wheels would be turning and set; when you finish, you would have a whole set of wheels, a whole drum consisting of wheels, and with the line all set up. You can even arrange it so that one side of the wheel is the typing side, and the other side is the side you could see to read the line if you wish, to see that the line is correct. Then, when you finish the line, you push a key which says, "Print," or if you like, "Shift Line," and the whole line would be printed at once with a single stroke. Of course, just before that happens the wheels would be either spread apart or pushed together to make a line come out a certain fixed length. I went to the Patent office to search this 1dea and discovered that not only was 1 there, but they have a whole class of what they call "Justifying Drum Printers." This Idea is very old, something like a hundred years old. I do not know why such typewriters were not made. Today, of course, you do not need 1t; you can put a Iine Into a computer, and the computer can justify the line and print it out because such machines now exist in large numbers. But it was fun, and I was very proud that I could win that $25 c$.

Now I would like to tell you about an invention that did make some money for me and was more useful than some of the ones $I$ have been telling you about. In 1945, my wife Gladys, who is here with me, gave me a watch as a birthday present. This was an ordinary good Swiss watch, made the same way as watches are made. It had a waterproof stainless steel case. The watch did not keep perfect time because no watch does. Watches are usually set at the factories slightly fast, since fast watches are less objectionable than slow watches.

Anyway, the watch did not keep perfect time, so I unscrewed the back, which you should not do unless you are a watchmaker; I scratched the case; I moved the regulator slightly, screwed the back on again, scratched it a little more, and the watch ran better. After doing this two or three times, the watch ran quite well. Then, a year or so later 1 t began to drift in the other direction because watches change their rate--perhaps the oil became thicker, there may have been some natural wear, or maybe I changed my method of wearing it. So, I did It again. Being an inventor, I decided something should be done about this; so I invented an automatic watch regulator. I am wearing a watch with it on my left arm. When people ask me, "Why do you wear two watches?" I say, "I do this because I am giving a lecture tonight." You, have to do some more explaining, and thank heaven, it does not happen often. The watch regulator works as follows: When you change the position of the hands, you also change the rate of the 
watch, that is, the position of the rate regulator inside the watch. If, for example, you move the watch forward, you also speed it up a little; if you move it back, you make the watch run slower. The question immediately arose, what does one do when one changes zones, for example, such as when going from Washington to Chicago? So, I arranged it in such a way that if you moved the hands more than ten minutes approximately, the device makes no correction at all because if you move the watch a whole hour, obviously you are not correcting the watch, but you have a different reason for doing it--like forgetting to wind it, for example. There were other details that had to be worried about, but they were relatively straightforward. I received a patent on this, and for the next nine years I tried to sell it to various companies, but no one wanted to buy it. Some people said, "Our watches are good enough; why bother? People will not know the difference." I tried watch companies in the United States and in Europe. I made many different models and received more patents; the models worked; the watches worked; the clocks worked, but I could not sell it.

In 1948 or so, I invented another thing called the magnetic particle clutch, for which the Government gave me a Gold Medal, and I received a great deal of publicity. As a result of this invention, I had to talk to some engineers at Chrysler; we had dinner together and talked about patents in general. I told them about the watch regulator by way of just making conversation. One of them said, "You know, my boss, the Chief Electrical Engineer at Chrysler, hates automobile clocks; I will tell him about this." I thought he was just being polite, but he was not. He did tell his boss, and the boss told the clock people he would like to have a regulator in automobile clocks. In any case, in 1954, which was some nine years after the invention was made, I did license General Time to use my patents in clocks, and my attorney and I received about a cent and a half for each clock. This was some considerable money because for the next 20 years we received some royalties. During this period, every automobile clock In the United States was made under my patents.

Some years later, Benrus, which is a company that manufactures and sells watches, was interested in getting a license for the fewel watch business. So, we made another deal where I would receive ten cents per watch. This is one of the watches that I am now wearing. I paid $\$ 60$ for this so I could get ten cents back. It was a very great failure in the marketplace--something that neither the president of the company nor I expected. There was nothing wrong with the watch, technically, but when a salesman showed a customer a watch and said to the customer, "This is a self-regulating Benrus," the customer always said, "What does this mean, please?" When the salesman started explaining it and said, "Well, if the watch is slow.. ." before he could finish the sentence, the customer would ask, "Why should the watch be slow?" There was a general feeling that if the watch had a regulator there must be something wrong with it. You were not going to be able to explain to the customer that all watches need 
regulation, that nothing is perfect in this world, and that this watch will regulate itself without your even being aware that you are regulating it. Anyway, they only made 40,000 watches and took them off the market. I am wearing one of the few that were built.

Let me tell you about another invention that did not make money. The story goes like this. I had a telephone call one day; the man on the other end said, "Mr. Rabinow?" I said, "Yes," and he said, "This is Bob Berks." I said, "Who are you, Mr. Berks? Where are you calling from?" He said, "I am calling from New York and I am the world's greatest portrait sculptor." I said, "That is quite a thing to say; what can I do for you?" He said, "They tell me you are a genius." I said, "If you are the world's greatest portrait sculptor, I am a genius." Well, he is not the world's greatest sculptor probably; certainly, I am not a genius. But, he is a good sculptor. Mr. Berks did the Kennedy head at the Kennedy Center. If you have been there, you have seen it. The problem he had was how to cut statues out of metal. I learned from him that the way statues are now made is that the clay model that the artist makes, or the plastic model, is copied in a wooden form; then it is cast piece by piece (usually in Italy, by the way) in bronze. Then the pieces are welded together and you then have a full-size statue. Mrr. Berks wanted a different technique. He wanted a statue to be cut from one large casting. It is, by the way, a hollow casting--but he wanted it cut in a final shape without being made in pieces, and he wanted it made out of stainless steel. The problem then is, how does one follow a small model, say 3 or 4 feet high, and cut a statue 17 or 18 feet high in a single structure? The technology of following a model in cutting metal is now new; it can be done today. The problem is that a large tool that has an arm 10 or 20 feet long, and then a cross-arm of another 10 feet, at the end of which is a cutting tool, will sag and vibrate. While you can direct the tool where you want it to go, the vibration and the weight of the tool affect the final position. So, it occurred to me that if the whole thing is done under water (in a large swimming pool, if you like) and if the tool and all its parts were made neutrally buoyant (that is, have the same specific gravity as water), then the tool would not sag, no matter how far it reached, and the vibration could be controlled. You could also control the temperature, take away the chips or the cutting products, and in general, the whole problem becomes very much easier. One does not have to use water; one could use oil, but water is as good as anything and most heavy metal cutting today is done with water running continuously over the tool. Anyway, I received a patent on this process, but we never had enough money to do it. The Ford Foundation did offer Mr. Berks some money to develop such a system so that the great statues of the world could be preserved; that is, the measurements of the great statues of the world could be preserved on tape and they could be duplicated in case of any damage or loss. When this was done, I thought that a quarter of a million dollars could build such a machine, and I am always dreading the fact that some day Mr. Berks will come to me with a check for a quarter of a million dollars and say, "O.K., build it." I am thinking 
of all sorts of excuses by which I can get out of the job. It is not something that one could do casually.

Some years later, when I was telling this story and giving this problem to a group of students of how does one keep an arm 30 feet long from sagging, a high school student came up with a new solution which startled me. He sald, "If you put the whole system (the tool, the statue, and everything else) into orbit where gravity is neutralized so that there is no sense of gravity, then of course, this whole problem of sagging would not exist." This is a very elegant solution, but it obviously has some minor commercial and economic problems, too.

Let me give you still another anecdote of how an invention is created. In this particular case, I was particularly aware of the whole process that occurred. This story will illustrate, particularly, about the ability of the human brain to work on a problem. My patent attorney and I were riding in a car coming back to Washington from Cleveland. He sald, "Jack, since you have nothing to do at the present time, design me a gadget that will light a light when my telephone rings so the light will stay 11t." I sald, "Why?" He sald, "Because I have an answering service, and when I am out of the offlce, the answering service takes messages. When I get back to the office, I have to call them to find out if there are any messages. Very often there are none, so I waste thelr time and mine. Or, I forget to call them and then, of course, it is the time when somebody is looking for me. I want a light that will light when the phone rings and stay 11t; then I will call the answering service and get the message." I sald, "Well, that is a simple problem. Get yourself a microphone, an amplifier, a locking relay, and a light; when there is a sound in the room or the phone rings, the light, of course, wlll light." Then he sald, "Well, you are not a very good engineer because anybody could do it that way. I am also an engineer; I could do it without you, but what I want from you is something simple and very inexpensive." I sald, "Of course, when you want something simple and inexpensive, it is much harder." So, we drove on. Then I suddenly remembered that in 1921 when I came to America and I was 11 years old, I worked in a store selling toys. One of the little toys was a cardboard box into which you pushed a little celluloid dog. When you clapped your hands or yelled "Rex," it jumped at you. The way 1 t worked was that at the back of the box were two very loose electrical contacts. A little plece of copper rested agalnst these contacts. This closed the circult of a battery and a magnet that held the armature away from the dog; there was a spring behind the armature. When you made a loud sound, the box vibrated, the contact was broken for an instant, the magnet let go, and the spring pushed the dog out of the box. I remembered the detalls of this suddenly, and you must understand that thls is interesting because the spread of time between the time I saw the toy and the time I thought of 1 t was 33 years. I had not thought of the dog; I had not seen the toy in all this time. So, I said to my attorney, "I think I know how to make a cheap, sound-operated device." I went home, took a 
cigar box, and made a poor contact under the cover; I used a neon light, instead of a magnet, and a couple of resistors. You can arrange it in such a way that when a contact breaks, the voltage on the neon light rises, because the contact removes a shunt, and the neon light has a property that once it is lit it can stay lit at a lower voltage. Therefore, one can arrange a simple circuit so that once you trigger a neon light it stays 1it. I brought it back to my attorney's office, showed him that it worked, and went home. In a few minutes he called me and said, "You are still a very terrible engineer. I cannot sneeze; I cannot close a door; I cannot touch my desk, because any sound in the room trips your device and the light lights." We put a time delay into this and made it so that it took a continuous sound of a few seconds before the light would stay lit, so that a single shock would not trip it. A few months after this, we found that the telephone company will install a red light in your phone that will tell you if the phone had rung, and you do not need this device. of course, it was not ever made commercially.

This story is interesting in a few more ways. My attorney went to the Patent Office to make a search on the toy dog just to see how well I remembered it. He found the patent on the toy, issued in 1918, and the drawing was exactly as I had made it. In other words, not only did I remember the principle, but I remembered the exact position of the contacts, the shape of the piece of copper, and so on. This is interesting because the brain is a wonderful device; it remembers useless information for a lifetime and can recall it when necessary, sometimes, and skips the whole intervening mass of information. We have not the vaguest idea how that is done. This story has a sequel. Some years later, I was speaking to a group of engineers in Erie, Pennsylvania, and somebody asked me how does an inventor work. I said, "Let me tell you a story of a toy dog." As I said this, a man in the audience, who is the head of an instrument company, said "Rex." I said, "That's right. That was the name of the dog. Do you remember how the toy worked?" He said, "Oh yes, there were loose electrical contacts that released the magnet." I said, "When did you see it?" He said, "When I was six years old." I said, "How long ago?" "Oh, " he said, "about 50 years ago." I said, "Have you ever seen it since?" and he said, "No." Now, this is interesting. Just my mention of a toy dog in a technical context triggered this man's mind, and he went back through a whole lifetime and out of all the fantastic amount of information that he must have in his head, he pulled out this one thing about a toy $\operatorname{dog}$, a loose contact, and the way it operated.

I have told you these stories to illustrate how the inventor operates; how, out of a tremendous mass of information--good, bad, or indifferent--he pulls together that which he needs to solve a particular problem. It is important to have this mass of information and, of course, the ability to wade through it to find something that fits. You can teach this ability, mostly by giving people the courage and the self-assurance necessary. One of the problems, which is not my own problem, is one that I gave some students at Berkeley when I 
was lecturing there on creativity. The problem goes like this: If you have a barometer which measures air pressure and you have a tall building, give me ten ways of finding out the height of the building using this barometer. Now, a well-trained scientist would tell you to go to the ground level, measure the barometric pressure, then go to the roof, measure the barometric pressure, and from the difference compute the height of the building. That is only one solution. There are many others. One way is to go to the architect and say, "I will make a deal with you; I will give you a barometer if you will tell me how tall the building is." Another way is to go to the roof, drop the barometer, and with a watch measure how long it takes before it crashes to the ground. You can tie a string to it and let it down. There are a great many other equally stupid solutions, but the important thing is that you have to be free enough and brave enough to think of them. After a while, the students got good at this, and they were not afraid to try unorthodox solutions.

There are a great many simple problems that one has to solve. I have a friend who invents fountain pens and pencils; I brought two of his inventions with me; I am holding them. He was a Latvian who went to Israel in 1948 and finally ended up in the United States. He decided long ago that the trouble with fountain pens, particularly with ballpoint pens, is that if you leave the tip out when you put them in your pocket (that is, if you forget to retract the tip), you will have a dirty shirt. So, he designed a fountain pen with a clip as the retracting mechanism. If the clip permits you to attach it to your pocket, you will know for certain that the tip is retracted. In fact, you cannot push the tip forward when it is in your pocket because the clip acts as an interlock. He invented this many years ago, and for nine years he could not get anybody to buy it. They all said, "That is very clever, but it does not work well." He said, "I have models. Look; feel them." They said, "Well, the models work, but production will not work." Anyway, they would not buy them. He did sell it to a small company that used them for advertising, and eventually a large company bought 1 . Now they make something like 60,000 a day. He has developed a new one--this flat one. I like it. He lives in Santa Barbara, has a swimming pool, and is doing very well.

I would like to tell you now about why do we do it. First of all, it pleases us ourselves; an inventor is happy when he solves a problem for himself, not necessarily because he is going to sell it; that will come later. I play with photography. Now and then I design a gadget for my own camera, but not because I want to sell my idea; in fact, I do not expect to sell it. I do it because there is something about the camera I do not like. For example, I like to use two eyes when I focus a camera; I get tired looking with one eye for a long period of time. As I get older, this gets more difficult. I have a Rolleiflex with a two-eye viewer. Why the manufacturers do not make it, I do not know. All good modern microscopes have two eyepieces. Good telescopes have two eyepieces; but cameras are designed for one eye. 
Another thing that drives us is that we would like to have the respect of other engineers, of other inventors, of our peers. It does not particularly flatter us when we get praise from nontechnical people who are impressed by what we do; but when another good technical man, a man whom you respect, looks at your gadget and says, "That is pretty good," you feel very good indeed. Then, too, of course, one gets honors and honors are useful, not only because they flatter you but because they help you have freedom to sell your ideas, not only for money but just to get your ideas adopted; it is easier to get a good job. For example, when I applied to the National Bureau of Standards after an absence from NBS of 18 years, I had amassed a great many patents in the meantime which impressed the Personnel Department. They do not necessarily know what is in a patent or whether the patents are good or bad, but when they see a long list they are impressed. Finally, of course, inventions help to earn money; not every invention--most do not, but now and then one does. Because one occasionally makes money on inventions, many people try, and that is good for society. It is important to soclety to have new ideas for reasons I have already stated. It also creates a climate, an excitement for technologically oriented people. One of my inventions is a phonograph with a straight-line moving arm. A very beautiful model is made by Bang and Olufsen in Denmark; it is in the Museum of Modern Art in New York; it sells for a great deal of money; I make no royalties on it; they are using a patent that expired. But, it plays very well; it is beautiful; it is very convenlent; and I feel very proud.

The thing that is wonderful about the human brain is not only that we are curious, that we like to solve problems, and that we like to know how things work and how they should work even better, but also that we get excited about this; that it is not only an intellectual problem, but we also have an emotional response to these things. This is true, of course, of people who paint or who compose music; they do not do it only for money; they do it because there is an emotional reaction. I feel that without this emotional feeling about elegance of machine design and of technical innovation, one cannot have great innovation, for practicality alone is not enough. Unless our engineers, the people who manage them, and the people who own our businesses have this personal involvement with inventions, the inventions will disappear. I think that in the United States our management is losing this interest. We have large corporations run by bookkeepers who only care about the money, the short-term profit. We have very few people like Mr. Land, who founded Polaroid and who still is a great inventor, to whom their achievement technically is very important. I am sure he has more money than he can spend, but I am also sure that he would like to be known as a great technical pioneer, a revolutionary in his field. RCA was run for many years by David Sarnoff, who was a radio operator originally. He loved radio; he supported research in television. For 20 years, television did not make money, but he supported it because he liked 1t; he was interested. Zenith had a president by the name of Commander McDonald who also loved radio. 
Zenith made good radio sets. He died and the chief engineer, who was a man like him, also died soon afterwards, and Zenith carried on the tradition for many years. Last week I was heartbroken to learn that Zenith is going to make their radios and TVs abroad, and they will no longer design them. It bothered me very much to learn that they abolished their laboratory. I was not worried about the men having jobs; the good research people immediately did get other jobs, but I did not like the fact that the bookkeepers have taken over the business.

I hope that you realize that in your countries if you want technology to flourish you should not just import things to build, but that you should create a spirit that will create your own innovations, your own inventions. You will copy the spirit that made the United States great: that to inventors like myself--I am sure I speak for all inventors, really-it is not just a question of making money, but it Is a question of living in an atmosphere where inventions are wanted and admired. If you want to have people invent, you should do what you do when you want great soccer players; if you want people like Pele in soccer, if you want people of that quality in technology, you must give them equal honors, if not equal money. So, if you want your nations to be great technically, you must depend not on cheap labor, which gives you a temporary advantage, but you must have a climate that will create great innovations. You want your scientists to have excitement just as you would want the excitement if you desire great opera. The whole country will be better off with this.

With this note, I would like to start a session of answering questions. Thank you very much. 


\title{
REMARKS
}

by

\author{
Dr. Victor Rabinowitch \\ Director, Board on Science and Technology \\ for International Development \\ Commission on International Relations \\ National Academy of Sciences \\ National Research Council
}

As a youngster growing up in the "middle west," I learned that the Bureau of Standards was the place where the standard measures were kept and that any of us who doubted the figures provided us in textbooks could prove to ourselves their validity by simply going to Washington and visiting the Bureau. "What a fantastic place," we all said; "it must be something of a museum!"

It was only much, much later that some of us learned that the Bureau of Standards is something other than a "museum," something much more than a museum, something vital to our national welfare, providing the very basis on which our industrial strength and vitality depends. It is this recognition, of course, that brings all of us together here today.

Though our professional, social, and political histories may be, indeed are, quite different, all of us here are concerned essentially with the same question--how can the processes of social and economic development in the industrializing countries be effectively accelerated in the best interest of society. As scientists, engineers, or policy makers, this is our goal, and in this effort, all of the technical resources we can muster will be required. At the same time, we have a responsibility to insure that technical development proceeds in a way that does not destroy the very values we hold so dear. This is the true challenge.

It is in this context that I should like briefly to describe the U.S. National Academy of Sciences-National Research Council and its program of international cooperation in science, technology, and international development.

Here in the United States, the National Academy of Sciences-National Research Council is often misunderstood or confused with other organizations. Abroad we are almost always confused with either the National Science Foundation or some other governmental agency concerned with science and technology or even with a national museum such as the Smithsonian museum. For these reasons, it is perhaps most appropriate if I begin by attempting to defin? for you the NAS-NRC. 
The National Academy of Sciences, established by an act of Congress in 1863, is a private, self-governing institution dedicated to the advancement of the sciences and to furthering their use for the general welfare. The Academy acts as an official yet independent adviser to the Federal Government, carrying out its Congressional charter "whenever called upon by any department of the government, (to) investigate, examine, experiment, and report upon any subject of science art ... ."

Members of the Academy are chosen on the basis of their outstanding contributions to knowledge. They are elected for life by the membership as a whole, which currently numbers 1,208. As the role of the behavioral and social sciences has become more widely recognized over the past decade, increasing numbers of behavioral and social scientists have been elected to the Academy, and there are now approximately 130 Academy members from these disciplines.

The expansion of scientific and technical knowledge and its role in public policy formation in recent years led to the creation, by the Academy and within its charter, of two other organizations: the National Academy of Engineering, established in 1964, which now has 765 members; and the Institute of Medicine, established in 1970, which now has 341 members. These three membership bodies jointly supervise the activities of the National Research Council.

\section{National Research Council}

The National Research Council was organized in 1916 in response to increasing demands upon the advisory services of the Academy and at the request of President Woodrow Wilson. Its present purposes and responsibilities, reflecting the growing significance of science and technology to the nation's needs and public policies, were defined in part by successive Executive Orders, the last of which was issued by President Dwight D. Eisenhower in 1956. Almost all the program activities of the Academy complex are conducted under the auspices of the National Research Council.

The National Research Council was restructured in 1974 to accommodate the increase in the scope and number of its activities. Its eight constituent parts include four Assemblies and four Commissions; in broad terms, the Assemblies follow traditional disciplinary lines and the Commissions are concerned with broad, multidisciplinary problem areas.

The work of the National Research Council is overseen by a Governing Board, which is made up of seven members of the Council of the National Academy of Sciences, four members of the Council of the National Academy of Engineering, and two members of the Council of the 
Institute of Medicine. The Chalrman of the Governing Board, who is the principal administrative officer of the National Research Council, is the elected President of the National Academy of Sciences.

Approximately 8,000 distinguished scholars representing the entire spectrum of the sciences and engineering particlnate annually in the work of more than 800 committees, subcommittees, and panels of the lational Research Council. These individuals receive no compensation, apart from actual expenses, for their efforts. They are supported by a staff of 1,000 and an operating budget of more than $\$ 50$ million. Last year, the work of National Research Counc1l committees resulted in more than 200 reports on a wide range of scientific subjects of relevance to public policy.

Having, I hope, provided the backdrop against which the program of the NAS-NRC can be painted, let me proceed with a brief description of our involvement in problems of economic and social development both in the United States and in cooperation with our colleagues in the developing countries.

My late father, Eugene Rabinowitch, was a firm believer in sclence and technology and dedicated his life to implementing the belief that with a proper concern for their social impact, sclence and technology were among the most vital tools of social and economic change. Indeed, he coined the phrase, "science, the common enterprise of all mankind," to reflect this recognition not only of the way in which science is done but also its impact. It is in the same spirit that we at the NAS have evolved an ever-growing program of activities relating science and technology to economic and soclal development. These activities are organized under the Board on Science and Technology for International Development (BOSTID).

The experience of developing countrles in recent years has provided considerable evidence that science and technology have an important role to play in the complex processes of economic and social development. It is not at all clear, however, how science and technology can both complement and stimulate social and economic development without introducing distortions in these processes. What kinds of sclence and technology are appropriate for specific countries? What scientific and technical manpower needs exist? What kinds of organizations and institutions need to be established? What are some of the policles needed to make science and technology significant elements in the development process? How can U.S. scientific and technological resources contribute to development abroad? These questions illustrate the range of 1ssues that the Board on Sclence and Technology for International Development continues to address.

Over the past 13 years, BOSTID has involved over 1,000 technical people from U.S. Institutions in examining development Issues with counterparts in developing countries through joint 
workshops and studies in 24 countries in Africa, Asia, and Latin America. The attractiveness of these meetings to both American and host country participants lies in their truly cooperative character with shared funding, planning, and organizational resnonsibilities. Most recently, in recognition of the growing desire of developing country officials to diversify their sources of scientific and technological knowledge and experience, a number of BOSTJi) prograns have included participants from developing countries with similar problems and opportunities, as well as representation from both national and international development institutions.

Through September 1977, workshops have been held in the following, countries:

Arab Republic of Egypt
Argentina
Brazil
Chile
Colombia
Ghana
Guatemala (regional)
Guyana

India

Indonesia

Korea

Nigeria

Pakistan

Peru

Philippines

Republic of China

\author{
Singapore (regional) \\ Sri Lanka \\ Sudari \\ Tanzania \\ Thailand \\ Tunisia \\ Venezuela \\ Zaire
}

(Taiwan)

Most have dealt with the general theme of science and technology in economic and social development and have emphasized priorities for joint study groups, which work over a longer time period, consider problems in greater depth, and have produced recommendations on such topics as industrial research in Brazil, graduate education in Colombia, agricultural extension in Ghana, and cemography in zaire. Specialized workshops in a particular topic, such as food, ocean resources, industrial research, aquatic plant managenent, natural resources, and water, have also been held.

BOSTID's program of studies has focused on issues and problems in relating science and technology to development, and on possible roles for U.S. scientific and technical resources in contriluting to their resolution. Fxamples of such studies are:

-- Research Yanagement and Technical Entrenreneurship: A V.S. Role in Improving Manaperial Slills in Develoning Countries

-- lleeting the Challenge of Industrialization: Feasibility Study for an International Industrialization Institute

-- U.S. International Tirms and R, D\&E in Developing Countries

-- The International Levelopment Institute

-- Solar inergy Utilization for Developins: Countries 
- Scientific and Technical Information for Developing Countries

-- Systems Analysis and Operations Research: A Tool for Policy and Program Planning for Developing Countries

-- Arid Lands of Sub-Saharan Africa

-- Feasibility of Establishing an International Manatee Research Center (Guyana)

-- The Peace Corps: Perspectives for the Future

-- Role of U.S. Engineering Schools in Technical Assistance

-- Appropriate Technologies for Developing Countries

-- Resource Sensing from Space: Prospect for Developing Countries

- Postharvest Food Losses in Developing Countries (in process)

A third BOSTID activity organized under an Advisory Committee on Technology Innovation (ACTI) has been the consideration of innovative applications of technology to problems of developing countries. ACTI identifies and brings attention to existing, and frequently simple, technologies that promise to be effective in helping solve critical development problems. Tynically, expert conmittees prepare reports on the state-of-the-art of various selected technologies with suggestions on potential applications.

Recent examples of studies by ACTI are:

-- Ferrocement: Applications in Developing Countries

-- Mosquito Control: Some Perspectives for Developing Countries

-- Toofing in Developing Countries: Research for New Technologies

- Food Science in Developing Countries: A Selection of Unsolved Problems

-- The Winged Bean: A High Protein Crop for the Tropics

-- Underexploited Tropical Plants with Promising Economic Value

-- :lore Vater for Arid Lands: Promising Technologies and Research opportunities

-- Energy for Rural Development: Renewable Resources and Alternative Technologies for Developing Countries

-- Methane Generation from lluman, Animal, and Agricultural Wastes 
-- Making Aquatic Weeds Useful: Some Perspectives for Developing Countries

-- Guayule: Rubber Producing Desert Shrub

- Leucaena leucocephala: New Forage and Tree Crop for the Tropics

-- Tropical Legumes: A Neglected Resource (in preparation)

- Firewood Crops: Bush and Tree Species for Energy Production (in preparation)

-- Microorganisms with Promising Economic Value (in preparation)

In addition to these efforts, the Board has established a number of ad hoc advisory panels to ássist it with specific problems and opportunities in technical assistance. At present such panels have been established in the following problem areas: International Health; Natural Resources; Industrialization; and Technology Education.

Finally, the Board and its staff have served as a resource to both the Agency for International Development in Washington and to its overseas missions, as well as to other U.S. Institutions broadly concerned with science, technology, and international development. Board and staff members have also participated in domestic and international conferences on science, technology, and development.

Besides the largely advisory activities described above, the Board has sponsored one experimental program with the Brazilian Research Council. This program attempts to establish a capability for highlevel research in the field of chemistry in two Brazilian universities (Federal University of Rio de Janeiro and University of Sao Paulo). Largely through the use of NAS overseas research fellowships awarded to outstanding young U.S. chemists, a special program of teaching and research in chemistry has been established in these universities. The program is a truly cooperative effort involving senior U.S. and Brazilian chemists and younger U.S. Fellows, supported financially from both Brazilian and U.S. public and private sources. The ultimate objective of the experimental program is the creation of a significant number of Brazilian Ph.D.s in fields of chemistry considered vital to Brazilian development.

Members of the Board on Science and Technology for International Development come from a broad range of scientific and technical disciplines and professions. Through formal meetings held several times a year, continual communication with the staff, and personal involvement in program activities, the members of the Board play an important role in the planning and evaluation of an innovative 
program of scientific and technical cooperation. Chaired by Dr. David Pimentel, Professor of Insect Ecology at Cornell University, its members are:

- Ruth Adams, American Academy of Arts and Sciences, Boston, Massachusetts

-- Edward S. Ayensu, Director, Endangered Species Program, Smithsonian Institution, Washington, D.C.

-- Pedro Barbosa, Department of Entomology, University of Massachusetts, Amherst, Massachusetts

-- Dwight S. Brothers, International Economist and Consultant, Fairhaven Hill, Concord, Massachusetts

-- John H. Bryant, Columbia University College of Physicians and Surgeons, New York, New York

-- George Bugliarello, President, Polytechnic Institute of New York, New York, New York

-- Elizabeth Colson, Department of Anthropology, University of California, Berkeley, California

-- Charles S. Dennison, International Consultant, Wainscott, New York

-- Brewster C. Denny, Dean, Graduate School of Public Affairs, University of Washington, Seattle, Washington

- Herbert I. Fusfeld, Director of Research, Kennecott Copper Corporation, New York, New York

-- Martin Goland, President, Southwest Research Institute, San Antonio, Texas

-- James P. Grant, President, Overseas Development Council, Washington, D.C.

-- George S. Hammond, Merrill College, University of California at Santa Cruz; Foreign Secretary, National Academy of Sciences ex officio

-- William A. W. Krebs, Vice President, Arthur D. Little, Inc., Cambridge, Massachusetts

- Frederick T. Moore, Economic Advisor, International Bank for Reconstruction and Development, Washington, D.C. 
-- W. Henry Mosley, Department of Population Dynamics, School of liygiene and Public health, Johns Hopkins University, Baltimore, Maryland

- Rodney W. ITichols, Vice President, Rockefeller University, INew York, New York

-- Joseph Pettit, President, Georgia Institute of Technology, Atlanta, Georgia

-- Joseph B. Platt, President, Claremont University Center, Claremont, California

-- James Brian Quinn, Amos Tuck School of Business Administration, Dartmouth College, Hanover, New Hampshire

-- Ralph W. Richardson, Jr., Director, Natural and Environmental Sciences, The Rockefeller Foundation, New York, New York

To enable the Board to carry out its responsibilities, it is supported by a professional staff of 12 natural and social scientists, with a wide experience in developing countries. These programs are mainly supported by a contract with the Office of Science and Technology of the Technical Assistance Bureau of AID. Additional funding is provided by other parts of AID, public and private U.S. sources, and, to a Iimited extent, foreign scientific organizations.

\section{Conclusion}

In the limited time available, I have tried to describe to you the institution, NAS-NRC, and that part of it concerned primarily with development (BOSTID). I hope that this introduction might be the beginning of a continuing relationship with you and that we shall meet again here or in your countries to discuss further our common interest in seeing that science and technology are effective instruments of development. 


\title{
PARTNERS IN THE PURSUIT OF PRECISION * (The Past as Prologue)
}

by

\author{
Mr. William A. Wildhack \\ Associate Director, Retired \\ National Bureau of Standards
}

It is always a pleasure to meet with colleagues in the fields of instrumentation, measurement, standardization, calibration, specifications, testing, or in the associated planning, directing, regulating, purchasing, training, etc. I am sure that all of you are engaged in some or all or even more aspects of what we call loosely the standards activities. It is a particular privilege to meet with colleagues from the far corners of the earth, and the dozen or so countries represented here provide an interesting sample of the one hundred-some corners of the U.N.!

It is for me a special pleasure to welcome the several ladies, whose presence testifies not only to their professional attainments but also to the good judgment of their respective organizations. It is generally known, although not so generally admitted, that women do most of the work of keeping the earth turning and are often more clever than men. To salute and toast these ladies and to give them our best wishes and support, the standard procedure nowadays is to say, "Right on!"

Over the years, I have had the pleasure of visiting with scientists and officials from many countries, not only at the National Bureau of Standards, but in my home or theirs, in my laboratory or theirs, or at technical conferences in my country or theirs. From such visits, I learned much technically but even more philosophically. I began to learn that the problems of the world can only be solved by persons who think and act as citizens of the world; and that all of us as national officials have a duty to our own country, to ourselves, and to humanity to search for ways to harmonize the "national good" and the "global good." I am sure that each of you has already discovered these added values, added opportunities, and added responsibilities.

Perhaps the phrase the "pursuit of precision" may sound to some of you a bit too narrow and idealized as a description of your own positions in your various organizations. If so, let us make it sound more practical and amend it to the "pursuit of proper precision," using the term "proper" to mean appropriate, fitting, suitable, adequate. I hope to persuade you that this phrase as amended combines fairly adequately several concepts which justify

* Publications referred to by the author are avallable on request. 
your various positions and your journey here. Your "pursuit of proper precision" involves your study, understanding, and evaluation of all scientific and technical instruments and instrument systems pertinent to your work in testing, measurement, automatic control, recording, translating, and analyzing data, as well as your work in obtaining and maintaining measurement standards and establishing and administering a calibration network, writing engineering or product standards or specifications or standards of practice. You are constantly concerned with the available precision of measurement, the cost of improving the precision, and arriving at a practical compromise between cost, time, and added precision.

I use the term precision in a popular sense meaning the closeness of a result of measurement to the demonstrably correct value, because it is a positive word and because it fits well in my alliterative title. At NBS I have long promoted the preparation and publication of charts illustrative of measurement capabilities in which the "precision of measurement" was indicated by its ugly counterpart--"uncertainty," expressed as, for example, a fraction of the quantity measured as one part in a thousand.

You have all probably seen such charts. I would recommend that you have similar charts made for each of the quantities of concern in your own laboratories. On these charts, it is instructive to plot also the "proper precision" for the various echelons in your calibration networks and to review them year by year.

"Proper precision" is not only an important goal in numerical measurement but also in the use of language. Adherence to standards of grammar, logic, and lexicology is important for all people--for those of us in the standards field, it is essential. As you well know, the difficulty of arriving at acceptable wording--0: "proper precision"--is multiplied n-fold (or $\underline{n}^{2}$-fold?) in trying to reconcile drafts in $\underline{n}$ different languages.

Some years ago, being frustrated by imprecise language in many engineering specifications and standards, promulgated by industrial, professional, or governmental bodies, I proposed--only half in jest-that INBS should establish a committee on definitions of scientific and technical terms to serve for the language of science as the French Academy does for the language of France. We did not go quite that far, but we did establish a committee on NBS usage, headed by one of our most erudite division chiefs, with long and efficient service on several ISO and IEC committees.

It was suggested that I should tell you something of my life and times at NBS. As a senior citizen, I am obviously "of the past," and my story can only be prologue--you, not I-will be the actors on the front and center of the stage for the next few decades. As you and your colleagues carry on your pursuit of precision, you will again till the fields in which I worked. You will attain still greater 
numerical precision in measurements, develop more effective methods of transferring precision to the point of practical application, and diffuse the art of determining the proper precision in practical affairs.

During the worldwide economic depression of the thirties, NBS was forced to curtail hiring staff for several years. In 1935, NBS began recruiting again and formal examinations for junior scientists in various specialties were announced. At that time, I was teaching mathematics and engineering at a college in the West. Like several thousand others, I spent three days taking these examinations. Shortly after, I received an offer from NBS. After I arrived in Washington, I was given a choice of several jobs and chose to work in the Aeronautical Instruments Section of the Mechanics Division.

A wide variety of testing and development work at NBS has always been at the request of, and with financial support from, other government agencies. The Bureau of Aeronautics (Navy Dept.), Civil Aeronautics Administration, Weather Bureau, and NSAS (then NACA) furnished support for a variety of research, development, and testing tasks to which I was assigned from time to time, in addition to "routine calibration." As examples of some of the projects in the thirties: we undertook a study of the load-deflection characteristics of circularly corrugated metal diaphragms used for aircraft altimeters, air-speed indicators, fuel gages, etc. We experimented with various mixtures of synthetic liquids to obtain a lubricant for aircraft clocks and other instruments which would not congeal at low temperatures, not spread or evaporate at high temperatures, and still would be effective as a lubricant. We developed better calibration and test methods for determining performance of aircraft instruments and equipment, and at the same time, we were encouraged to suggest improvements in the design and to analyze sources of error, malfunction, or failure.

In my spare time, aside from NBS work, I ran down some of the misconceptions regarding the aerodynamics of falling bodies and published an article on "Optimum Time of Delay for Opening of Parachutes." I worked with and studied under theoretical physfcists George Gamov and Edward Teller--both then at George Washington University--and published a study on energy production in super dense stars due to the proton-deuteron fusion process. For a few years, I taught evening courses in physics at that University.

World War II brought many pressures and urgent projects. By chance I got into work on oxygen breathing apparatus for aviation; I published a paper on the ratio of added oxygen needed at various altitudes by fliers in unpressurized aircraft to maintain their blood oxygen at "sea-level" equivalent (or at any other level). Later I invented a self-sufficient, quick pressurizing liquid-oxygen vaporizer for aircraft or industrial use. 
With other technical people in the Washington area involved in instrument design, development, manufacture, use, or calibration, I became a charter member of the Instrument Society of Washington (ISA). After the war, similar groups in other areas joined to create the Instrument Society of America which now has about 20,000 members, approximately 100 sections in this country, and 5 to 10 in other countries. Steffen Peiser, I understand, can familiarize you with their important publications. With the acquiescence and support of my superiors, I worked in various capacities to help the ISA promote the science and art of instrumentation and to create wider understanding of the importance of measuring instruments and control systems in science, industry, education, and trade.

My connection with NBS and other government agencies made it possible for me to enlist cooperation among various technical societies in arranging conferences on general or specialized fields. Some symposia--on temperature and humidity, for example--were jointly sponsored by NBS, several technical societies, and sometimes by other government agencies as well. The published proceedings of such symposia provided authoritative surveys of the state of the art and were published commercially. Some of the conferences, e.g., on temperature measurement, have been repeated several times. Since NBS moved to its present more spacious quarters in the suburbs, it regularly holds conferences or symposia in the fields of activity of its technical and scientific divisions.

Shortly after World War II, I was serving as Chairman of a Committee on Instrumentation in the National Research Council (International Relations Division). Our concern was to help educational and scientific laboratories abroad to replace, refurbish, or modernize their research facilities. After some fumbling and false starts, we finally prevailed on the Economic Cooperation Administration (the AID of the time) to authorize use of funds for this purpose. Later I was asked to visit a number of countries as a consultant for ECA, and to screen the requests for aid under this program, which continued for a number of years.

The program was of great value in both education and research, but there were many problems for the person in the laboratory abroad struggling with long-distance procurement. First, he had only catalog descriptions--sometimes out of date-and the manufacturers' data and claims on which to base his choice. As all of you are well aware, there are revlewing officials, procurement officials, customs officials, budget officials, etc., between the laboratory technologist and the delivery of the instrument ordered. Without his knowledge, they may "edit" his specifications, add the infamous "or equivalent" to his specification of manufacturer or model, chop off the last ten items of his list of requests--or pigeon-hole all of them for a few months. Any of these disasters may jolt the technologist as much as the vagaries of overseas shipment may jolt the sensitive instruments. 
To keep NBS screening from becoming another hurdle for the foreign laboratories, I soon proposed that we should serve as consultant to them, rather than as a critic of their requests. From then on, we received informal copies of their lists in parallel with procurement-not in series--provided advice when asked, and commented only on those items which we thought could be obtained abroad without U.S. dollars or those for which we believed superior items had become available. Our comments were forwarded to the requesting laboratory for such action as they wished to take. But the problems of getting instruments of adequate performance, with compatible accessories, is not simple, even in the high technology countries, and the problems increase exponentially with geographic distance and with language specification uncertainties.

As the international aid programs widened, a number of NBS staff or retirees, were recruited by AID to spend some time--a month to two years--in another country to help in planning programs, facilities, and equipment for standards laboratories. This was also a valuable program, but for many reasons not as productive as we hoped. Delays seem to be endemic in most such programs. (I recall one country which was visited three times by such consultants over several years-only one, I think from NBS in this case, and including one sent by the U.N.

Then, the AID officials arranged for NBS to play host to visiting officials or technologists from particular institutions for periods of a few weeks up to a year, so that they might learn at firsthand how standards activities were carried on at NBS and how instruments were procured, evaluated, calibrated, or tested in our regular work, so that they might visit other laboratories as well as manufacturers. But our success with the individual trainee program was not uniformly satisfactory. Too many times the visiting technologists were grossly under-educated, lacked a minimum command of the English 1naguage, or both. In some cases, I suspect that cultural hang-ups kept some of our guests from ever touching an instrument! Although Washington has many national or ethnic groups and centers, some of our long-term guests seemed to be entirely without social contacts, although most of them made strong friendships with NBS staff members. Sometimes food habits apparently did not fit the limited menu of our cafeteria.

From all of these recollections, I am led to urge all of you, as officials who may be responsible for selecting personnel to visit or to train abroad, TAKE CARE! Send your brightest and best, and send them to language school first and also to study courses in science and metrology if needed. Their gains in knowledge will be shared with your whole staff, and their gains in friendship and understanding will have favorable ripples in both countries.

A most important step in the evolution of the AID programs has been the group visits, such as yours, wherein officials from a number of countries meet, travel, confer, and study together in this country. 
After World War II, also I was concerned about the tensions between the United States and the U.S.S.R. and felt that my country should rapidly develop the art of precision guidance and control for rocket propelled missiles. NBS had been working on this project with Navy support during the war, and when an expansion of this effort was planned, I accepted a position as Chief of the Missile Instrumentation Section. Two years later the project was transferred to the West Coast, and I decided to remain in Washington. I had already initiated a small project on "Instrumentation for Scientific Research," with support from other government agencies, and proposed to the NBS Director, then Dr. E. U. Condon, that NBS should expand this project into a strong cooperative program of research and information. After much good-natured joking and repeated requests to explain to visiting officials and scientists "just what is 'instrumentation'?" I finally persuaded him to write an article for Science, "Is There a Science of Instrumentation?" This paper, together with additional views on aspects of instrumentation as a scientific specialty developed at many conferences and meetings, formed the basis for a program of research by a new Office of Basic Instrumentation established at NBS in 1950.

This office promoted and supported laboratory and theoretical work on many aspects of instrumentation. Projects were carried on in the appropriate technical divisions of NBS or in a small laboratory directly under my supervision. OBI served as a central consulting staff and information center to other agencies on measurement problems in any of their research and development programs and especially on their R\&D projects on instrumentation. It helped the Economic Cooperation Administration (the AID of its time) review requests for aid involving special modern instruments. The OBI developed a central information service, relating to all aspects of instrumentation, promoted cooperation among technical and professional societies having measurement interests, hosted individual researchers from universities or other agencies, and arranged for development or reviewed target specifications for special instruments for aviation, medicine, oceanography, etc. OBI also sponsored publication of a number of surveys of the literature on specific types of instruments.

In the great majority of problems submitted to OBI, the objective was not to make a measurement with the highest obtainable precision; rather, it was how to make a measurement of acceptable precision and compatibility under special conditions or to develop a method of measurement or a measuring device which would be simpler, more stable, or more reliable than those available. Of course, many of our own projects were aimed at attaining improved precision or in exploring measurement applications of new physical phenomena or determining the achievable precision of instruments utilizing new principles of operation. Thus, the major work of the office could be broadly defined as the "pursuit of proper precision." 
In early 1958, I received from the Director what I thought was another routine task: To suggest names of several NBS staff scientists who would be competent to assist the staff of the House Appropriations Committee of the Congress in an investigation of the reliability (or lack thereof) in the defense missile program. This request came only a few months after the Soviet Union had successfully launched their first Sputnik. Our own Vanguard satellite program, under pressure to skip some essential testing, had seen its first attempt end in a fizzle on the launching pad. Some of the military test rockets were also failing. Some went off course and had to be destroyed, and others, not off course, were destroyed by safety officers reputedly because of erroneous indications of their tracking instrument. The Congress was naturally concerned, as was the general public. I discussed my recommendations with the Director and he sent them on. A few days later, he called to say that the Committee's Chief of Staff had "persuaded" him to change his selections and that Dr. R. D. Huntoon (later Deputy Director) and I were to direct this investigation; Huntoon was to spend half time and $I$ was to devote nearly full time. The study took eight or nine months and naturally involved a great deal of travel. We contracted with an indenendent laboratory, specializing in reliability engineering studies and design for the aviation industry, to help us collect and analyze our data. We set up a prestigious committee of industrialists, reliability engineers, and former Defense Department officials. Early in our planning, we proposed that the terms of the directive for our study should be reworded to put the emphasis, not on finding who or what was to blame for a specific fallure, but rather on finding out which policies, procedures, and regulations relating to the organization of reliability efforts, which purchasing methods, which testing and calibration programs of contractors and sub-constractors, and which organizational patterns appeared to be best suited for attaining consistently high reliability. The Committee staff agreed that this approach would be more likely to be of lasting significance. The mere fact that we were acting under a Congressional request insured that each of the defense laboratories and contractors did its best to show that it had the best and most comprehensive programs for quality control and reliability. So, we got an intensive education in the field as did many officials who needed it. Reliability staffs in both the Defense Department and their contractors were expanded and upgraded, military specifications for contractors' reliability programs were rewritten, greater attention was given to calibration programs, and reliability in the missiles program improved.

Just as we finished our report, the Committee asked us to make a study of the Vanguard satellite program which had gotten off to such an inauspicious start. We concluded, after another six weeks' study, that the Vanguard program had accomplished very much more than might have been expected in view of the low priority which it had been given before Sputnik. 
The next year I became Special Assistant to the Director. The OBI was broken up and various segments were absorbed into several of the operating technical divisions.

Soon afterward, while attending a conference on electromagnetic measurements, one of my Boulder colleagues, reporting on NBS radio standards calibration activities, referred to the large number of questions received from government contractors and instrument manufacturers on how best to organize calibration programs in their own establishments. He added that he wished he could refer such requests to "somebody." Feeling that the best way to help people is to help them help themselves, I asked him to announce an early morning. meeting of those interested in a possible organization of standards laboratories. A goodly number appeared, an organizational committee was established, and from this evolved the National Conference of Standards Laboratories, which is loosely sponsored by iNBS. Each of you probably has been given some literature describing its activities and objectives. Not all, perhaps none, of your countries will need an NCSL, but you may find it useful to sponsor meetings or to establish committees having similar goals.

We had established an Advisory Committee on Measurement Services, comprised mainly of directors of calibration services in large industrial organizations heavily engaged in development work for government agencies. This Committee and several other advisory committees were continually urging NBS to undertake research in various areas and to provide various additional calibration services. We often could not accede to these requests immediately, or even after several years, since increases in our Congressionally appropriated funds were not easy to obtain.

When I became Associate Director with broader responsibilities for these matters, I missed the freedom I had had earlier in OBI in negotiating directly with officials of other agencies for support of the OBI program. NBS is directed by law to provide calibration services, and so it must look for the administration to propose, and the Congress to provide, the funds for basic research and development on calibration methods, techniques, and instruments. In general, only the cost of staff time spent on calibration work was covered in fees. (Fees now cover a larger share of the costs.)

In a program review with Commerce Department officials, I pointed out that there are many groups concerned with measurement: scientists and engineers, scientific and technical societies, technical publications, standardizing organizations, independent testing laboratories, regulatory agencies, weights and measures officials in the states as well as calibration laboratories of commercial organizations and other government agencies, etc. I explained that each of these groups had some need for services from NBS ranging from time signals, technical data, standard material samples, and calibration, to consultation and 
cooperation to support with NBS personnel on committees and jointsponsorship of symposia or research programs, etc. On a chart, I outlined some of the groups and types of services with estimates of additional funds required to improve our services to these groups and to properly fill a leadership role in "the National Measurement System." This was received with considerable interest, but I do not recall that we received any sizable increase in appropriations that year. We kept on, however, analyzing and describing the "System" and debating just what role NBS could, or should, try to fill. Dr. Huntoon later developed this theme in much more detail and gave several excellent talks on "The National Measurement System." The changing programs and structure of NBS have reflected his analysis and his leadership. I urge you to look for Dr. Huntoon's paper, "Compatibility in Measurement Systems," in a report of the NBS/AID/OAS Workshop on Standardization and Measurement Services in Industrializing Economies (NBSIR 75-769), or to request a copy from the NBS Office of International Relations.

So closes the story of my time at NBS, 1935-70. The moral of my story is simple:

I. All who work in the standards field must perforce pursue "proper precision" persistently using today's progress for more progress to meet the needs of tomorrow.

II. The key to building competence in this work is a wide, thorough, and up-to-date knowledge of all aspects of instrumentation and measurement, collectively shared and permeating the entire organization.

Good luck! 



\section{QUESTIONS AND ANSWERS}

ADDRESSED BY PARTICIPANTS 



\section{QUESTIONS AND ANSWERS ADDRESSED BY PARTICIPANTS \\ OF THE NBS/AID WORKSHOP \\ OCTOBER 1977}

\section{A. Relevance to your Programs in your Country}

\section{Question:}

1. What fraction of the presentations had any relevance

to your

a. present needs?

b. future needs (as seen by you now)?

\section{Answers:}

a. present needs?

Dr. Mohammed H. AMMAR: All presentations.

Mrs. Sriati DJAPRIE: 70 percent.

Nir. James D. GIKANDI: Mostly the basic standards as we are establishing a new laboratory for calibration purposes.

Mr. Abu Hossain KHAN: 60 percent.

Mrs. Anacleta B. MASCARINAS: All parts of the presentations had relevance to the present needs of the Philippines Bureau of Standards.

Mr. Hernando MONTANO V.: The fraction corresponding to institutions dealing with standardization and measurement services such as NBS and Bureau of Weights and Neasures in Harrisburg.

Dr. RHEE, Choonghi: 100 percent.

Mr. Chaiwai SANGRUJI: Mass testing of products. We do not test the products ourselves but send to authorized labs. PVC insulated wire, for example, can be tested at a rate of 100-150 samples per month. We have approximately 2,500 in a bottleneck and need testing at a rate more than all labs combined can handle.

b. future needs (as seen by you now)?

DJAPRIE: 30 percent.

GIKANDI: With the growth of our measurement facilities, we 
should act as a calibration center for our East African neighbors.

KHAN: 100 percent.

MASCARINAS: Most of our future needs have relevance to all presentations.

MONTANO: The part corresponding to several institutes and laboratories of INBS.

PHEE: 90 percent.

SANGRUJI: Dependence on authorized labs has reached a stage when most of our testings become a bottleneck. There are about 20 products at present that we are not able to find any lab to test for us now. We have to make plans and think very seriously of a lab of our own now.

\section{Question:}

2. Which presentations could have been omitted
a. in Gaithersburg?
b. in Boulder?
c. elsewhere?

Answers:

a. In Gaithersburg?

Eng. Kamal I. ABULYOSR: Nothing.

DJAPRIE: None.

GIKANDI: None.

Dr. Bambang H. HADIWIARDJO: None.

KHAII: None.

MASCARINAS: iothing should be omitted. I profited in one way or another from all presentations.

MONTANO: None, but some of them could be approached more deeply and with more time.

Mr. Mohammad MOS-HAFI: Nothing.

SANGRUJI: It is not to be omitted, but I almost do not know any about computer science. The presentation was 
beyond my background, but I belleve it will be very useful, I am sure, for people who can follow. Cyclotran was enlightening, but it may be years before we can find some usefulness.

b. In Boulder?

DJAPRIE: None.

GIKANDI: None.

HADIWIARDJO: None.

KHAN: None.

c. elsewhere?

DJAPRIE: None.

GIKANDI: None.

HADIWIARDJO: One or two universities; Chemical Abstracts.

KHAN: None.

MONTANO: I think the presentation In Colorado School of Mines, because of 1ts superficial approach. The presentation carried out at MIT, Boston, because I think it was not well prepared and organized by its authorities.

RHEE: Chemical Abstracts Service, Columbus, OhIo.

SANGRUJI: Presentations on some of the universities could have been shorter. I was a little confused. On one hand, the state limits number of foreign students, and on the other, the professors seemed to encourage.

\section{Question:}

3. Which presentations were too brief
a. In Galthersburg?
b. In Boulder?
c. elsewhere?

\section{Answers:}

a. In Gaithersburg?

DJAPRIE: ISO and IEC matters; the role of standardization In development. 
GIIANDI: None.

HADIWIARDJO: NBS laboratories.

KHAN: None.

MONTANO: The visits to some laboratories were too brief, and I think they should be longer with more explanations.

RHEE: Executive Session to summarize participants' own papers was too short.

SANGRUJI: Dr. Horowitz mentioned line control has a job to develop careers and confidence of staff. This is extremely interesting, and I wish he would expand much more on ways and means used.

b. In Boulder?

DJAPRIE: None.

GIKANDI: None.

HADIWIARDJO: NBS laboratories.

KHAN: None.

SANGRUJI: I think some idea on metrication would be useful. I was rather disappointed that too little was mentioned.

c. elsewhere?

ABULYOSR: Visit to Weights and Measures Department in Pennsylvania.

DJAPRIE: None.

GIKANDI: None.

HADIWIARDJO: ITone.

KHAN: None.

MASCARINAS: Department of Agriculture, Commonwealth of Pennsylvania.

MONTANO: Hewlett-Packard; AMP Corporation.

RHEE: At MIT we missed laboratory tours. 
SANGRUJI: Solar energy on the technical side. They spent too much time on the organization, but perhaps it was too early for our visit.

\section{Question:}

4. What presentations should have been added?

\section{Answers:}

ABULYOSR: Visits to standardization associations.

AMMAR: Some of the most important work in metrology done by NBS staff should be presented.

DJAPRIE: An overview of the U.S. standardization system; 1ts relation with U.S. government. Role of AiSI in coordination of the system. Safety standards.

GIKANDI: It would be more beneficial if some more presentations concerning quality control and certification marking were included.

HADIWIARDJO: More industries. Research institutes hich have close relationships with standardization and measurement services.

KHAN: More on quality control through standardization.

MONTANO: For example, one at ASTM because it is an organization that deals in work similar to that carried out in Ey country in the field of standardization. In the same way, there should have been added a visit to ANSI for those reasons.

MOS-HAFI: Visits to ANSI and ASTM.

SANGRUJI: Food standards and control. Most of the courtries that participated can do better on agricultural products than industrial products. Also, most of us are or the director level so the organization, planning, and anagerert would be very useful.

\section{Question:}

5. Did you appreciate the presentations from other participacts to such an extent that you wish more time could have been devcted to them
a. by longer sessions?
b. additional sessions?
c. reduction of other presentations? 
a. by longer sessions?

ABULYOSR: Yes.

DJAPRIE: Yes.

GIKANDI: Yes, some participants had no chance for presentations at all.

HADIWIARDJO: Yes, to some extent.

MASCARINAS: By longer sessions to give all participants the chance to present their papers in brief and answer questions from other participants.

MOS-HAFI: Yes.

SANGRUJI: Yes.

b. additional sessions?

ABULYOSR: Yes.

DJAPRIE: Yes.

GIKANDI: I suggest that additional sessions be included in future Workshops.

HADIWIARDJO: Yes, to some extent.

KHAN: Yes.

MOS-HAFI: Yes.

RHEE: Yes.

SANGRUJI: Yes.

c. reduction of other presentations?

HADIWIARDJO: Yes, to some extent.

MASCARINAS: No.

SANGRUJI: No. 
B. Quality of Presentations and NBS/AID Programs

\section{Question:}

1. Which presentation was the best for you
a. In Gaithersburg?
b. in Boulder?
c. elsewhere?

\section{Answers:}

a. In Gaithersburg?

DJAPRIE: All were excellent.

GIKANDI: All were equally presented.

MONTANO: Dr. E. Horowitz, Institute for Materials Research.

SANGRUJI: Institute for Materials Research.

b. in Boulder?

DJAPRIE: All were excellent.

GIKANDI: AlI were equally presented.

c. elsewhere?

DJAPRIE: All were excellent.

GIKANDI: All were equally presented.

HADIWIARDJO: General Radio.

MASCARINAS: Department of Agriculture, Commonwealth of Pennsylvania.

MONTANO: Hewlett-Packard Company; Bureau of Weights and Measures, Harrisburg.

MOS-HAFI: Hewlett-Packard; General Radio.

RHEE: Bureau of Standard Weights and Measures, Commonwealth of Pennsylvania.

SANGRUJI: Earthquake (Colorado School of Mines); Toledo Scale. 
2. Do you plan in the future
a. to request NBS 11terature?
b. to request U.S. standards 1iterature?
c. SRM's?
d. a guest worker stay at NBS for yourself?
e. a guest worker stay at NBS for others?
f. to suggest to your Government to invite a survey?
g. to suggest to your Government to seek to send trainees?
h. to recommend that others from your country go to NBS/AID Workshops?
1. to recommend that others from other countries go to NBS/AID Workshops?
j. to recommend that your country host a regional seminar?

Answers:

\begin{tabular}{lcccccccccc} 
& a. & b. & c. & d. & e. & f. & g. & h. & 1. & $j$. \\
ABULYOSR & Yes & Yes & Yes & $-\infty$ & $-\infty$ & Yes & Yes & Yes & Yes & Yes \\
AMMAR & Yes & Yes & Yes & Yes & Yes & Yes & Yes & Yes & $-\infty$ & Yes \\
DJAPRIE & Yes & Yes & $(1)$ & $-\infty$ & Yes & $-\infty$ & Yes & Yes & $-\infty$ & Yes \\
GIKANDI & Yes & Yes & Yes & $?$ & $?$ & Yes & $(2)$ & Yes & Yes & Yes \\
HADIWIARDJO & Yes & Yes & Yes & Yes & Yes & No & Yes & Yes & Yes & Yes \\
KHAN & Yes & Yes & Yes & $-\infty$ & Yes & Yes & Yes & Yes & Yes & Yes \\
MASCARINAS & Yes & Yes & $-\infty$ & No & $?$ & $(3)$ & Yes & Yes & Yes & $(4)$ \\
MONTANO & Yes & Yes & Yes & $-\infty$ & Yes & $-\infty$ & $-\infty$ & Yes & $-\infty$ & $-\infty$ \\
MOS-HAFI & Yes & Yes & $-\infty$ & $-\infty$ & $-\infty$ & $-\infty$ & Yes & Yes & Yes & $-\infty$ \\
RHEE & Yes & Yes & Yes & Yes & $-\infty$ & Yes & Yes & Yes & $-\infty$ & Yes \\
SANGRUJI & Yes & Yes & $?$ & No & No & Yes & $?$ & $?$ & Yes & $-\infty$ \\
\hline
\end{tabular}

(1) After setting up an interlaboratory testing program, LIPI would like to use some of the SRMs available in the laboratory testing evaluation: cement for building materials testing; chemicals for chemical laboratories analysis.

(2) There should be one week of general overview, and then industrial and scientific visits should be divided into groups of special interests, e.g., (i) one group for people interested in engineering, and (ii) one group for others, 1.e., food and agriculture, textiles, science, etc.

(3) A follow-up.

(4) Perhaps in the future if budget permits. 


\section{Question:}

3. What suggestions would you make for the organizational arrangements for NBS/AID Workshops?

\section{Answers:}

AMMAR: To have more time to visit the metrology labs.

DJAPRIE: (1) Concentration in Washington one week--al1 information, lectures, etc. (2) Field trips and visits during second week. (3) Evaluation meeting-one or two days.

GIKANDI: That there should be one week of general overviews and then industrial and scientific visits should be divided into groups of special interest, such as (1) for people interested in engineering, (2) others interested in food and agriculture, textiles, science, etc.

HADIWIARDJO: (1) Choose the proper institute/industry which has very close relations with standardization and measurement services. (2) Make the program not too tight, without decreasing the scope. (3) Some "dinner and talk" can be omitted. Most of the participants are already tired.

(4) The outline of the standardization and measurement service system in the U.S.A. can be presented in the first days of the Workshop.

KHAN: The present arrangement is all right.

MASCARINAS: The present arrangement is believed sufficient.

MONTANO: I suggest better arrangement of the NBS presentations, because they were too fast. Visits to places such as ASTM and ANSI should be added. The schedule must not be so busy and crowded. Let the participants have some time for add1tional arrangements.

RHEE: Arrangement of half-day or one-day discussion of participants' own papers and problems in their own countries, and overviews of institutions of each participant will give exchange of ideas and benefits to participants from abroad and the States.

SANGRUJI: I think what has been organized was best, and I disagree with the suggestion of splitting up the group after the overview. Participants are of director level. If my particular or specialized fields are needed, there should be another workshop on another level. 


\section{Personal Questions}

\section{Question:}

1. Did you

a. enjoy the NBS/AID Workshop?

b. regret attending the NBS/AID Workshop?

Answers:

a. enfoy the NBS/AID Workshop?

ABULYOSR: Yes.

AMMAR: Yes.

DJAPRIE: Was very useful for knowledge and experience.

GIKANDI: Very much.

HADIWIARDJO: Yes.

KHAN: Yes, very much.

MASCARINAS: Yes.

MONTANO: Yes, during almost all the schedule.

MOS-HAFI: Yes.

RHEE: Yes.

SANGRUJI: Very much. The program was very rich in every respect. Comments made above to the negative are the result of microscopic attempts to find a flaw.

b. regret attending the NBS/AID Workshop?

GIKANDI: No.

HADIWIARDJO: No.

MASCARINAS: No.

MONTANO: No, I absolutely don't regret having attended the IJBS/AID Workshop.

SANGRUJI: No, definitely not. 


\section{Question:}

2. Did you profit professionally in some way?

\section{Answers:}

\section{ABULYOSR: Yes.}

AMMAR: Yes.

DJAPRIE: Yes!

GIKANDI: Yes, especially concerning basic standards and calibration measurements.

HADIWIARDJO: Yes, for comparison study of how to develop our institute and the KIM program in the best and most appropriate way.

KHAN: In every way, I have profited professionally.

MASCARINAS: Very much.

MONTANO: Yes, because I could see many ways by which standardization and measurement are developed in the U.S.A., and some of them could be adapted to my country.

MOS-HAFI: Yes, I did.

RHEE: I have learned many metrological activities in the States, the national standard system, measurement system, and quality control, etc.

SANGRUJI: Yes, sir, and in many ways.

\section{Question:}

3. Do you feel you have established personal and useful contacts

a. with NBS staff?

b. other U.S. colleagues?

c. with other Workshop participants?

Answers:

a. with NBS staff?

ABULYOSR: Yes.

AMMAR: Yes. 
DJAPRIE: Yes!

GIKANDI: Yes.

HADIWIARDJO: Yes.

KHAN: Yes.

MASCARINAS: Yes.

MONTANO: Yes, especlally with people like Dr. Brady and Mr. Peiser.

MOS-HAFI: Yes.

RHEE: Yes.

SANGRUJI: Yes.

b. other U.S. colleagues?

AMAR: Yes.

DJAPRIE: Yes !

GIKANDI: Yes.

HADIWIARDJO: Yes.

KHAN: Yes.

MONTANO: No, I couldn't establish this kind of contact.

RHEE: Yes.

SANGRUJI: Yes.

c. with other Workshop participants?

ABULYOSR: Yes.

AMMAR: Yes.

DJAPRIE: Yes!

GIKANDI: Yes.

HADIWIARDJO: Yes.

KHAN: Yes. 
MASCARINAS: Yes.

MONTANO: Yes, with all participants from abroad, and I hope this will be the beginning of useful contacts and friendships.

MOS-HAFI: Yes.

RHEE: Yes.

SANGRUJI: Yes.

\section{Question:}

4. Do you feel your country should have sent someone else of
a. greater senfority (in job)?
b. lesser seniority (in fob)?
c. greater technical experience?
d. lesser technical experience?

\section{Answers:}

a. greater senfority (in job)?

DJAPRIE: No.

GIKAINDI: Although not involved in top management and decision making, my organization has very qualified and experienced senior officers who would very much benefit from this Workshop. I suggest that NBS give consideration to this for future Workshops.

HADIWIARDJO: No.

KHAN: Director of BDSI was the right person.

MASCARINAS: No.

RHEE: No.

SANGRUJI: After thorough medical checkup, perhaps.

b. lesser seniority (in fob)?

DJAPRIE: No.

HADIWIARDJO: Yes.

MASCARINAS: No. 
RHEE: No.

SANGRUJI: I thought the NBS invitation was directed to me.

c. greater technical experience?

ABULYOSR: Yes.

DJAPRIE: No.

MASCARINAS: Not necessary.

MONTANO: In a complementary way, I feel my country should have sent a member of our staff in the fleld of metrology.

RHEE: No.

SANGRUJI: Yes.

d. lesser technical experience?

DJAPRIE: No.

MASCARINAS: No.

RHEE: No.

SANGRUJI: I thought the Workshop was organized for the managerlal level. If this was the case, greater or lesser technical experlence has 1ittle welght.

D. Any other Remarks (including comments on the Seminar, Oct. 17-18)

ABULYOSR: Both Workshop and Seminar were very condensed. I would prefer this program to be extended to two months, at least, to benefit more from visits to different laboratorles, lectures, etc.

AMMAR: (1) Exhlbition of new equipment used in metrology and designed at NBS. (2) Preparation of the papers to be presented by NBS staff in advance so that they can be read before presentation.

DJAPRIE: (1) Some more light could be thrown on safety standards.

(2) Role of professional organization in standardization activities.

(3) The voluntary standard system in the U.S. and Its relation to the new bill in Congress. (4) It has been a very interesting and most frultful two weeks, but also very tiring.

GIKANDI: The two-day Seminar was conducted in a very orderly atmosphere, and during this time It was emphasized that standards can be used as a tool for the transfer of technology. Unfortunately, most of 
the developing countries are not able to be full members of ISO or IEC nor can they attend some of the important meetings even if they were members. It was therefore suggested (by a participant) that NBS or AID be requested to sponsor some countries so that they can attend these meetings, from which a lot of knowledge can be acquired. I think this is a very good suggestion and should be considered.

It was also clarified that organizations which are not full members of IEC can also attend as observer members, but they have no right of voting. This will enable me or some of the officers in my department to attend IEC meetings as observers.

KHAN: The Seminar was a success. The fundamental aims of the Seminar, i.e., propagating the various aspects of standardization, quality control, and metrology, and contact with various persons engaged in these activities, were achieved.

This type of Workshop should always end with a Seminar.

MASCARINAS: The Seminar, for my part, was very informative, fruitful, and enjoyable. It covered all important aspects of standardization and measurement services. The subject matters were varied, as varied as the different interests of the different participants from the different countries of the world.

However, the Seminar was quite tiresome as the schedule was very tight, in the American way. It was an excellent accomplishment.

For the Seminar from October 17-18, it was very exciting, educational, and informative. However, there were speakers whose subject matter was of special interest to many participants, but there was not enough time to ask questions and listen to the answers.

In the final analysis, the NBS/AID program for developing countries is very meaningful. It has opened the eyes of developing countries to the advancement or growth of technology in developed countries and to do our part, at least, to get abreast of them.

Finally, particularly the Philippines, as represented by me, is happy to know that a great country, the U.S.A., takes sincere concern in the development of my country through standardization.

MONTANO: I think the Seminar is a good way to finish the Workshop, and the conclusions and recommendations that the representatives are elaborating will be helpful for the sponsorship of the event.

MOS-HAFI: Both Workshop and Seminar were very interesting and useful for me. In my opinion, if this program can be extended for one month, the efficiency shall be better.

SANGRUJI: I entirely agreed with Dr. Oteng's summary of the Workshop. 
I cannot express it as clearly or as well as he, and this goes for the Seminar, too. Except that I cannot agree with him on the suggestion to split up the group after an overview to go to different places (please see B.3).

I also think that dinner and lunch speeches were very great, too, especially Mr. Rabinow's. It was both enjoyable as well as enlightening. (It was the first time that I had met an inventor.) The others were also as good, and in all, they comprised a very excellent blend.

The outcome was far more than what was imagined before I started for the United States. It would be most regretful had I turned down Mr. Pelser's offer. 
BIBLIOGRAPHIC DATA SHEET

4. TITLE AND SUBTITLE

REPORT TO AID OH AN XBS/AID WORRSHOP ON

STANDAREIZATION: AID MEASLREMENT SERVICFS

5. Publication Date

May 1979

\section{AUTHOR(S)}

I. Steffen Peiser, Charles C. Raley, Penelope M. Cdar

\section{PERFORMING ORGANIZATION NAME AND ADDRESS}

10. Project/Task/Work Unit No.

NATIONAL BUREAU OF STANDARDS

DEPARTMENT OF COMMERCE

WASHINGTON, DC 20234

11. Contract/Grant No.

PASA TA (CE) 6-71.

12. SPONSORING ORGANIZATION NAME AND COMPLETE ADDRESS (Street, City, State, ZIP)

13. Type of Report \& Period Covered

Agency for International Development

Fina 1

Department of State

Washington, D.C. 20523

6. Performing Organization Code

8. Performing Organ. Report No.

\section{SUPPLEMENTARY NOTES}

L-7 Document describes a computer program; SF-185, FIPS Software Summary, is attached.

16. ABSTRACT (A 200-word or less factual summary of most significant information. If documeat includes a significant bibliography or literature survey, mention it here.)

From Cctober 1-18, 1977, a Workshop was held at the National Bureau of Standarcis, Gaithersburc, and at selected universities, research institutes, standarçs ceveloping organizations, test centers, and industrial companies, under the sponsorship of AID. The object of the Workshop was to Eive standards officials of industrializing nations insight into the standards and measurement systems of the tnited States and the role of the National Bureau of Standards, so that these officials might consider what parts of the U.S. system might usefully be adafted to conditions in their home countries. An exchange of standarcization experience in each of the participant's countries was presented by delivered papers which are reproduced here. Countries represented included Argentina, Bangladesh, Bolivia, Egypt, Ghana, Indonesia, Iran, Kenya, Korea, Philippines, and Thailand. In addition, there were representatives from the Arab Organization for Standardization and Metrology and the International Organization for Standardization.

17. KEY WORDS (six to twelve entries; alphabetical order; capitalize only the first letter of the first key word unless a proper namo; separated by semicolons) AID; assistance; ceveloping economies; foreign relations;

industrializing nations;international relations;LDC's; measurement services; standardization

For Official Distribution. Do llot Release to NTIS

Order From Sup. of Doc., U.S. Government Printing Office, Washington, DC 20402, SD Stock No. SNÖ03-003-

X Order From National Technical Information Service (NTIS), Springfield, VA. 22161
19. SECURITY CLASS (THIS REPORT)

\begin{tabular}{|l|l|}
\hline $\begin{array}{l}\text { 19. SECURITY CLASS } \\
\text { (THIS REPORT) } \\
\text { UNCLASSIFIED }\end{array}$ & $\begin{array}{l}\text { 21. NO. OF } \\
\text { PRINTED PAGES }\end{array}$ \\
\hline $\begin{array}{l}\text { 20. SECURITY CLASS } \\
\text { (THIS PAGE) } \\
\text { UNCLASSIFIED }\end{array}$ & 22. Price \\
$\$ 8.0 \mathrm{C}$ \\
\hline
\end{tabular}




